University of Tennessee Health Science Center

UTHSC Digital Commons

\title{
Cellular Corrosion of CoCrMo Total Knee Implants: Understanding Underlying Mechanisms Through Retrieval Analysis and Simulated Inflammatory Conditions
}

Griffin Heise

University of Tennessee Health Science Center

Follow this and additional works at: https://dc.uthsc.edu/dissertations

Part of the Analytical, Diagnostic and Therapeutic Techniques and Equipment Commons

\section{Recommended Citation}

Heise, Griffin (https://orcid.org/0000-0002-3767-0468), "Cellular Corrosion of CoCrMo Total Knee Implants: Understanding Underlying Mechanisms Through Retrieval Analysis and Simulated Inflammatory Conditions" (2019). Theses and Dissertations (ETD). Paper 502. http://dx.doi.org/10.21007/ etd.cghs.2019.0565.

This Thesis is brought to you for free and open access by the College of Graduate Health Sciences at UTHSC Digital Commons. It has been accepted for inclusion in Theses and Dissertations (ETD) by an authorized administrator of UTHSC Digital Commons. For more information, please contact jwelch30@uthsc.edu. 


\title{
Cellular Corrosion of CoCrMo Total Knee Implants: Understanding Underlying Mechanisms Through Retrieval Analysis and Simulated Inflammatory Conditions
}

\author{
Abstract \\ Introduction. Total joint arthroplasty is considered one of the most beneficial aspects of modern \\ orthopedic surgery. Due to the increase in population, obesity rates, and medical advances, total joint \\ replacements have become more commonplace in the United States. Recently, a unique type of damage \\ has been investigated in cobalt-chrome ( $\mathrm{CoCr}$ ) implants that remains poorly understood and highly \\ controversial. Originally, it was believed that this damage type was caused by inflammatory cells directly \\ attacking the metal surface, leading to damage of the oxide layer. However, damage caused by \\ electrocautery tools has shown identical characteristics, leading some to believe this is the true cause. \\ This study aims to distinguish between these two damage mechanisms and investigate the biological \\ response of inflammatory cells to common orthopaedic metal alloys.Methods. Following institution \\ review board approval, 41 Cobalt-Chromium-Molybdenum (CoCrMo) cadaveric primary total knee \\ arthroplasty specimens were collected. After removal and cleaning, light microscopy was utilized to \\ identify areas of ICIC-like damage scares. CoCrMo, zirconium nitride ( $\mathrm{ZrN}$ )coated, and Oxinium knee \\ implants were intentionally damaged by electrocautery from both Bovie and Aquamantys sources by a \\ three second hover method. Bovie electrocautery damage was done at $30 \mathrm{~W}, 45 \mathrm{~W}$, and $60 \mathrm{~W}$. Aquamantys \\ electrocautery damage was done at $140 \mathrm{~W}, 180 \mathrm{~W}$, and $220 \mathrm{~W}$. Using a scanning electron microscope $20 \mathrm{kV}$ \\ backscatter detection (BSD), and energy dispersive X-ray spectrometry (EDS) (Oxford, High Wycombe, UK) \\ corroded regions were analyzed for both groups and the elemental compositions were reported. White \\ light interferometry was utilized to examine the surface topography of the implants. Average roughness \\ (Ra), max peak-to-valley height (Rmax,), kurtosis (Rk), and skewness (Rsk) measurements were collected \\ to represent the topography on the damaged areas for the $\mathrm{CoCr}$ and Zirconium Nitride coated implants. \\ After failing normality testing, Mann Whitney Rank Sum tests were utilized to determine any significant \\ differences.In a separate experiment, IC-21 ATCC peritoneal macrophages were cultured with growth \\ medium of RPMI 1640 with $10 \%$ fetal bovine serum (FBS), L-glutamine, and gentamicin. Interferon \\ Gamma (IFNY) and Lipopolysaccharide (LPS) were used to induce activation of macrophages. Stainless \\ Steel, $\mathrm{CoCr}$, and Titanium (Ti) discs were cut, polished, and placed into a 96 well plate. Stainless steel \\ testing included 6 groups: standard medium, 20,000 cells, 40,000 cells, 20,000 activated cells, 40,000 \\ activated cells. $\mathrm{CoCr}$ and $\mathrm{Ti}$ testing included the following: medium, 40,000 cells, 20,000 activated cells, \\ cells, no disc $+20,000$ cells, no disc $+40,000$ cells. After cells were attached to the surface, culture \\ medium was replaced and collected every 24 hours for stainless steel and every 12 hours for $\mathrm{Ti}$ and CoCr. \\ Cell viability and number were measured with CellTiter $96 \AA$ Aqueous One Solution Assay (Promega). The \\ Griess Reagent Assay (ThermoFisher) was used to indirectly measure nitric oxide (NO) production from \\ supernatant. Inductively coupled plasma mass spectrometry (ICP-MS), conducted at Brooks Applied Labs \\ (Bothell, WA), was utilized to determine metal concentrations found in the supernatant. All statistical \\ analysis was conducted using SigmaPlot (Systat Software, Chicago, IL)Results. Necropsy implants \\ showed signs of ICIC in 7 out of 41 implants (17\%) examined. Iron (Fe), Nickel (N), Carbon (C), and \\ Oxygen ( 0 ) content were taken from the data collected to serve as surrogate markers of corrosion. Fe/C \\ ratios of the Bovie electrocautery damaged knee implant were shown to be statistically higher than that of \\ necropsy retrieved implants. Median Ra measurements were shown to be statistically less $(p=0.008)$ for \\ Bovie damaged areas compared to ICIC damaged areas on CoCr. Median Rmax and Ra measurements \\ were shown to be statistically less ( $p=0.012, p<0.001$ respectively) for Aquamantys damaged areas \\ compared to ICIC damaged areas on CoCr. Median Rmax, Ra, and Rk, measurements were shown to be \\ statistically higher for Bovie damaged areas compared to non-damaged areas on ZrN coated implants. \\ Rsk measurements were shown to be statistically lower for both Bovie and Aquamantys damaged areas \\ compared to non-damaged areas on ZrN coated implants.Activated IC-21 cells on stainless steel discs \\ produced significantly more NO compared to their control counterparts after 8-10 days and remained
}


elevated for the duration of the experiment. Cell viability and cell coun

Document Type

Thesis

Degree Name

Master of Science (MS)

Program

Biomedical Engineering

Research Advisor

William M. Mihalko, MD, PhD

Keywords

biological response, cellular corrosion, electrocautery, ICIC, Knee arthroplasty, orthopaedics

Subject Categories

Analytical, Diagnostic and Therapeutic Techniques and Equipment | Medicine and Health Sciences 
MASTER OF SCIENCE THESIS

Cellular Corrosion of CoCrMo Total Knee Implants: Understanding Underlying Mechanisms Through Retrieval Analysis and Simulated Inflammatory Conditions

Author:

Griffin Heise
Advisor:

William M. Mihalco, Ph.D.

A Thesis Presented for The Graduate Studies Council of The University of Tennessee Health Science Center in Partial Fulfillment of the Requirements for the Master of Science degree from

The University of Tennessee

in

The Joint Graduate Program in Biomedical Engineering: Biomechanics College of Graduate Health Sciences 
Copyright (C) 2019 by Griffin Heise. All rights reserved. 


\section{DEDICATION}

I would like to dedicate this research to my family and friends for all their love and support they have given to me over the years. First I would like to thank my parents, Jean and John, for teaching me to always to work to the best of my abilities and never give up on my dreams. I would also like to thank my older sister and brother, Sommer, Brandon, and Austin, for always having my back as I was growing up and keeping me on the right path in a way a parent never could. Thank you to my twin brother, Alex, for always being able to lift my spirits when I am stressed and being the best friend I could ever ask for. Finally, thank you to all of the friends I have made over the past two years for the great company. We got each other through graduate school and I could not have had a better time. 


\section{ACKNOWLEDGEMENTS}

I would like to thank my advisor, Dr. William M. Mihalko, for giving me the opportunity to pursue a graduate degree and the guidance over the past two years. Thank you for dedicating countless hours and energy to my work and teaching me to be a better student. Your drive and passion for advancing the biomedical field has inspired me to grow both personally and professionally.

I would like to thank Dr. Richard Smith for the guidance throughout my thesis and allowing me to use their laboratory for cell culture testing. Thank you to Dr. Denis DiAngelo for the guidance, support, and feedback over the past two years. Thank you to Dr. Joel Bumgardner for the guidance on the design of my cell culture experiment. Thank you to Jameson Sorrels for assisting me with data collection on electrocautery damage. Thank you to Caitie Black for teaching me and helping me throughout the cell culture process. Thank you to Brian Morrow for allowing me to use the equipment in their lab and keeping me company throughout the testing process. I also owe a big thank you to everyone in Dr. Kurtz's lab at Drexel University, especially Christina Arnholt, for allowing me train there and assisting me with testing throughout the process of my research. I would also like to thank Mrs. Anita Kerkhof for the support and guidance you have shown me.

Finally, I would like to thank all of my friends and classmates. Vaik Giri and Blass Watson, thanks for being great friends and study partners and encouraging me when times got rough. I would also like to acknowledge my predecessor, Meredith Perkins for teaching me the ins and outs of making it as a graduate student. Our personalities might have been polar opposites, but you were a true friend and made the lab a much better place. 


\begin{abstract}
Introduction. Total joint arthroplasty is considered one of the most beneficial aspects of modern orthopedic surgery. Due to the increase in population, obesity rates, and medical advances, total joint replacements have become more commonplace in the United States. Recently, a unique type of damage has been investigated in cobalt-chrome $(\mathrm{CoCr})$ implants that remains poorly understood and highly controversial. Originally, it was believed that this damage type was caused by inflammatory cells directly attacking the metal surface, leading to damage of the oxide layer. However, damage caused by electrocautery tools has shown identical characteristics, leading some to believe this is the true cause. This study aims to distinguish between these two damage mechanisms and investigate the biological response of inflammatory cells to common orthopaedic metal alloys.
\end{abstract}

Methods. Following institution review board approval, 41 Cobalt-ChromiumMolybdenum (CoCrMo) cadaveric primary total knee arthroplasty specimens were collected. After removal and cleaning, light microscopy was utilized to identify areas of ICIC-like damage scares. CoCrMo, zirconium nitride ( $\mathrm{ZrN})$ coated, and Oxinium knee implants were intentionally damaged by electrocautery from both Bovie and Aquamantys sources by a three second hover method. Bovie electrocautery damage was done at $30 \mathrm{~W}$, $45 \mathrm{~W}$, and $60 \mathrm{~W}$. Aquamantys electrocautery damage was done at $140 \mathrm{~W}, 180 \mathrm{~W}$, and 220W. Using a scanning electron microscope $20 \mathrm{kV}$ backscatter detection (BSD), and energy dispersive X-ray spectrometry (EDS) (Oxford, High Wycombe, UK) corroded regions were analyzed for both groups and the elemental compositions were reported. White light interferometry was utilized to examine the surface topography of the implants. Average roughness $\left(\mathrm{R}_{\mathrm{a}}\right)$, max peak-to-valley height $\left(\mathrm{R}_{\max }\right)$, kurtosis $\left(\mathrm{R}_{\mathrm{k}}\right)$, and skewness $\left(\mathrm{R}_{\mathrm{sk}}\right)$ measurements were collected to represent the topography on the damaged areas for the $\mathrm{CoCr}$ and Zirconium Nitride coated implants. After failing normality testing, Mann Whitney Rank Sum tests were utilized to determine any significant differences.

In a separate experiment, IC-21 ATCC peritoneal macrophages were cultured with growth medium of RPMI 1640 with 10\% fetal bovine serum (FBS), L-glutamine, and gentamicin. Interferon Gamma $\left(\mathrm{IFN}_{\gamma}\right)$ and Lipopolysaccharide (LPS) were used to induce activation of macrophages. Stainless Steel, CoCr, and Titanium (Ti) discs were cut, polished, and placed into a 96 well plate. Stainless steel testing included 6 groups: standard medium, 20,000 cells, 40,000 cells, 20,000 activated cells, 40,000 activated cells. CoCr and Ti testing included the following: medium, 40,000 cells, 20,000 activated cells, cells, no disc $+20,000$ cells, no disc $+40,000$ cells. After cells were attached to the surface, culture medium was replaced and collected every 24 hours for stainless steel and every 12 hours for Ti and CoCr. Cell viability and number were measured with CellTiter 96® Aqueous One Solution Assay (Promega). The Griess Reagent Assay (ThermoFisher) was used to indirectly measure nitric oxide (NO) production from supernatant. Inductively coupled plasma mass spectrometry (ICP-MS), conducted at Brooks Applied Labs (Bothell, WA), was utilized to determine metal 
concentrations found in the supernatant. All statistical analysis was conducted using SigmaPlot (Systat Software, Chicago, IL)

Results. Necropsy implants showed signs of ICIC in 7 out of 41 implants (17\%) examined. Iron $(\mathrm{Fe})$, Nickel $(\mathrm{N})$, Carbon $(\mathrm{C})$, and Oxygen $(\mathrm{O})$ content were taken from the data collected to serve as surrogate markers of corrosion. $\mathrm{Fe} / \mathrm{C}$ ratios of the Bovie electrocautery damaged knee implant were shown to be statistically higher than that of necropsy retrieved implants. Median $\mathrm{R}_{\mathrm{a}}$ measurements were shown to be statistically less $(\mathrm{p}=0.008)$ for Bovie damaged areas compared to ICIC damaged areas on CoCr. Median $R_{\max }$ and $R_{a}$ measurements were shown to be statistically less $(p=0.012, p<0.001$ respectively) for Aquamantys damaged areas compared to ICIC damaged areas on CoCr. Median $R_{\max }, R_{a}$, and $R_{k}$, measurements were shown to be statistically higher for Bovie damaged areas compared to non-damaged areas on $\mathrm{ZrN}$ coated implants. $\mathbf{R}_{\mathrm{sk}}$ measurements were shown to be statistically lower for both Bovie and Aquamantys damaged areas compared to non-damaged areas on $\mathrm{ZrN}$ coated implants.

Activated IC-21 cells on stainless steel discs produced significantly more NO compared to their control counterparts after 8-10 days and remained elevated for the duration of the experiment. Cell viability and cell count increased throughout the 30 days of culture with no significant differences in cell counts across the experimental groups. SEM analysis of select discs demonstrated macrophage-sized corrosive pits on stainless steel discs with cells. No significant difference in NO content was seen among $\mathrm{Ti}$ and $\mathrm{CoCr}$ groups and no indentions were found on the surface of these discs. On stainless steel, both nonactivated and activated cell groups were shown to have a statistically significant increase in metal ion release for $\mathrm{Cr}, \mathrm{Fe}$, and $\mathrm{Ni}(\mathrm{p}<0.05)$ compared to medium only. On $\mathrm{Ti}$, there was a significant increase in aluminum (Al) $(<0.001)$ and decrease in vanadium $(\mathrm{V})$ $(\mathrm{p}=0.003)$ among all groups compared to medium. No differences were seen among disc groups on CoCr. No difference was seen among activated and non-activated cells placed on all three types of discs.

Discussion. While the visual patterns seen in necropsy retrieved implants with ICIC and electrocautery damaged implants appear similar, the contents of the corroded regions are unique. The results of this study indicate that determining the ratio of $\mathrm{Fe} / \mathrm{C}$ for ICIC afflicted implants could distinguish between the two damage modes for future studies. The difference in roughness values found on ICIC damaged regions and electrocautery damaged regions also indicate examination of surface topography as another possible way to distinguish between the two damage mechanisms. Unlike electrocautery, the damage caused by ICIC takes place over many years, thus it is not surprising that the surface area is rougher. In vitro results showed that macrophages were able to attach and corrode the surface of stainless steel and titanium discs. No differences where seen among $\mathrm{CoCr}$ disc groups, therefore we cannot determine if corrosion is occurring during the 30 day period. However, evidence of cellular corrosion has been observed in $\mathrm{CoCr}$ retrieval studies. To get a more accurate representation a longer testing time may be necessary. The findings from this work serve as a good step towards understanding the underlying mechanisms of ICIC and electrocautery and will help future studies build upon the knowledge of the possible biological responses to implant materials. 


\section{TABLE OF CONTENTS}

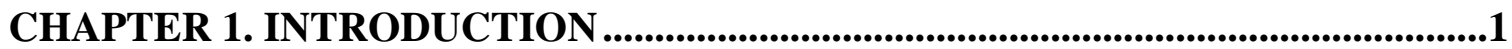

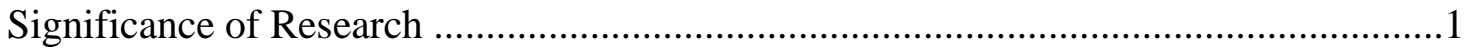

Biological Response to Wear Debris ..................................................................... 1

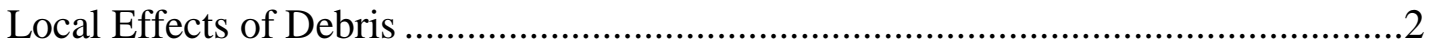

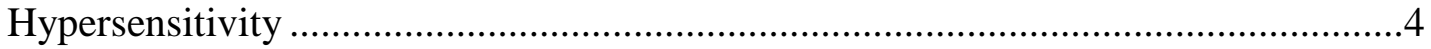

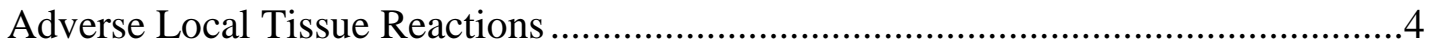

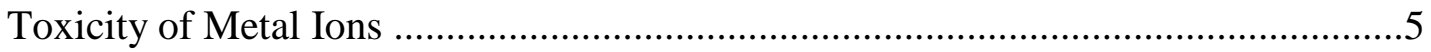

Inflammatory Cell Induced Corrosion ................................................................... 6

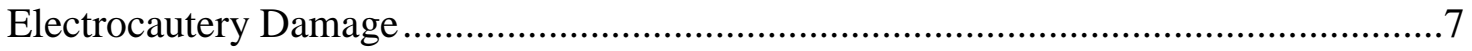

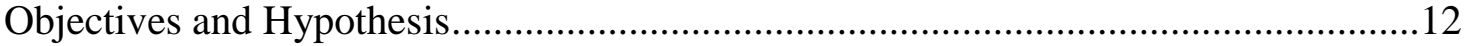

\section{CHAPTER 2. COMPARISON OF INFLAMMATORY CELL- INDUCED CORROSION (ICIC) AND ELECTROCAUTERY INDUCED DAMAGE OF TOTAL KNEE IMPLANTS .............................................................................14}

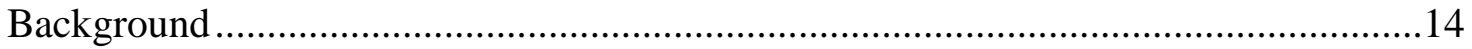

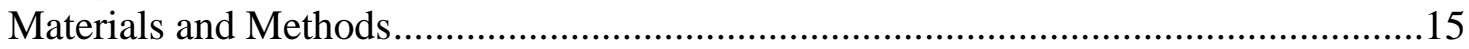

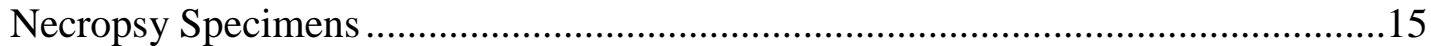

Electrocautery Damaged Specimens .............................................................. 16

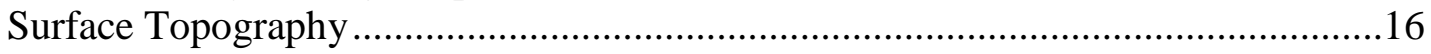

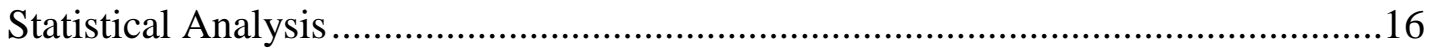

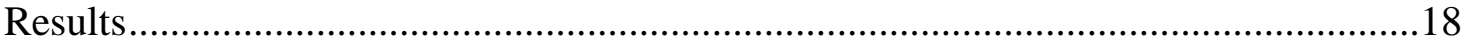

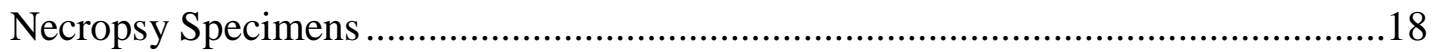

Electrocautery Damaged Specimens................................................................ 18

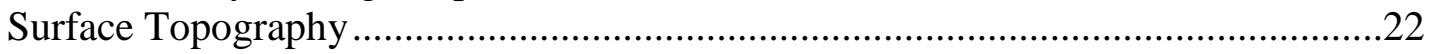

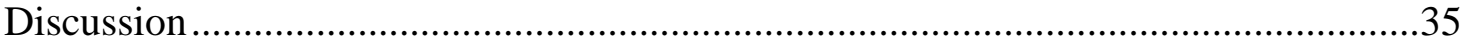

\section{CHAPTER 3. IN VITRO EFFECTS OF MACROPHAGES ON ORTHOPAEDIC IMPLANT ALLOYS AND LOCAL RELEASE OF METALLIC ALLOY COMPONENTS..................................................................................38}

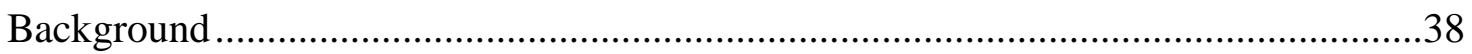

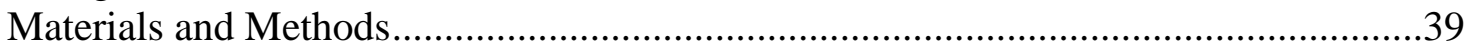

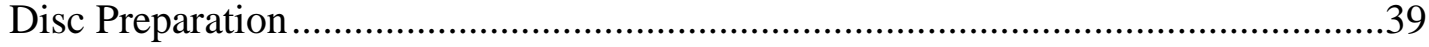

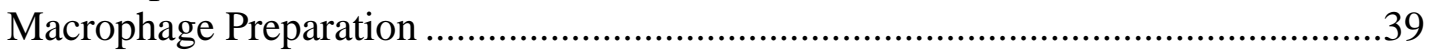

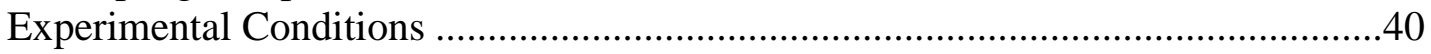

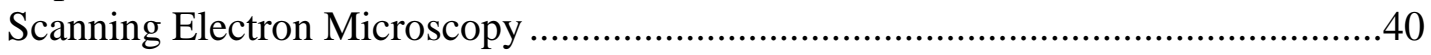

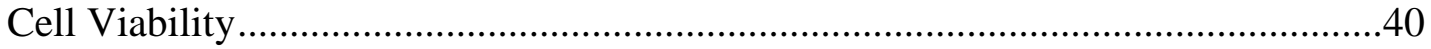

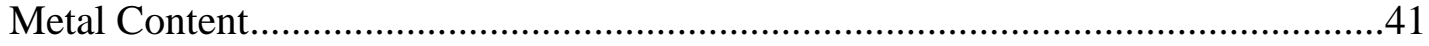

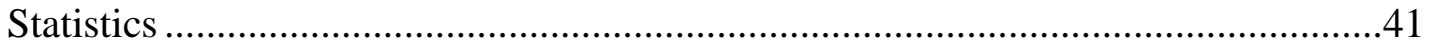

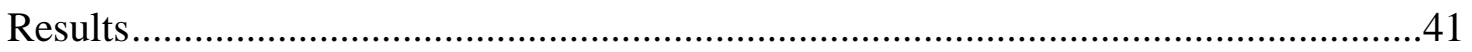

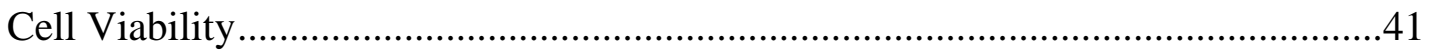

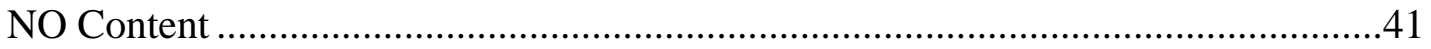

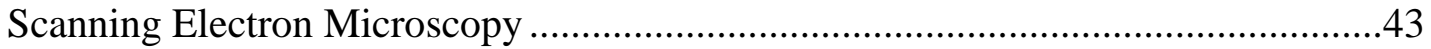

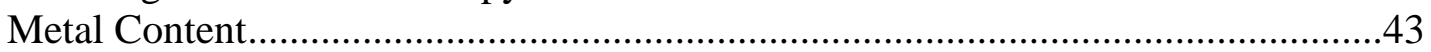


Discussion

CHAPTER 4. GENERAL DISCUSSION

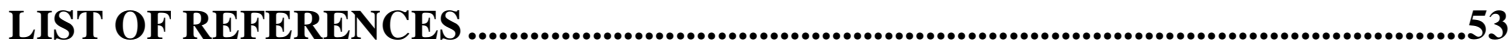

APPENDIX A. SURVEY ON ELECTROCAUTERY USE ANSWERED BY 102

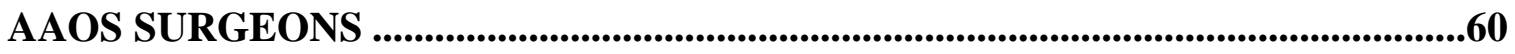

APPENDIX B. SUMMATION OF METAL CONTENT COLLECTED FROM 30 DAY IN VITRO STUDY ..............................................................................64 APPENDIX C. CLINICAL INFORMATION FOR IMPLANTS EXAMINED

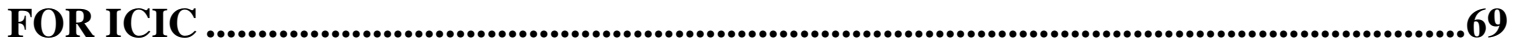

VITA 


\section{LIST OF TABLES}

Table 2-1. Median (IQR) measurements of $R_{\max }, R_{a}, R_{s k}$, and $R_{k}$ obtained via white light interferometry of $\mathrm{CoCr}$ implants

Table 2-2. Median (IQR) measurements of $R_{\max }, R_{a}, R_{s k}$, and $R_{k}$ obtained via white light interferometry of a Zirconium Nitride coated implant

Table 3-1. Median metal concentrations found the supernatant collected off stainless steel.....

Table 3-2. Median metal concentrations found the supernatant collected off Titanium alloy

Table 3-3. Median metal concentrations found the supernatant collected off $\mathrm{CoCr}$......45

Table C-1. Patient information for implants examined for ICIC .69 


\section{LIST OF FIGURES}

Figure 1-1. Biologic principles involved in wear particle-induced periprosthetic osteolysis .

Figure 1-2. The positive feedback loop created by ICIC................................................

Figure 1-3. Digital optical micrographs of ICIC damaged CoCr hip implants .................9

Figure 1-4. Diagram showing the application of a monopolar electrosurgery system....11

Figure 2-1. Damaged areas for the Zirconium Nitride (left), CoCrMo (middle), and Oxinium (right) implants............................................................................. 17

Figure 2-2. SEM images of ICIC on CoCr knee implants.............................................19

Figure 2-3. EDS results at two points of interest in ICIC damaged areas .......................20

Figure 2-4. Electrocautery damage done to the surface of $\mathrm{CoCr}$ knee implant at 500x magnification ...................................................................................... 21

Figure 2-5. Average percent weight of key elements detected by EDS at the base of pits on the surface of CoCr knee implants

Figure 2-6. Ratio of the percent weight of iron to the percent weight of carbon found at the base of pits on the surface $\mathrm{CoCr}$ knee implants.

Figure 2-7. Damage done to the surface of Zirconium Nitrate knee implant at 500x .....24

Figure 2-8. Damage done to the surface of Oxinium knee implant at 500x....................25

Figure 2-9. Average percent weight of each element detected by EDS at the base of pits on the surface of a Zirconium Nitride knee implant

Figure 2-10. Average percent weight of each element detected by EDS at the base of pits on the surface of an Oxinium knee implant.

Figure 2-11. $\mathrm{R}_{\max }(\mu \mathrm{m})$ measurements of $\mathrm{CoCr}$ damage groups obtained via white light interferometry

Figure 2-12. $R_{a}(\mu \mathrm{m})$ measurements of $\mathrm{CoCr}$ damage groups obtained via white light interferometry

Figure 2-13. $\mathrm{R}_{\mathrm{sk}}(\mu \mathrm{m})$ measurements of $\mathrm{CoCr}$ damage groups obtained via white light interferometry.

Figure 2-14. $R_{k}(\mu \mathrm{m})$ measurements of $\mathrm{CoCr}$ damage groups obtained via white light interferometry..... 
Figure 2-15. $\mathrm{R}_{\max }(\mu \mathrm{m})$ measurements of Zirconium Nitride damage groups obtained via white light interferometry....

Figure 2-16. $\boldsymbol{R}_{\mathrm{a}}(\mu \mathrm{m})$ measurements of Zirconium Nitride damage groups obtained via white light interferometry.

Figure 2-17. $\mathrm{R}_{\mathrm{sk}}(\mu \mathrm{m})$ measurements of Zirconium Nitride damage groups obtained via white light interferometry....

Figure 2-18. $R_{k}(\mu \mathrm{m})$ measurements of Zirconium Nitride damage groups obtained via white light interferometry.....

Figure 3-1. Cell count among the various groups involved in the stainless steel experiment at day 30

Figure 3-2. Griess assay results showing the amount of $\mathrm{NO}_{2}$ in the collected supernatant over the course of 30 days

Figure 3-3. SEM image at 500x showing macrophage-sized indentions found on the surface of $316 \mathrm{~L}$ stainless steel.

Figure 3-4. Total Co content found in the supernatant over the course of 30 days .46

Figure A-1. When you perform a primary total knee replacement do you use an electro-cautery or Aquamantys device?

Figure A-2. How often do you use the electro-cautery or the Aquamantys AFTER you have implanted your prosthetic components in a primary TKA?

Figure A-3. How often do you use the electro-cautery or the Aquamantys AFTER you have implanted your prosthetic components in a primary THA?

Figure A-4. After your prosthetic components are implanted during a primary TKA or THA do you ever touch the prosthetic metallic surfaces with the electro-cautery or the Aquamantys?

Figure A-5. When performing a revision TKA do you ever touch the metallic surfaces of the implants with the electrocautery or the Aquamantys prior to removal of the implants?

Figure A-6. When performing a revision THA do you ever touch the metallic surfaces of the implants with the electrocautery or the Aquamantys prior to removal of the implant?

Figure A-7. Do you believe that touching the metallic implant surface of a THA or TKA implant with the electrocautery or the Aquamantys can cause damage to the bearing surface of the implant?. 
Figure B-1. Summation of Cr content collected off Stainless Steel over 30 days ...........64

Figure B-2. Summation of Fe content collected off Stainless Steel over 30 days ..........64

Figure B-3. Summation of Mn content collected off Stainless Steel over 30 days..........65

Figure B-4. Summation of Ni content collected off Stainless Steel over 30 days ..........65

Figure B-5. Summation of Al content collected off Ti6Al4V over 30 days ..................66

Figure B-6. Summation of Ti content collected off Ti6Al4V over 30 days ..................66

Figure B-7. Summation of V content collected off Ti6Al4V over 30 days ...................67

Figure B-8. Summation of Co content collected off CoCrMo over 30 days....................67

Figure B-9. Summation of Cr content collected off CoCrMo over 30 days ...................68

Figure B-10. Summation of Mo content collected off CoCrMo over 30 days..................68 


\section{LIST OF ABBREVIATIONS}

Al

ALTR

$\mathrm{C}$

Co

$\mathrm{Cr}$

EDS

FBS

FBS

$\mathrm{Fe}$

ICIC

ICP-MS

IFN $\gamma$

IL

LPS

MHC

Mo

$\mathrm{N}$

NO

$\mathrm{O}$

OPG

PE

RANKL

ROS

SEM

TDTH

THA

TKA

TNF- $\alpha$

$\mathrm{V}$

$\mathrm{ZrN}$

MOM

MOP
Aluminum

Adverse local tissue reaction

Carbon

Cobalt

Chromium

Energy dispersive X-ray spectrometry

Fetal bovine serum

Fetal bovine serum

Iron

Inflammatory-cell induced corrosion

Inductively coupled plasma mass spectrometry

Interferon Gamma

Interleukin

Lipopolysaccharide

Major histocompatibility complex

Molybdenum

Nickel

Nitric oxide

Oxygen

Osteoprotegerin

Polyethylene

Receptor activator of nuclear factor kappa B ligand

Reactive oxygen species

Scanning Electron Microscopy

Delayed typed hypersensitivity t cells

Total hip arthroplasty

Total knee arthroplasty

Tumor necrosis factor- $\alpha$

Vanadium

Zirconium nitride

Metal-on-metal

Metal-on-polyethylene 


\section{CHAPTER 1. INTRODUCTION}

\section{Significance of Research}

Total joint arthroplasty is considered one of the most beneficial aspects of modern orthopedic surgery. It involves the removal and replacement of damaged or arthritic joints with an artificial device called a prosthesis, which is used to mimic the function of a normal joint $(1,2)$. Due to the increase in population, obesity rates, and access to medical care, total joint replacements have become more commonplace in the United States. Currently, more than 436,000 THAs and more than 680,000 TKAs are performed each year (3). Using data collected from 2000 to 2014, it is projected that by 2030 these numbers will grow $71 \%$ for THAs, to 635,000 , and $85 \%$ for TKAs, to 1.26 million (4). This has led to concerns about the longevity of orthopaedic implants and factors leading to implant failure. In 2014, Sharkey et al. investigated the most common causes of revision surgery (5). They reported the most common causes of implant failure are aseptic loosening, periprosthetic joint infection, instability, periprosthetic fracture, arthrofibrosis, patella resurfacing, polyethylene wear, patella loosening, malalignment of the implant, and extensor mechanism deficiency. Infection, observed in $37.6 \%$ of revision cases, was shown to be the most common reason for revision in patients within two years of their primary TKA. The most common mechanism of long term implant failure was shown to be aseptic loosening, responsible for $51.4 \%$ of patients undergoing revision surgery more than two years after their primary TKA. Compared with the results from the same group in 2002 (6), failure due to PE wear has drastically decreased in recent years from $55.6 \%$ to $3.5 \%$. This decrease is likely due to the development of more wear resistant biomaterials and improvement in locking mechanisms into the tibial tray (7). Recently, a new type of damage has been investigated in implants that remains poorly understood and highly controversial. Originally, researchers believed this damage type is caused by inflammatory cells directly attacking the metal surface, leading to damage of the oxide layer. However, damage caused by electrocautery tools often used in revision surgeries has shown identical characteristics, leading some to believe this is the true cause. This study aims to distinguish between these two damage mechanisms and investigate the biological response of inflammatory cells to common orthopaedic metal alloys.

\section{Biological Response to Wear Debris}

In order to understand the choice of materials used in total joint arthroplasty, one must first understand the term "biocompatibility. Biocompatibility is often defined as "The ability of a biomaterial to perform its desired function with respect to a medical therapy, without eliciting any undesirable local or systemic effects in the recipient or beneficiary of that therapy, but generating the most appropriate beneficial cellular or tissue response in that specific situation, and optimizing the clinically relevant performance of that therapy" (8). In the case of metals involved in arthroplasty, the goal of total biocompatibility is unrealistic. Any type of implant regardless of the material 
used will result in some type of response (8). Instead, implant requirements are geared towards maximizing suitable mechanical properties (toughness, fatigue strength, corrosion resistance, wear resistance, etc.) to maximize their longevity in vivo (8). Normal motion of the implant in the joint following surgery leads the production of polyethylene (PE) and metallic debris, made up of soluble ions and insoluble metal particles. These particles have the possibility to induce a response from the body.

\section{Local Effects of Debris}

There are currently four different biomaterials mainly used in total joint replacement surgeries: polyethylene (PE), metal, ceramic, and polymethylmethacrylate. The focus for this discussion will involve metal and PE particles. Particles of micrometer and sub-micrometer size are phagocytosed by macrophages, fibroblasts, neutrophils, lymphocytes, giant cells, and osteoclasts [9-10]. Studies have suggested the cellular response to wear particles vary with size, composition, shape, charge, and number of particles present (11-12).

The precise nature of how cells are stimulated remains unknown, but it is believed that recognition of wear particles takes place during phagocytosis of the small particles by macrophages and interactions with toll-like receptors on the cell surface [13]. Once they are recognized macrophages enlarge their cytoplasm within 48 hours initiate an inflammasome cascade leading to chemokine and cytokine production (Figure 1-1). Not all pathways involved with macrophage response to wear debris are fully understood, but the central proinflammatory cytokines released are believed to be tumor necrosis factor- $\alpha$ (TNF- $\alpha$ ) and interleukin family cytokines (IL-1 $\alpha$, IL-1 $\beta$, IL-6, IL-10, IL-11, IL-15), macrophage colony-stimulating factor (M-CSF) and the central chemokines are IL-8, monocyte chemoattractant protein-1 and macrophage inflammatory protein-1 $\alpha(10,13$ $17)$.

Osteoblasts have been shown to produce the receptor activator of nuclear factor kappa B ligand (RANKL) in response to wear debris and proinflammatory cytokines. These products lead to the upregulation of osteoclast differentiation, maturation, and function in the adjacent area to bone-implant interfaces and the downregulation of osteoblast activity. Osteoclasts then lead to resorption of the bone around the implant. When RANKL binds to RANK on the surface of osteoclast precursor cells it allows them to differentiate into functioning osteoclasts. Osteoprotegerin (OPG) acts as a decoy receptor for RANKL to naturally control the number of osteoclasts (18). When an influx of chemokines and cytokines are present and osteoblasts react to wear debris, the RANKL/OPG balance becomes imbalanced, thus leading to a disruption of bone homeostasis. The RANK/RANKL pathway is considered the principal axis regulating osteoclastogenesis and studies have shown that the erratic activity of this pathway leads to aseptic loosening of the implant, one of the primary causes of implant failure (16-18). 


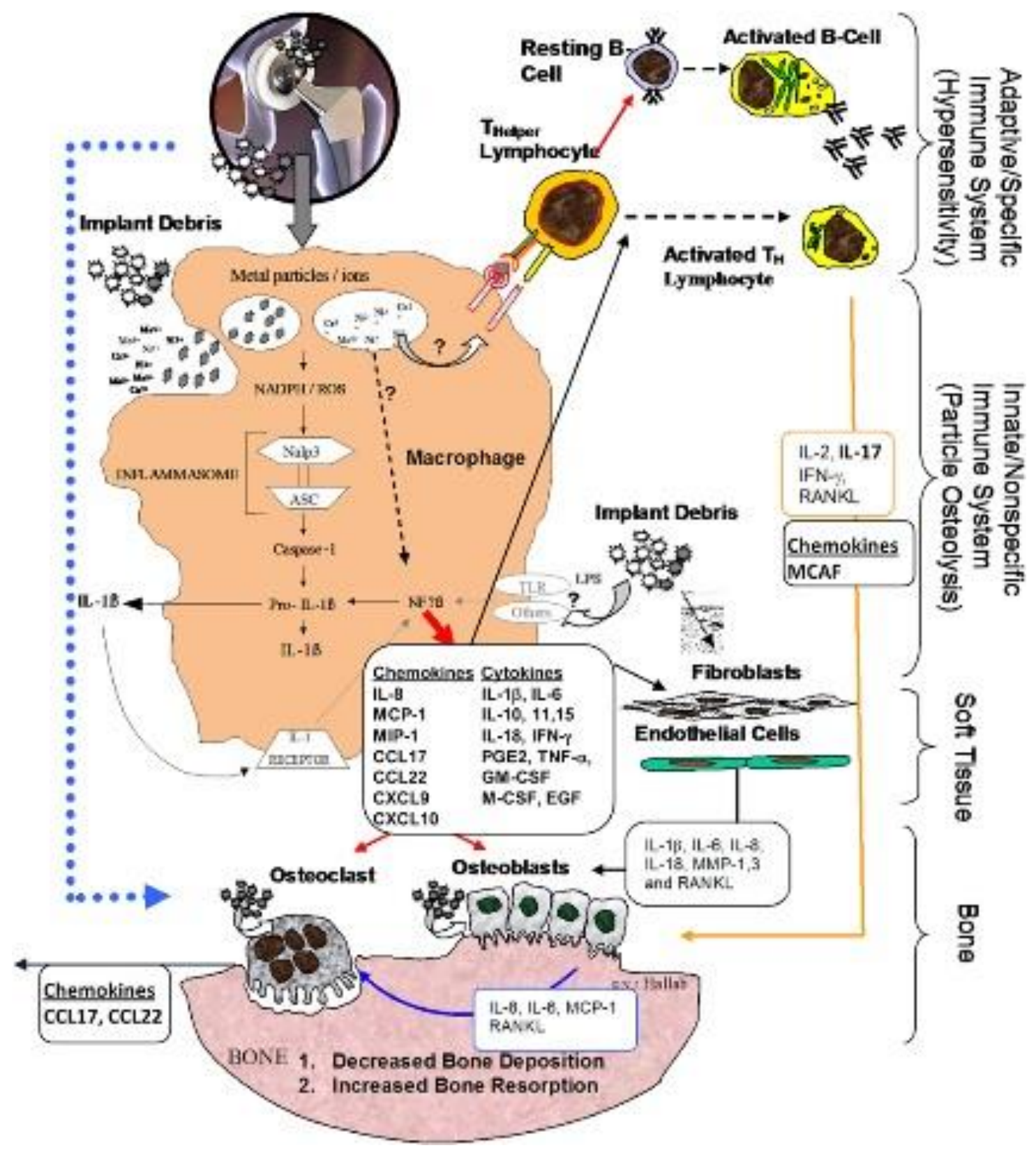

Figure 1-1. Biologic principles involved in wear particle-induced periprosthetic osteolysis

Reprinted with open access permission. Hallab NJ, Jacobs JJ. Chemokines associated with pathologic responses to orthopedic implant debris. Frontiers in endocrinology. 2017 Jan 19;8:5 [14]. 


\section{Hypersensitivity}

Many studies have been conducted in the past on the potential association of orthopaedic implants and hypersensitivity reactions such as dermatitis, vasculitis, urticaria, and osteolysis leading to aseptic loosening (9). Dermal hypersensitivity to metal has been reported in $10 \%$ to $15 \%$ of the general population. Women tend to be more at risk for hypersensitivity issues, with $17 \%-32 \%$ of the female population responding to dermal testing $(19,20)]$. Among patients that have undergone a total joint replacement, metal sensitivity was reported for approximately $25 \%$ of patients with well-functioning implants and $60 \%$ of patients with failed or failing implants. While this is significantly higher than the incidence rate found among the general population, making a conclusion based on symptomatic patients is still not possible. It remains unclear whether these patients had a preexisting metal sensitivity that led to implant failure, or if the implant failure led to a metal sensitivity (21). Metals known as sensitizers include nickel, cobalt, chromium, beryllium, tantalum, titanium, and vanadium (21). The most common allergyinducing metals are nickel, followed by cobalt and chromium.

Implant related hypersensitivity reactions tend to be a cell mediated type IV delayed hypersensitivity reaction. In this case, the metal ions bind with native proteins and form haptens. These metal hapten complexes are recognized by antigen presenting cells, such as macrophages and $\mathrm{B}$ cells, and present antigens to $\mathrm{T}$ cells. The reaction occurs when $\mathrm{T}_{\mathrm{DTH}}$ ( $\mathrm{T}$ cells involved with delayed-type hypersensitivity) lymphocytes, a subset of CD4+ helper lymphocytes, are activated and interact with major histocompatibility complexes (MHC) class II molecules to release interferon-gamma. Macrophages are then activated to secrete cytokines, such as IL-3, granulocytemacrophage colony stimulating factors, monocyte chemotactic activating factors, and migration inhibitory factors. Monocyte chemotactic activating factor promote movement of monocytes towards areas of a delayed hypersensitivity reaction. Migration inhibitory factors prevent migration of macrophages that are already at the site of a delayed hypersensitivity reaction. Due to macrophages ability to present class-II MHCs and IL-1, they can trigger further activation of $\mathrm{T}_{\mathrm{DTH}}$ cells, leading to a forward feedback loop of even more cells migrating to that area, creating a self-perpetuating reaction causing severe damage to the neighboring tissue and loosening of the implant (21-23).

\section{Adverse Local Tissue Reactions}

Adverse local tissue reactions (ALTR) result from an immune-mediated biological reaction to metal wear debris that lead to an undesired effect on the tissue surrounding an implant. This inflammatory response can lead to metallosis, synovitis, and degradation of capsule, and soft tissues in the area. One study (24) examined THA patients showing signs of ALTR ranging from within a year of implantation to several decades after. The most common symptom is pain around the groin, buttock, thigh, or peritrochanteric region. Other symptoms include swelling or fluid collection around the hip. Serum metal levels showed an increase in both chromium and cobalt levels (24). There have been numerous accounts associating ALTR with patients with failed metal- 
on-metal (MOM) bearings (25-27). However, in recent years ALTRs appear to be increasing in metal-on-polyethylene (MOP) THAs. It is unknown if the prevalence is truly increasing or if it is just an increase in awareness (25).

The three major types of ALTR include, osteolysis, pseudotumors, and aseptic lymphocyte-dominated vasculitis-associated lesions (ALVAL). Osteolysis refers to osteoclast resorption leading to the degradation of bone surrounding an implant. Aseptic loosening due to osteolysis is responsible for 75 percent of all total joint replacement implant failures over time (14). Wiley et al. examined 14 articles, with a cohort of 13,898 MoM hips total, and found the incidence rate of pseudotumors/ALVALs ranged from 0 $\%$ to $6.5 \%$ (26)]. Histologically, pseudotumors are characterized as large cyst-like masses with heavy infiltration of $\mathrm{T}$ lymphocytes and macrophages with extensive necrosis (28). Patients with pseudotumors often have severe pain, nerve palsy, and spontaneous dislocation of the afflicted joint. However, not all cases of this type of ALTR have shown to be symptomatic. Due to this reason, many researchers believe the prevalence of pseudotumors is greater than that represented in literature (29). ALVALs displays a reaction similar to that of a type IV hypersensitivity reaction in the soft tissue around the implant site. It is characterized by soft tissue necrosis, infiltration of lymphocytes, and abnormal joint fluid. ALVAL tissue samples collected post revision surgery have shown an infiltration of T-cells and B-cells, but to a lesser extent than those found in pseuodotumors (30).

\section{Toxicity of Metal Ions}

There remains concern regarding the release of soluble metal ions from implants which bind to proteins and disseminate into the surrounding tissue, bloodstream, and organs. Normal values of common orthopaedic metal ion concentrations naturally found in human serum are as follows: 1 to $10 \mathrm{ng} / \mathrm{ml} \mathrm{Al,} 0.15 \mathrm{ng} / \mathrm{ml} \mathrm{Cr}$, less than $0.01 \mathrm{ng} / \mathrm{ml} \mathrm{V}$, 0.1 to $0.2 \mathrm{ng} / \mathrm{ml} \mathrm{Co}$, and less than $4.1 \mathrm{ng} / \mathrm{ml} \mathrm{Ti}(31)$.

Co and $\mathrm{Cr}$ have proven to be toxic in high concentrations and even wellfunctioning implants have shown to lead to an increase of up to three to five times the normal concentrations (31). Co and $\mathrm{Cr}$ generated from implants have shown to travel via blood and lymph to bone marrow, lymph nodes, the spleen, the liver, and the heart (32). Excess Co in the body can lead to neurological (tinnitus, vertigo, blindness, deafness, convulsions), endocrine (hypothyroidism), and cardiological (cardiomyopathy) symptoms (33). Cr ions primarily show in two valence states, $3+$ and $6+$. Cr3+ ions are generally considered nontoxic in low amounts and can even commonly be found in food. Cr6+ however, has proven to be highly toxic and is now regarded as a group 1 carcinogen that can lead to pulmonary epithelial cancer (34)]. Both $\mathrm{Co}$ and $\mathrm{Cr}$ has shown to have shown possibly genotoxicity problems as a result of oxidative stress. Co has shown genotoxic effects through single strand breaks during a Fenton like reaction, inhibition of topoisomerase II, and inhibition of DNA repair mechanisms $(35,36)$. Cr is believed to damage DNA through production of reactive oxygen species when $\mathrm{Cr} 4+$ is reduced to $\mathrm{Cr} 3+$. Cr3+ damages DNA via cross-linking, and both single and double strand breaks 
(37). In vivo studies among CoCr MOM patients have shown a correlation between metal ion levels and increased lethal and non-lethal aneuploidy and chromosomal translocations. Both metal ions, especially $\mathrm{Co}$, have also shown to be highly cytotoxic. Kwon et al. showed a significant decline in macrophage viability in the presence of Co nanoparticles, where $\mathrm{Cr} 3+$ particles showed no significant reduction at equal concentrations (38). Both types of ions stimulate TNF- $\alpha$ secretion and macrophage and lymphocyte apoptosis (23). The exact cause for the decrease in cell viability remains unknown. A study by Papageorgiou et al. used electron microscopy to examine response of fibroblasts to these ions. An excess of nanoparticles was reported on the outside of the cell where it is believed they crossed the cell membrane and disintegrated within cellular vacuoles. Results showed damage to these vacuoles, concentrations of $\mathrm{Cr}$ in the cytoplasm, and concentrations of Co in electron-dense particulate deposits (39).

The main components of stainless-steel alloys are $\mathrm{Fe}, \mathrm{Cr}$, and $\mathrm{Ni}$. Fe is abundant in the body and has shown to only be toxic when in extreme excess within the body. The most concerning ions release from stainless-steels are $\mathrm{Cr}$ and $\mathrm{Ni}$. $\mathrm{Cr}$, as previously mentioned, can lead to cytotoxic and genotoxic issues within the body. Ni and $\mathrm{Cr}$ are also known sensitizers and can lead to a hypersensitivity reaction. The released corrosion products of stainless steel has been shown to inhibit osteoblast activation and stimulate inflammation. Bailey et al. examined the effect of macrophages on 316 and nitrogenated stainless steel and discovered significant increase in IL-1ß and TNF- $\alpha$ expression among both alloy groups (40). Cadosch et al. investigated the release of stainless-steel particles when osteoclasts were placed on the surface of stainless-steel discs and discovered increased IL-1ß, IL-6, and TNF- $\alpha$ expression. These proinflammatory cytokines are known to enhance osteoclast activity, leading to possible osteolysis around the implant (41)

Ti6Al4V (ASTM F136) is the most commonly used titanium alloy used in orthopaedic implants and has been known to stimulate inflammation and bone resorption (42). Ti, Al, and V are genotoxic and are believed to cause damage by DNA breakage through attack on free radicals, or by inhibiting the repair mechanisms of DNA in cells that take up the metal particles (43). While Ti alloys are known be have few toxicity issues, Ti particles appear to release more inflammatory mediators such as IL-1ß, IL-6, and TNF- $\alpha$ compared to Co or Cr particles. Al toxicity has been correlated with a variety of neurological conditions such as memory loss, disruption of gait, involuntary movement, or amyotrophic lateral sclerosis. Possible correlations have also been seen in Al concentrations in the brain with development of Parkinson's disease or Alzheimer's $(44,45)$.

\section{Inflammatory Cell Induced Corrosion}

Cocr alloys are widely used in total knee arthroplasties (TKAs). Recently, a new type of damage has been investigated in $\mathrm{CoCr}$ components termed "inflammatory cellinduced corrosion" (ICIC). Direct in vivo ICIC of CoCrMo alloy in retrieved MOM and MOP hip and knee implants has been first reported by Gilbert et al (46). They 
hypothesized that metallic ions and wear particles brought about by mechanically assisted corrosion mechanisms could lead to an immune response in some patients, resulting in the attack of inflammatory cells or phagocytic cells in the skeletal system such as osteoclasts, foreign body giant cells, macrophages, and polymorphonuclear leucocytes on the surface of metal implants (47-49). Gilbert's group stated that these cells attached to the surface and release reactive oxygen species (ROS), specifically $\mathrm{H}_{2} \mathrm{O}_{2}$, that can lead to damage of the oxide film of cobalt-chromium-molybdenum alloy (CoCrMo).

The corrosion is likely to lead to another inflammatory response, thus creating a positive feedback loop (Figure 1-2). These attacks create to a unique damage pattern typically found on non-contacting regions of retrieved components. This pattern consists of individual spots of discolored regions consisting of ruffled topography, small pits or circular/crater-like features, large hazy surfaces, and discolored pattern of ruffles or raised edges in sizes ranging from $10-100 \mu \mathrm{m}$ (46) (Figure 1-3). These sizes are consistent with the sizes of inflammatory cells. Iron nodules are consistently observed in ICIC regions. Iron has been known to further aggravate inflammation when ROS are present $(39,40)$ and is a fundamental component of phagocytic cells. The presence of these iron nodules suggests a fenton-like reaction is taking place.

With ICIC gaining attention, many groups have moved toward examining the prevalence of ICIC among implants. Gilbert et al. (46) investigated a total of 69 different CoCrMo retrieved components from 51 implant systems were investigated including 18 hip acetabular liners, 37 heads, and 14 knees. Seventy four percent showed signs of ICIC damage . Di Laura et al. (50) investigated the clinical relevance of ICIC in $100 \mathrm{CoCr}$ alloy hips and found 59\% of the implants showed evidence of surface damage associated with ICIC and there was a significant association between the ICIC patterns and aseptic loosening. Kurtz et al. (51) investigated a total of 52 TKA femoral components with only 15 of them showing signs of ICIC damage (29\%). They estimated that ICIC damage covered $0.11 \pm 0.12 \mathrm{~mm}^{2}$ (Range: $0.01-0.46 \mathrm{~mm}^{2}$ ) of surface area on the implant. It was also observed that over $50 \%$ of the observed ICIC femoral components also had mechanically assisted crevice corrosion, suggesting a possible correlation between the two (51) Hart et al. investigated $28 \mathrm{CoCr}$ femoral components and 9 tibial components, with evidence of ICIC being present in $71 \%$ and $100 \%$ respectively. ICIC was shown to be significantly more present on non-articulating regions $(\mathrm{p}<0.0001)$ and there is a correlation between the presence of ICIC and implant instability ( $\mathrm{p}=0.0113)(51)$.

\section{Electrocautery Damage}

Electrosurgery is the clinical use of a high frequency alternating electrical current cut and coagulate tissues (52). The resistance of the tissue, which is dependent on its water content (53), causes it to heat up as the electrical energy is converted into thermal thermal energy. As the temperature rises, the thermal energy dissipates into the surrounding tissue, thus causing cauterization of the area (52). 


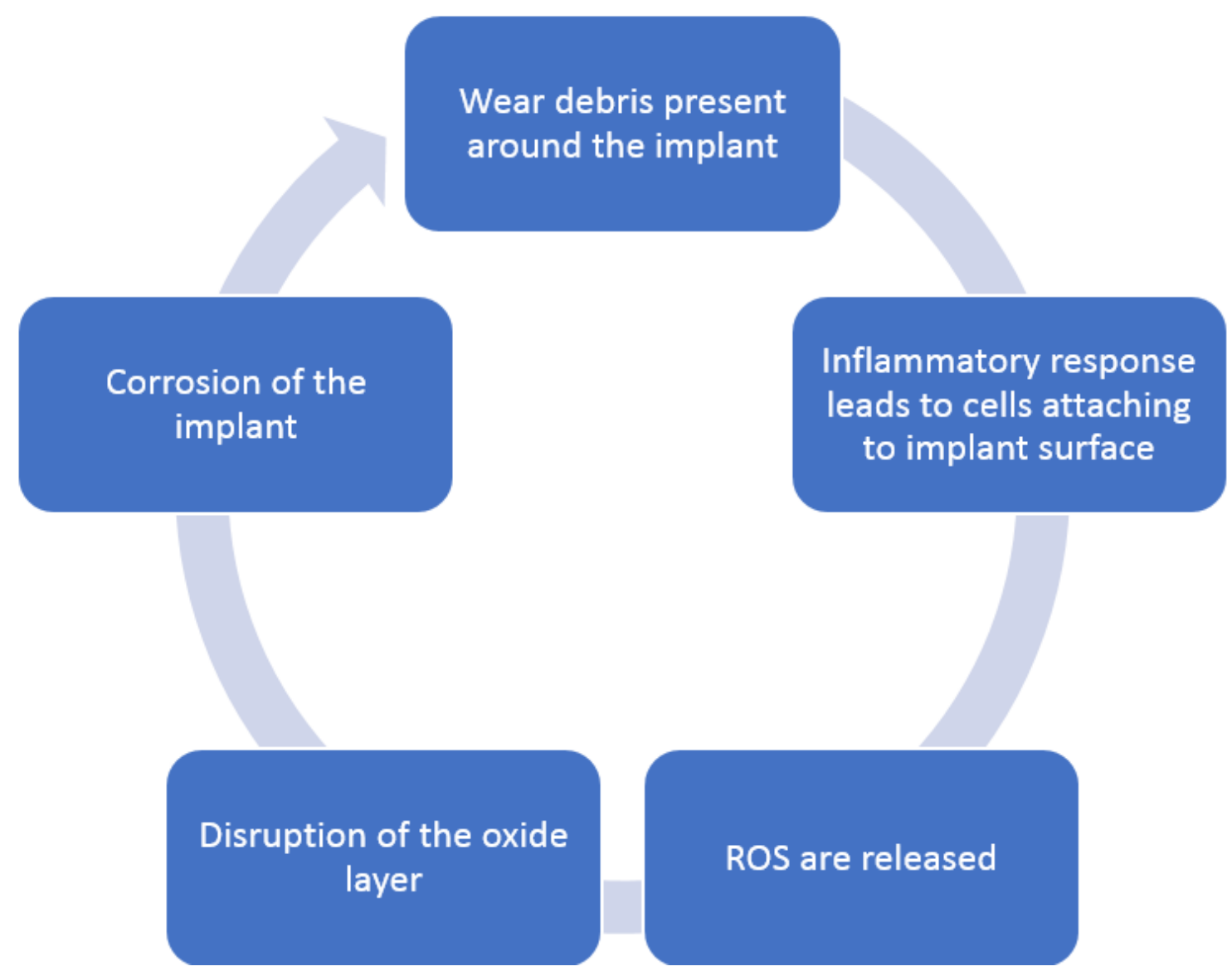

Figure 1-2. The positive feedback loop created by ICIC 


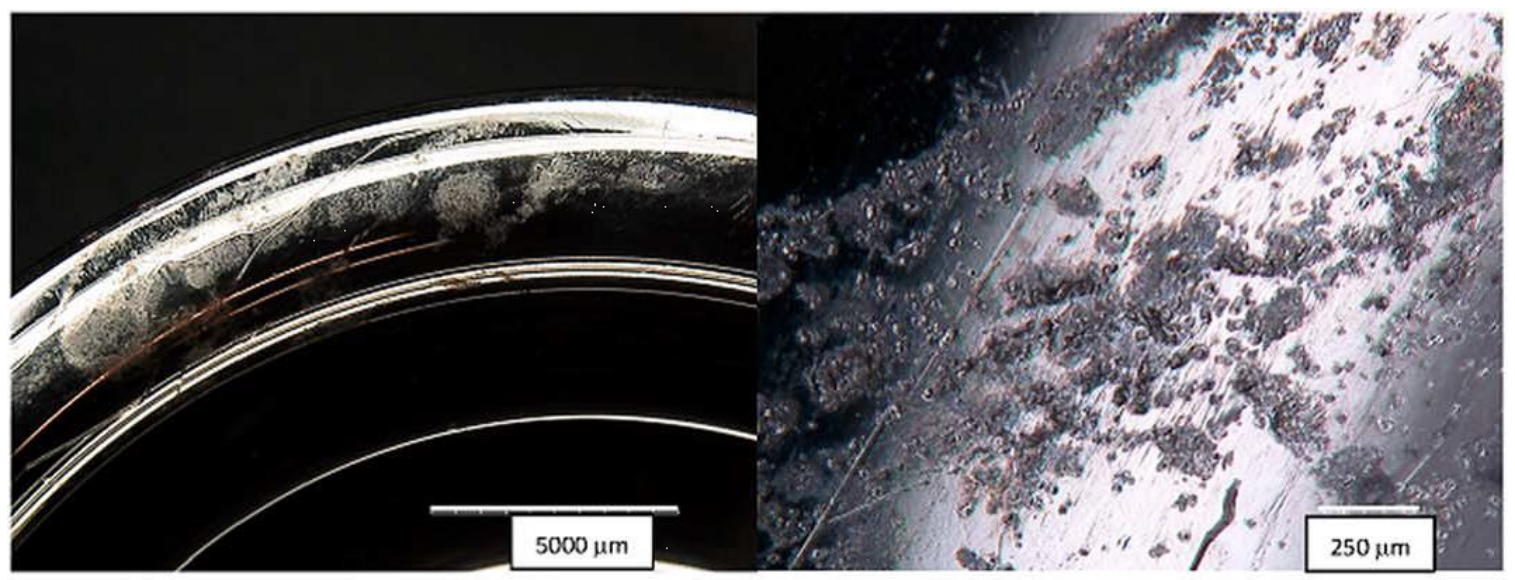

A

B

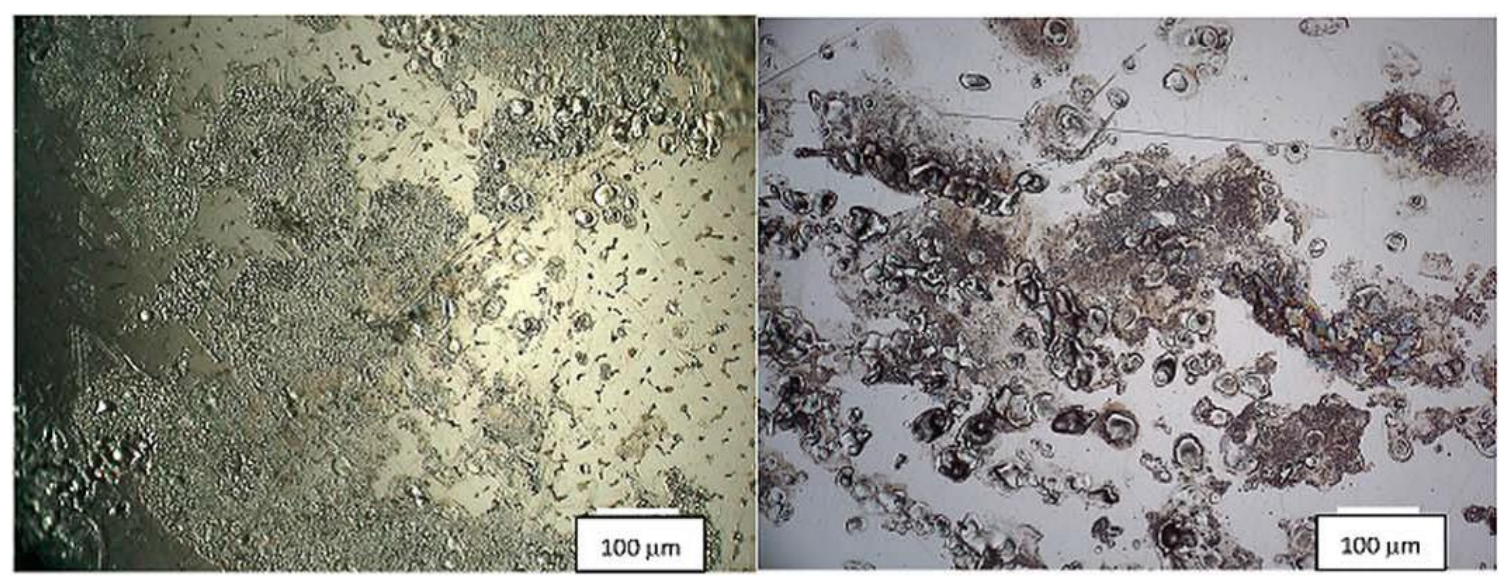

C

D

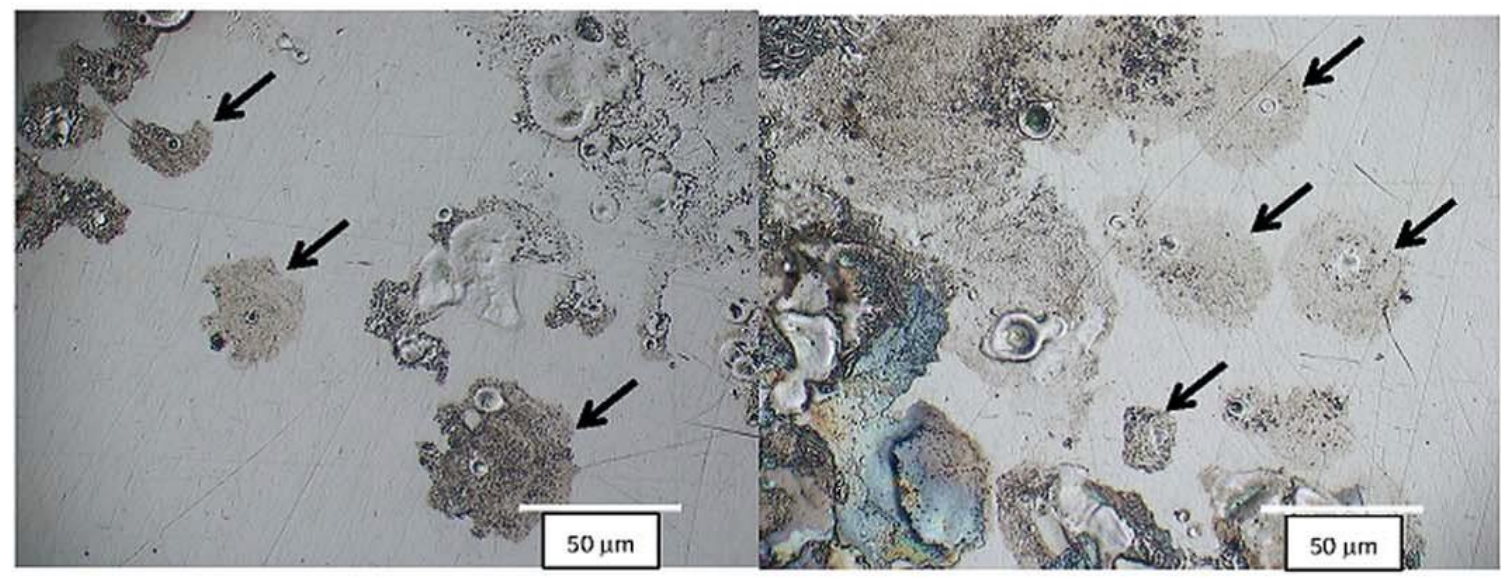

$\mathbf{E}$

$\mathbf{F}$

Figure 1-3. Digital optical micrographs of ICIC damaged CoCr hip implants

Reprinted with permission. Gilbert, Jeremy L., et al. "Direct in vivo inflammatory cellinduced corrosion of CoCrMo alloy orthopedic implant surfaces." Journal of Biomedical Materials Research Part A 103.1 (2015): 211-223 [46]. 
Cauterization use dates back as far as prehistoric times, when stones were heated in order to close wounds and obtain hemostasis. Conductive heating of tissue became a tool in medicine in the sixth century B.C. During the $18^{\text {th }}$ century, discoveries involving electricity and its effect on tissue started becoming more commonplace (45). In 1786, Luigi Galvani's experiments led to the birth of electrophysiology when he accidently brushed frogs' legs hanging from copper hooks against his iron balustrade and noticed the muscles starting to spasm. In 1881, Morton discovered that an oscillating current can pass through the human body without causing spasm, pain, or burning if held at a frequency of $100 \mathrm{kHz}$ (54). During the $19^{\text {th }}$ century, medical uses of electricity were being realized; such as the treatment of articular and circulatory ailments from the application of electrical currents, the removal of ulcers on the hand, or lesions of the skin, bladder, and oral cavity, as well as coagulation of hemorrhoids and vascular tumors (54). In 1910, William Clark created an apparatus capable of penetrating deep into tissues by increasing the amperage and decreasing the voltage in previous designs. The first to develop an instrument capable of utilizing cauterization in a practical manner was the "father of electrosurgical devices", William T. Bovie (55). In 1927, he created a diathermy unit that produced a high frequency current that could be used for cutting, coagulation, and desiccation. This invention was the prototype to the current monopolar Bovie design used today. Currently, electrosurgery has a variety of uses in the operating room, with cauterization being the most common application.

Monopolar electrosurgery device designs have the active electrode at the site of the surgery, while the return electrode, often referred to as a dispersive pad, is placed elsewhere on the body (Figure 1-4) (56). When activated, the current passes through the body from the active electrode to the return electrode. Monopolar devices should not be used on patients with internal devices, such as pacemakers, as the current can meet the device as is travels through the body. Bipolar electrosurgery device designs, such as the Aquamantys, involve both the active and return electrode being place at the surgical site using one handheld instrument connected to a generator. These systems have shown to have more control over where the current passes through the tissue and can be used in patients with implantable devices. While both styles have shown to be effective, monopolar designs remain the most commonly used due to their versatility (57).

Some believe that the unique damage characteristics attributed to ICIC are instead damage created by electrocautery tools during surgery. Survey results from 102 surgeons from the American Academy of Orthopaedic Surgeons (Appendix A) show that it is possible that electrocautery tools can come into contact or come to close proximity with the implant in both primary and revision surgery. A study by Campbell et al. examined 1859 metal implants for damage indicative to ICIC found in previous studies. [58]. Next, they marked a cleaned, flat, polished, CoCrMo disc using a standard Bovie tip set at the standard cautery mode of 70 Volts. A dispersive plate with a conductive self-adhesive was used to ground the disc before marking. Dotting (repeated on and off contact with 


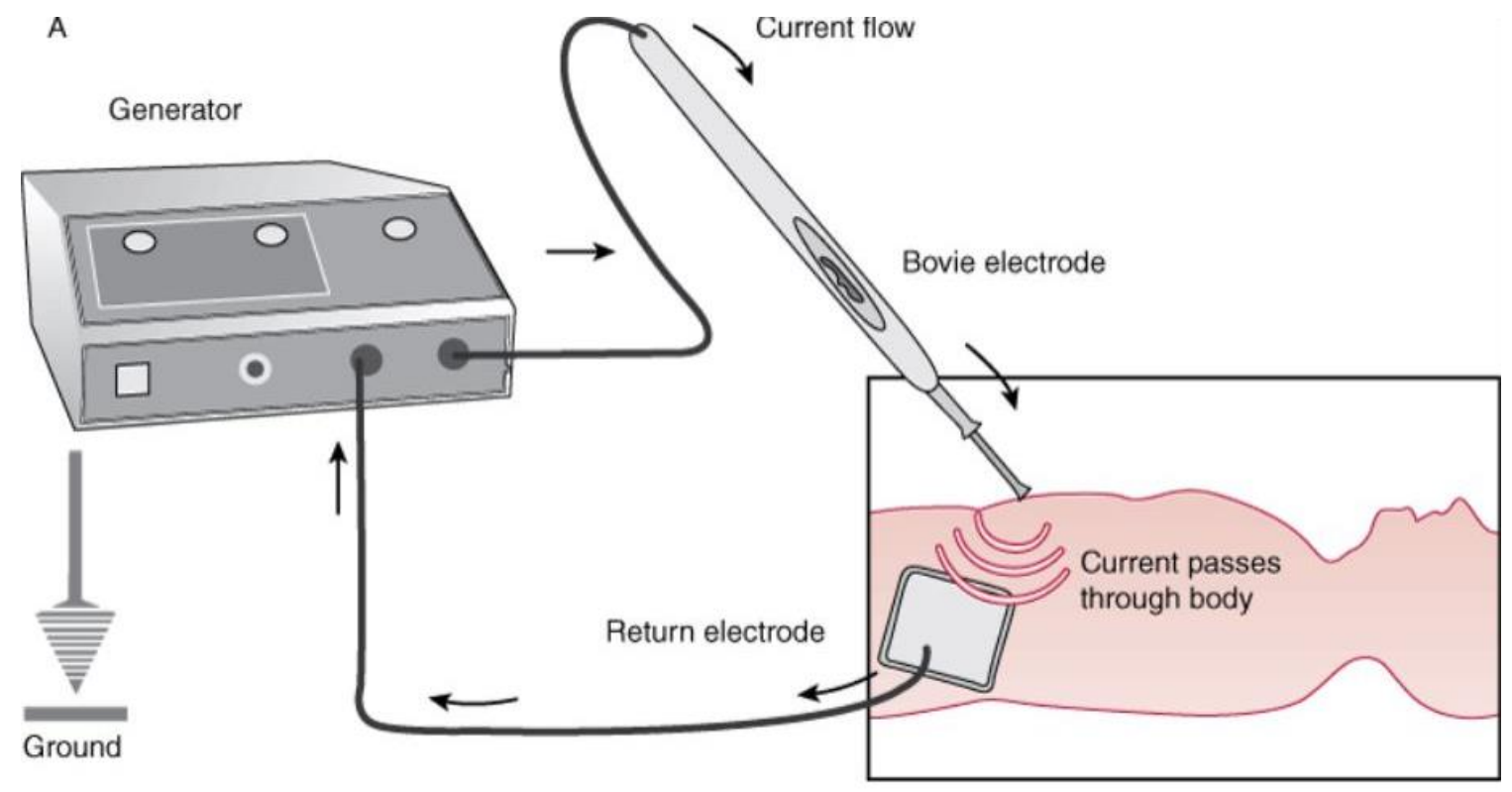

Figure 1-4. Diagram showing the application of a monopolar electrosurgery system

Reprinted with permission. Doherty, Gerard M., ed. Current diagnosis \& treatment: surgery. Lange Medical Books/McGraw-Hill, 2010. Doi:

http://accessmedicine.mhmedical.com.ezproxy.uthsc.edu/content.aspx?bookid=1202\&sec tionid=71516149. [56] 
the direct surface), dragging (surface contact remaining constant), and hovering (holding several millimeters above the surface) techniques were used to mimic surgeon behavior. The pits and markings left by the electrocautery damage proved comparable to those found in ICIC like damage patterns found in implants. Other studies have done comparisons of the two theories using CoCrMo and Ti-6Al-4V discs with the use of a Conmed reusable electrosurgical pencil set in monopolar mode (59). The observed damage included melting, pitting, and oxide formation. These results closely resembled that of ICIC, especially the damage examined on discs that were wetted with $10 \mu \mathrm{L}$ phosphate buffered saline. They also tested the ability of the plasma arc to travel through a hydrated 5\% agarose hydrogel covering the disc with the active electrode coming into contact with gel surface. It was discovered that damage was produced through $3 \mathrm{~mm}$ of gel, suggesting that the plasma arc generated from electrocautery tools such as the Bovie could still damage the surface of the implant by passing through the neighboring tissue. While many features indicative of ICIC can be explained, there are still many damage modes seen in previous retrieval studies that were not seen with electrocautery damage, such as the presence of cellular material inside or around damaged areas and corrosive streaks indicative to the paths of migratory inflammatory cells (59).

\section{Objectives and Hypothesis}

With increasing population, obesity rates, and medical advances, total knee arthroplasty is growing more commonplace with each passing year. In turn, this leads to an increase in revision arthroplasties due to complications. For this reason, understanding the mechanisms leading to these complications is crucial for moving forward with orthopaedic research. The biological response to implants remains complex and poorly understood. Recently discovered ICIC damage in retrieval studies shows one mechanism on how the body can respond to implants. Previous retrieval studies have focused on examination of failed implants retrieved at the time of revision surgery $(46,47,50,51)$, leading to the possibility that this type of damage was instead caused by electrocautery tools, commonly used in knee revisions. By selecting only wellfunctioning implants retrieved at time of necropsy, our first objective of this study was to find the true incidence rate of ICIC, without the possibility of electrocautery damage obscuring the results. The second objective to examine the contents of the pits left on the surface of ICIC damaged necropsy retrieved specimens and electrocautery damaged specimens by examining their elemental concentrations detected via SEM in order to create a distinction between the two damage mechanisms. We hope to find further distinction between the two damage types by examining the topography of the damaged areas, represented as various roughness parameters. Additionally, the elemental profiles and topography results will be presented for Oxinium and Zirconium Nitride electrocautery damaged implants and how they compare with that found on CoCr. The final objective is to examine the effect macrophages have on the surface of common stainless steel, titanium and CoCr alloys used in orthopaedics by allowing IC-21 macrophages to adhere to the surface of metal discs for 30 days and activate them using LPS and IFN $\gamma$. To this end, the following hypotheses were tested: 
a) The prevalence of ICIC among the retrieved implants will be lower than that of past retrieval studies because there is no possibility of electrocautery damage being mistaken as ICIC.

b) Examination of the surfaces of necropsy retrieved and electrocautery damaged implants will show similar visual patterns. However, the elemental compositions found in the pits on the surface will be unique. Necropsy retrieved implants will show evidence of a biological response, thus carbon and salts will be more prominent.

c) Roughness measurements will be higher for electrocautery damaged areas compared to ICIC damaged areas because it of the extreme nature of the damage mechanism itself occurring over a short period of time.

d) Increased NO expression will be found when macrophages attached to the surface of the various metal discs are activated with LPS and IFN $\gamma$. This increase will show that the cells are indeed activating and are affecting the metal.

e) Increased metal concentrations will be found in the supernatant collected from wells containing discs with macrophages attached to the surface when compared to the supernatant of wells containing discs with only medium. There will be an even greater increase in concentration when those macrophages are activated with LPS and IFN $\gamma$. The increase in metal ions found via ICP-MS will indicate that the macrophages are disrupting the surface oxide layer of the metals, leading to corrosion 


\title{
CHAPTER 2. COMPARISON OF INFLAMMATORY CELL- INDUCED CORROSION (ICIC) AND ELECTROCAUTERY INDUCED DAMAGE OF TOTAL KNEE IMPLANTS
}

\begin{abstract}
Background
TKA has been shown to be an effective means for the treatment of diseases such as osteoarthritis and rheumatoid arthritis as well as damage done to the joint in cases of severe trauma. However, $10 \%$ to $15 \%$ of patients have reported unsatisfactory results compared to their expectations and up to $20 \%$ of patients have reported long term pain (60-62). The most common causes of implant failure are aseptic loosening, periprosthetic joint infection, instability, periprosthetic fracture, arthrofibrosis, patella resurfacing, polyethylene wear, patella loosening, malalignment of the implant, and extensor mechanism deficiency (5). Recently, a unique type of damage has been observed of CoCr knee implants. Retrieval studies have found evidence of what appears to be direct pitting of Cobalt-Chromium-Molybdenum alloy (CoCrMo) implants. The mechanism of how this unique type of damage occurs is controversial, and two hypotheses have been suggested in the literature. The first hypothesis was put forth in a recent article by Gilbert et al., termed "inflammatory cell-induced corrosion" (ICIC) (46). They hypothesized that metallic ions and wear particles brought about by mechanically assisted corrosion mechanisms could lead to an immune response in some patients (46). This could lead to the attack of inflammatory cells or phagocytic cells in the skeletal system such as osteoclasts, foreign body giant cells, macrophages, and polymorphonuclear leucocytes on the surface of metal implants (47). Gilbert's group stated that these cells attached to the surface and released reactive oxygen species (ROS), specifically $\mathrm{H}_{2} \mathrm{O}_{2}$, leading to damage of the oxide film the CoCrMo alloy.
\end{abstract}

An alternative hypothesis is that this damage is caused by the plasma arc from electrocautery tools that interact with the implant during surgery. Electrosurgery is the clinical use of a high-frequency alternating electrical current to cut and coagulate tissues (52). The resistance of the tissue, which is dependent on its water content (53), causes it to heat up as the electrical energy is converted into thermal energy. As the temperature rises, the thermal energy dissipates into the surrounding tissue, thus causing cauterization (52).

Previous studies have examined the characteristics caused by purposefully damaging $\mathrm{CoCr}$ and $\mathrm{Ti}$ discs using electrocautery tools $(58,59)$. The resulting damage characteristics closely resembles those found in ICIC. They also tested the ability of the plasma arc to travel through a hydrated 5\% agarose hydrogel covering the disc with the active electrode coming into contact with the gel surface. It was discovered that damage was produced on the surface of the implant through $3 \mathrm{~mm}$ of gel. This indicates that the plasma arc generated from electrocautery tools such as the Bovie could still damage the surface of the implant by passing through the neighboring tissue (59). Therefore, surgeons do not have to directly touch the surface of the implant for damage to occur. The goal of this study is to compare the profile of the bearing surface of an implant that 
has been intentionally damaged by an electrocautery with that of retrieved implants from a donor program at time of necropsy to determine if the source of corrosion is indeed from electrocautery tools during surgery or from inflammatory cells.

\section{Materials and Methods}

\section{Necropsy Specimens}

Following institution review board approval, 41 cadaveric primary total knee arthroplasty specimens were collected from two sources, the Medical Education and Research Institute (Memphis, TN) and RestoreLife USA (Elizabethton, TN), and kept frozen until retrieval took place. Fluoroscopy was utilized to assess the fixation of the implants and examine them for osteolysis, as well as determining if any screws were preventing the usual extraction methods. An OrthoScan HD (Model 1000-0001, OrthoScan, Scottsdale, AZ) was used to take anterior-posterior and lateral view images. All implants were determined to have no signs of loosening. The implants were then removed from the bone by ASTM Standard F561-13 [63] regulations and shipped to Drexel University (Philadelphia, PA) for further cleaning and testing. Only CoCrMo alloy implants were selected for this study.

Upon arrival at Drexel University, the femoral components were set aside and photographed in their received condition with implant number visible to ensure all parts were present. Cleaning was done in accordance to ASTM Standard F561-13. Each component was rinsed in cold water in a biohazard sink to wash away loose tissue. Next, components were then cleaned by two 20-minute soaks in separate 1: 10 ratio of detergent to water solutions. In between soaks, the components were brushed carefully to remove the remaining tissue without damaging or scratching the surface. At this stage, the components were no longer considered a biohazard and were placed in an ultrasonic bath for two consecutive 30-minute periods. The implants were then laid out on Versidry sheets (Thermo Fisher Scientific Inc, Rochester, NY) and left to dry overnight within the fume hood. Finally, they were then packaged in separate bags to avoid scratching one another and labeled to await future testing.

To identify regions of possible ICIC damage, the femoral components were initially examined visually at low magnification by two researchers. A light microscope (Keyence, Osaka, Japan) was utilized to verify these areas of interest indicative of ICIClike damage scares. Areas of interest were identified as having frosted regions or discolored patterns of ruffles or raised edges in sizes ranging from 10 to $100 \mu \mathrm{m}$. Scanning electron microscopy (SEM) (Zeiss, Oberkochen, Germany) was used to perform detailed microscopic analysis of the areas identified from the initial visual assessment. Second Electron Imaging at $20 \mathrm{kV}$ was used. High energy electron beams gave topographic information of the implant. Energy dispersive X-ray spectrometry (EDS) (Oxford, High Wycombe, UK) was utilized to assess the elements present in the pits displayed in the corroded areas by focusing the electron beam and capturing the 
characteristics of the X-rays emanating from the surface. SEM and EDS were also utilized to process non-damaged areas that served as a baseline for comparison.

\section{Electrocautery Damaged Specimens}

Three different types of femoral components were selected for this study: CoCrMo alloy, Zirconium Nitride, and Oxinium. All three implants were taken to the operating room at Methodist University Hospital (Memphis, TN) and intentionally damaged using the electrocautery plasma arc from both Bovie and Aquamantys sources by a three second hover method (Figure 2-1). Bovie electrocautery damage was done at $30 \mathrm{~W}, 45 \mathrm{~W}$, and $60 \mathrm{~W}$. Aquamantys electrocautery damage was done at $140 \mathrm{~W}, 180 \mathrm{~W}$, and $220 \mathrm{~W}$. The implants were then cleaned in order to remove any loose debris from the corrosive process. They were first soaked in separate solutions of water and detergent at a ratio of 10:1 for two consecutive 20-minute rounds. In between soaks, implants were rinsed in cold water. Next, they were ultrasonicated in a bath of water with a few drops of detergent for two consecutive 30 minute increments. Finally, they were rinsed off in cold water once again and set to dry overnight under a fume hood. SEM and EDS data were collected using an identical method to that of the retrieved implants. Finally, the data generated were compared to the seven knee implants retrieved from necropsy donors that are believed to have ICIC changes on their surfaces, both visually for damage patterns and using EDS for elemental analysis.

\section{Surface Topography}

White light interferometry (Zygo, NewView 6000, Middlefield, Connecticut) was utilized to examine the surface topography of the necropsy retrieved implants and the electrocautery-damaged implants. Each damage area was valuated in 3 locations with a measurement area of 537 x 403 microns. The $\mathrm{R}_{\mathrm{a}}$ (arithmetic average height parameter) is the most universally used roughness parameter for general quality control. It represents the average absolute deviation of the roughness from the mean line. $\mathrm{R}_{\max }$ measurements represent the maximum distance between the highest peak and the lowest valley. Kurtosis $\left(R_{k}\right)$ and skewness $\left(R_{\mathrm{sk}}\right)$ measurements were also collected to represent the topography on the damaged areas

\section{Statistical Analysis}

Before statistical analyses was performed, all data were tested for normality. Using Microsoft Excel (Microsoft, Redmond, WA), Shapiro-Wilk normality tests revealed the data sets were not normally distributed. Upon failing the normality tests, unpaired non-parameteric Mann Whitney rank sum tests were performed in order to identify any significant difference in the $\mathrm{Fe} / \mathrm{C}$ ratios constructed from the EDS results between necropsy retrieved implants and the electrocautery damaged implants. 


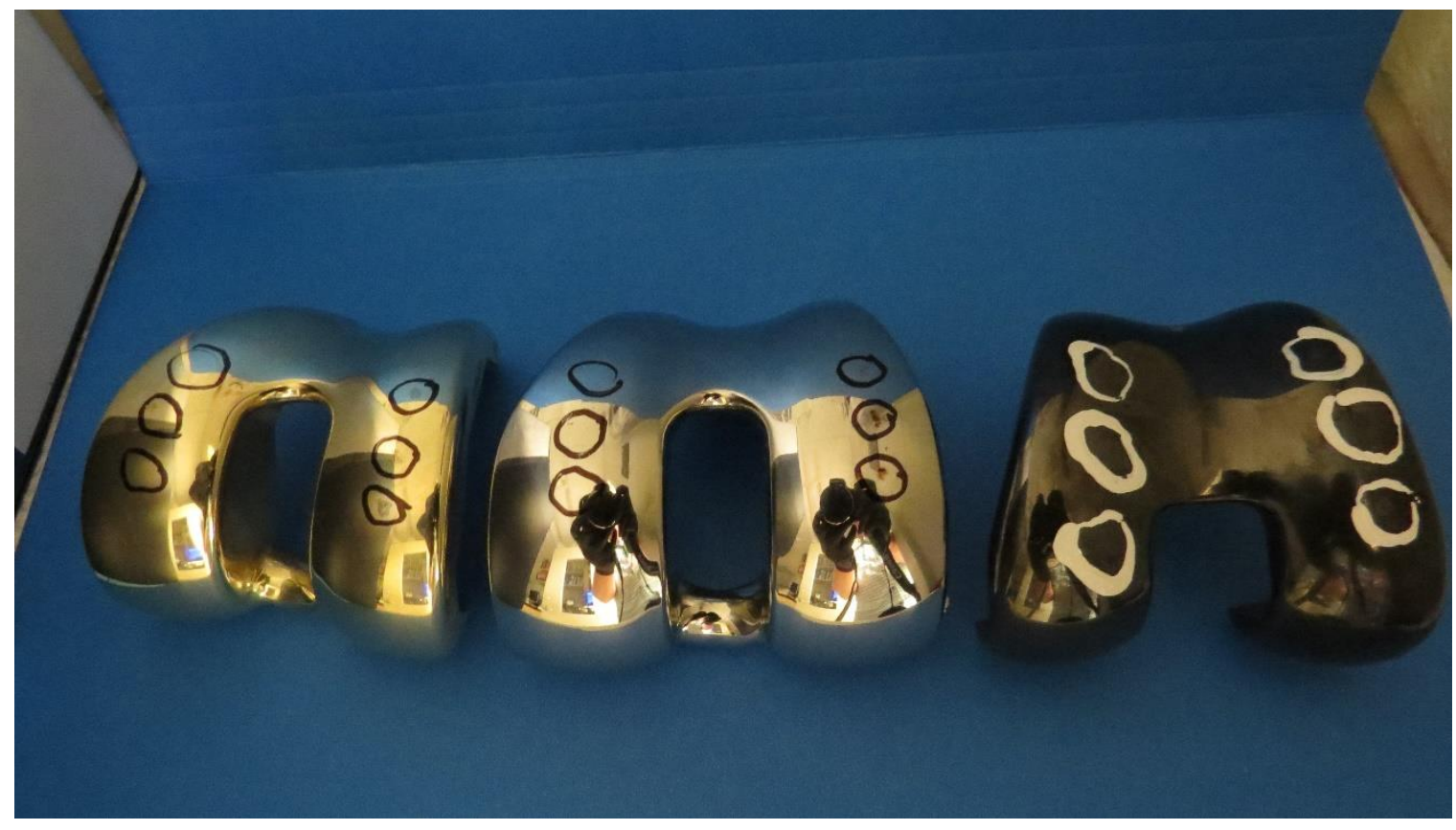

Figure 2-1. Damaged areas for the Zirconium Nitride (left), CoCrMo (middle), and Oxinium (right) implants 
Comparisons were made for both Bovie and Aquamantys sources at the various energy levels. Mann Whitney rank sum tests were also conducted to determine any statistical differences between $R_{a}, R_{\max }, R_{k}$, and $R_{s k}$ roughness parameters among the necropsy retrieved implants and the electrocautery damaged implants. A Kurskal-Wallis test and post hoc Dunn's multiple comparison test was utilized for comparing the $\mathrm{R}_{\mathrm{a}}, \mathrm{R}_{\max }, \mathrm{R}_{\mathrm{k}}$, and $\mathrm{R}_{\mathrm{sk}}$ of electrocautery damaged areas with the non-damaged areas of the Zirconium Nitride coated implant. All statistical tests were conducted using SigmaPlot statistical software with an assumed significance of $\alpha=0.05$.

\section{Results}

\section{Necropsy Specimens}

Our study revealed that 7 out of 41 femoral components showed signs of ICIC like damage. SEM confirmed our visual assessment of ICIC damage scares (Figure 2-2). Frosted regions can be seen made up of fine pits and streaks. Circular regions can be observed consisting of small pits and interconnected crater-like features. In some cases, there was evidence of a potential migration path of the cell as it was corroding the surface. Damaged areas were typically found on non-articulating surfaces of the implant. Of the 7 implants, only a single area on one of the implants showed signs of ICIC on the bearing surface. SEM imaging shows other evidence of direct cellular attack. Cellular corrosion can be seen as areas of ruffled topography with a central crater-like feature. A closer view shows these pits vary in size between 10-20 $\mu \mathrm{m}$. Damaged areas often appeared going along in a single direction as a streak. Evidence of ICIC is further supported by what looks like a migration path of the cell as it was corroding the surface.

Elemental analysis from EDS (Figure 2-3) of the necropsy retrieved implants revealed high concentrations of carbons and salts in the areas where damage was present. These results suggest cellular remnants and biological materials present, especially in the pits spread out in the damaged region. It also showed the presence of iron nodules present in the proximity of the corrosive patterns.

\section{Electrocautery Damaged Specimens}

SEM and EDS were also used to analyze the damage left by both Aquamantys and Bovie electrocautery sources. Visual assessment showed pitting similar to that seen in the necropsy retrieved implants. Surface melting and material buildup was seen as a result of the plasma arc discharge from the electrocautery tip. Damaged areas appear as a central spot surrounded by small pits. Visual inspection showed an overall ruffled appearance like that seen in cases of ICIC in CoCr implants (Figure 2-4). Iron, Nickel, Carbon, and Oxygen content were taken from the data collected to serve as surrogate markers of corrosion. An elemental profile (Figure 2-5). was created for each electrocautery energy type by finding the means of these select elemental percentages 

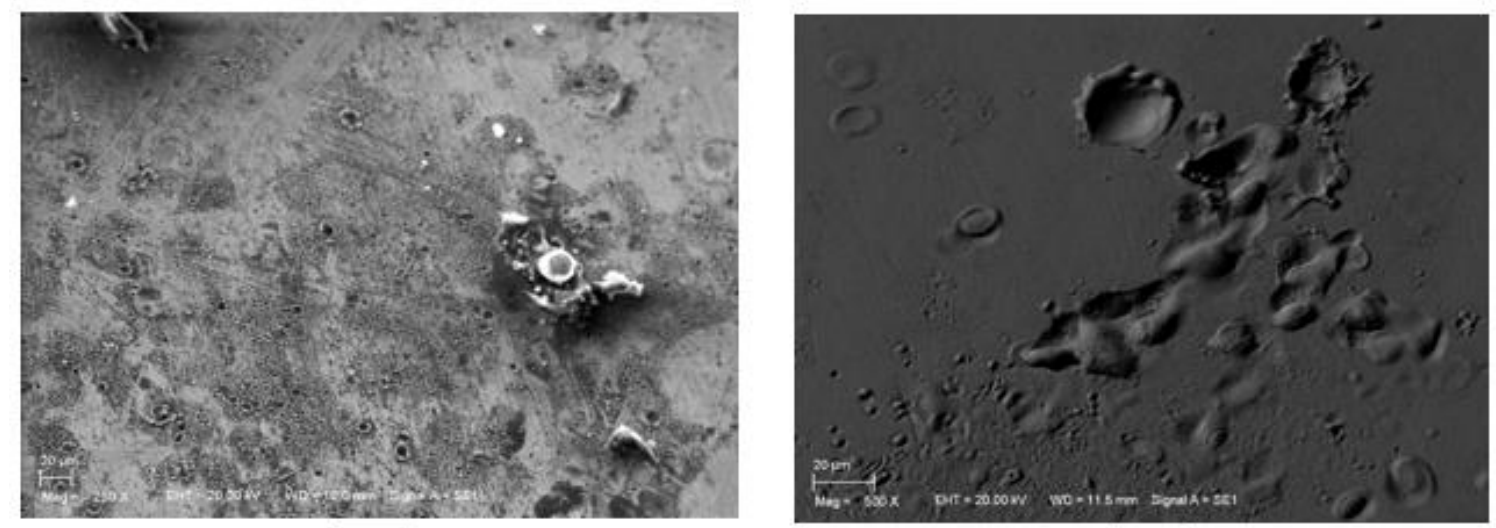

A
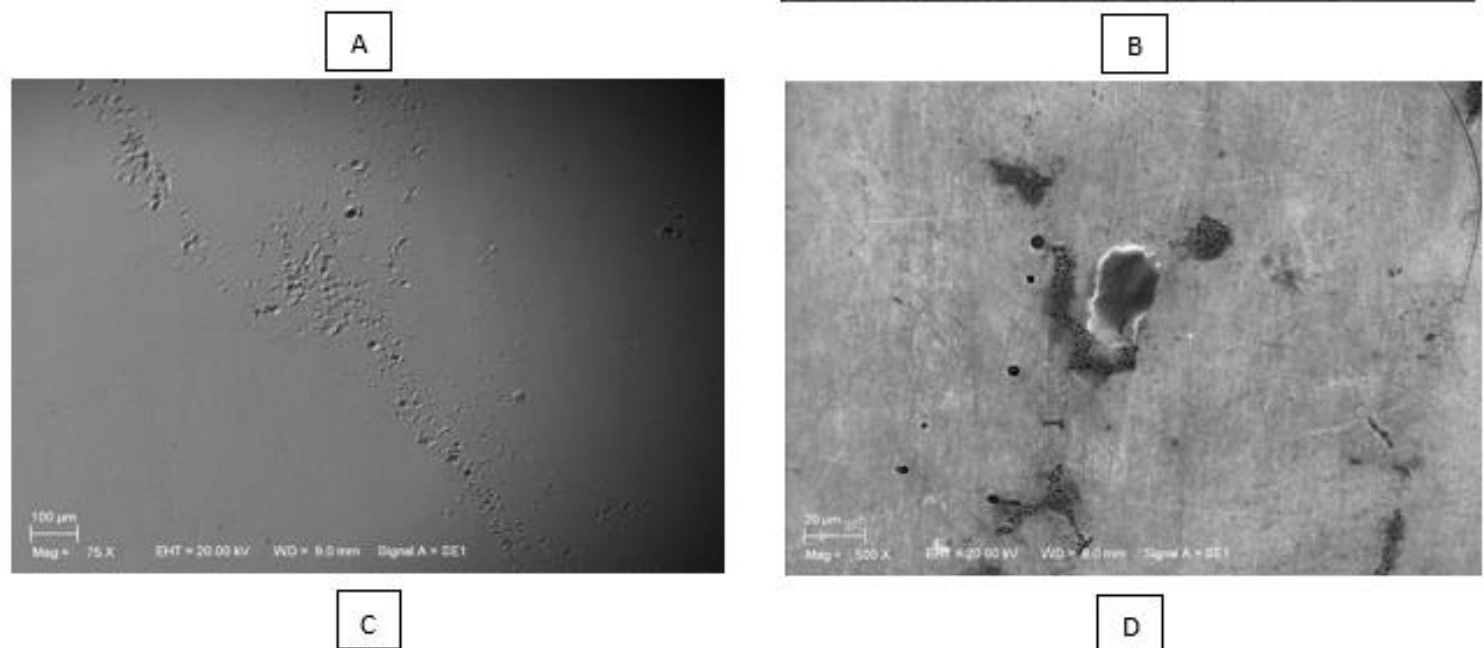

\section{Figure 2-2. SEM images of ICIC on CoCr knee implants}

Images were taken using a SEM: Hazy, discolored regions consisting of pits and craterlike features were seen (A, B). Corrosion in some areas going in a single directional pattern giving the appearance of a streak (C). Pattern were present suggesting the possible migratory path of a cell as it corroded the surface (D). 


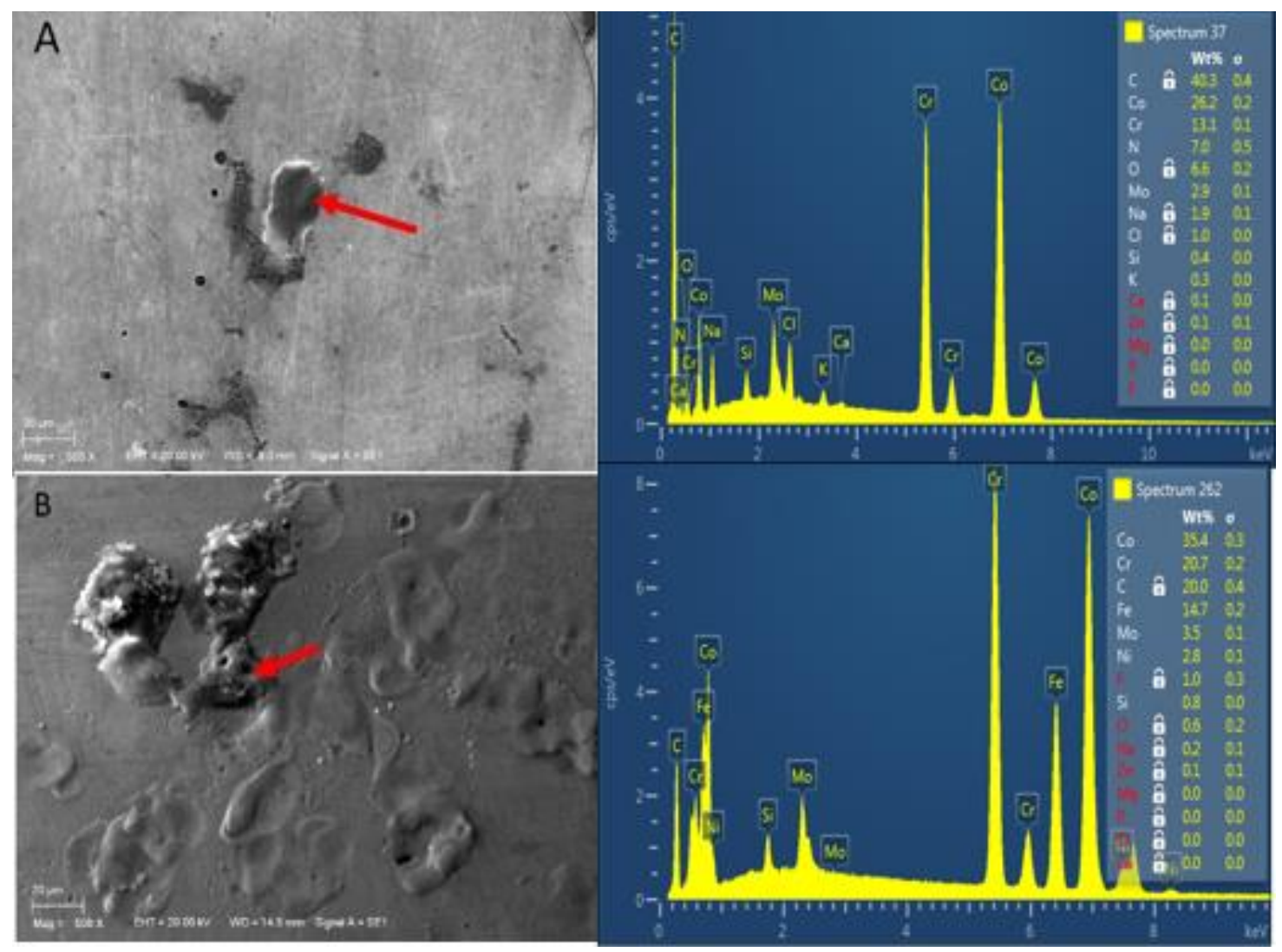

Figure 2-3. EDS results at two points of interest in ICIC damaged areas

EDS results showed high concentrations of carbon and salts (A) in ICIC damaged areas. Iron nodules were also found suggesting a Fenton-like reaction is taking place (B). 
A

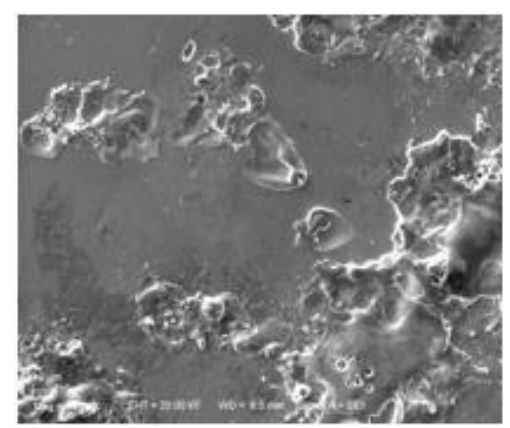

D

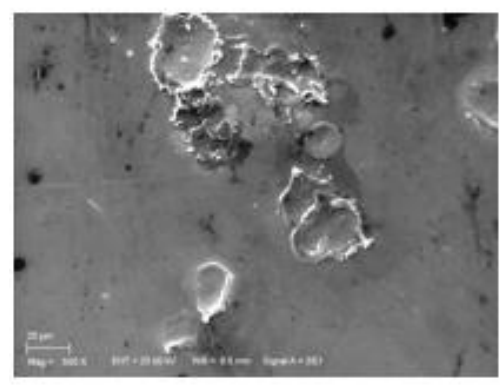

B

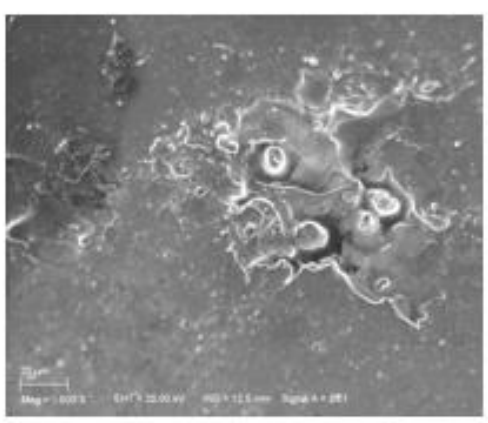

$\mathbf{E}$

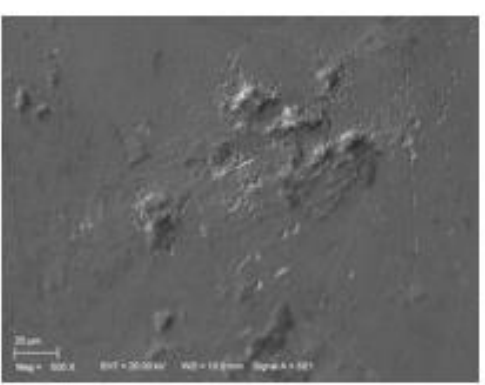

C

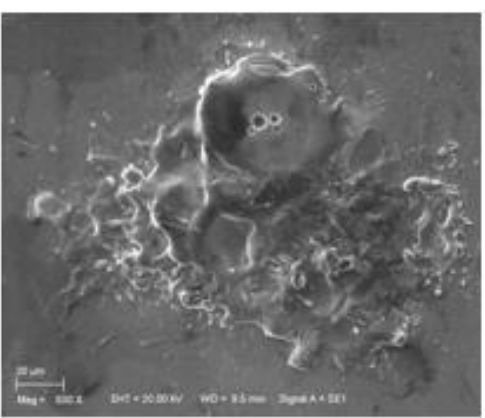

$\mathbf{F}$

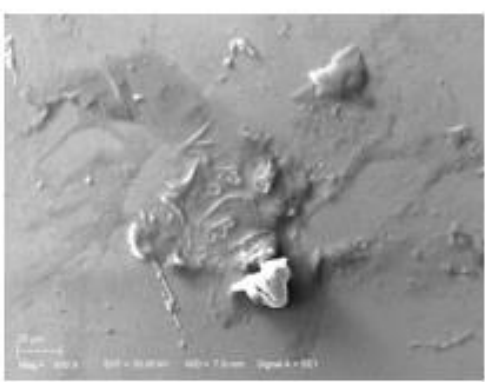

Figure 2-4. Electrocautery damage done to the surface of $\mathrm{CoCr}$ knee implant at 500x magnification

(A) Bovie 30W (B) Bovie 45W (C) Bovie 60W (D) Aquamantys 140W (E) Aquamantys 180W (F) Aquamantys 220W

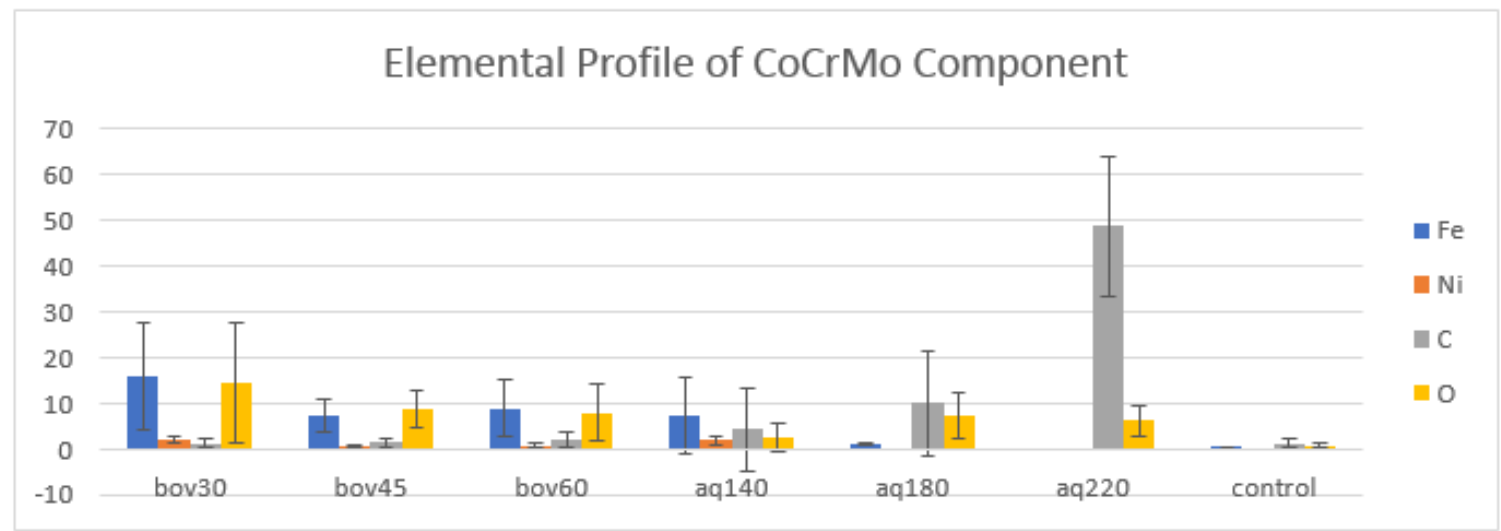

Figure 2-5. Average percent weight of key elements detected by EDS at the base of pits on the surface of CoCr knee implants

Error bars indicate mean \pm one standard deviation 
among all EDS results. Elevated levels of iron, nickel, oxygen, and carbon were seen in all 3 energy levels of Bovie electrocautery damage, while Aquamantys cautery damage results did not show a trend. A visual representation of the Iron/Carbon ratio of the Bovie electrocautery damaged knee implant was created for comparison to the necropsy retrieved knee implants (Figure 2-6). Due to the non-normal distribution of the samples groups all ratios in the graph were represented as medians and interquartile ranges (IQR). The median iron to carbon ratios for the $30 \mathrm{~W}, 45 \mathrm{~W}$, and $60 \mathrm{~W}$ Bovie damage groups are $11.2,4.12$, and 2.24 respectively. The median iron to carbon ratios for the $140 \mathrm{~W}, 180$, and $220 \mathrm{~W}$ Aquamantys damage groups are 0.18, 0.00 and 0.00 respectively. All Bovie damage groups were shown to have significantly higher $\mathrm{Fe} / \mathrm{C}$ ratios compared to the ICIC damaged areas found of necropsy retrieved implants.

SEM results for the Zirconium Nitride (Figure 2-7) and Oxinium implants (Figure 2-8) showed similar results to that of electrocautery damage on the CoCrMo implant. Damage of the Oxinium by the Bovie appeared especially severe compared to the other implant materials, with minimal visual change among the three energy settings. Elemental profiles were created using iron, nickel, carbon, and oxygen as markers to represent the change in elemental percent compositions among the Bovie and Aquamantys damaged areas at the various energy levels (Figures 2-9, 2-10). Traces of iron were found among damaged areas of the Zirconium Nitride implant, except for the Aquamantys as $140 \mathrm{~W}$. Iron concentrations were higher for both electrocautery sources at their highest levels with mean values of $7.25 \%$ for Bovie at $60 \mathrm{~W}$ and $10.9 \%$ for Aquamantys at $220 \mathrm{~W}$. The percentage of nickel also increases among the electrocautery damaged areas, but to a lesser extent. Traces of iron were also left over on the surface of the Oxinium implant for damaged areas from the Bovie at $30 \mathrm{~W}(9.9 \%)$ and $45 \mathrm{~W}(8.8$ $\%)$ and from the Aquamantys at $140 \mathrm{~W}(3.0 \%)$ and $220 \mathrm{~W}(1.9 \%)$.

\section{Surface Topography}

Roughness measurements were calculated using White light interferometry to represent the overall topography of the surface. Non-parametric statistical analysis was performed so all data values are presented as median and interquartile ranges (IQR) (Table 2-1) (Figures 2-11 through 2-2-14) Median $\mathrm{R}_{\mathrm{a}}$ measurements were shown to be statistically less $(\mathrm{p}=0.008)$ for Bovie damaged areas compared to ICIC damaged areas on CoCr. Median $R_{\max }$ and $R_{a}$ measurements were shown to be statistically less $(p=0.012$, $\mathrm{p}<0.001$ respectively) for Aquamantys damaged areas compared to ICIC damaged areas on CoCr. No statistical difference was found between bearing and non-bearing surfaces among the ICIC damaged areas. There was no significant difference in $R_{\text {sk }}$ and $R_{k}$ measurements between ICIC damaged areas and both Aquamantys and Bovie electrocautery sources damaged areas.

Roughness measurements were calculated on the $\mathrm{ZrN}$ coated implant for Bovie and Aquamantys damaged areas, as well as on the non-damaged surface. Non-parametric statistical analysis was performed so all data values are presented as medians and IQRs (Table 2-2) (Figures 2-15 through 2-2-18). Median $\mathrm{R}_{\max }, \mathrm{R}_{\mathrm{a}}$, and $\mathrm{R}_{\mathrm{sk}}$, measurement 


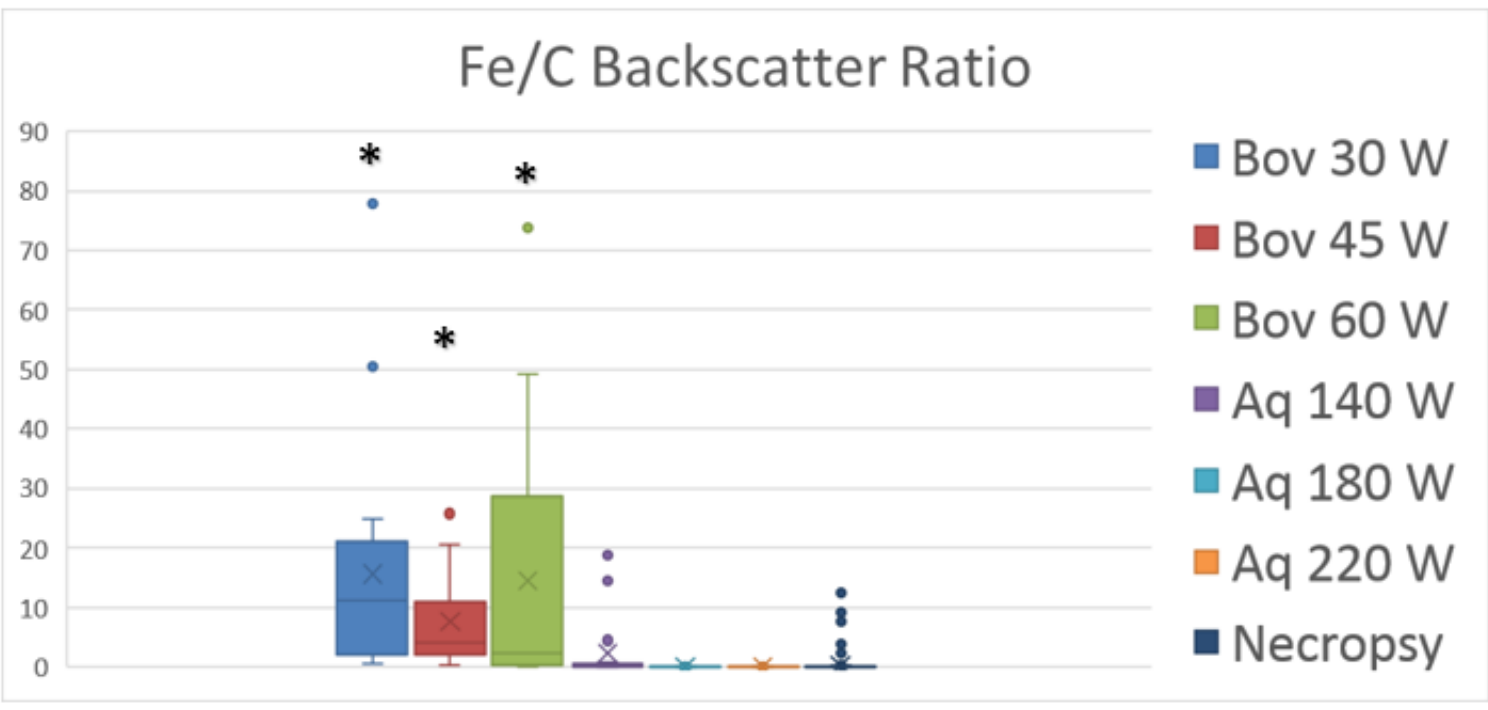

Figure 2-6. Ratio of the percent weight of iron to the percent weight of carbon found at the base of pits on the surface $\mathrm{CoCr}$ knee implants.

* indicates statistical difference compared to necropsy group. Within each box, horizontal lines denote median values; boxes extend from the 25 th to the 75 th percentile of each group's distribution of values; extending vertical lines denote 1.5 times IQR; dots denote outliers outside the 1.5 times IQR range. 
A

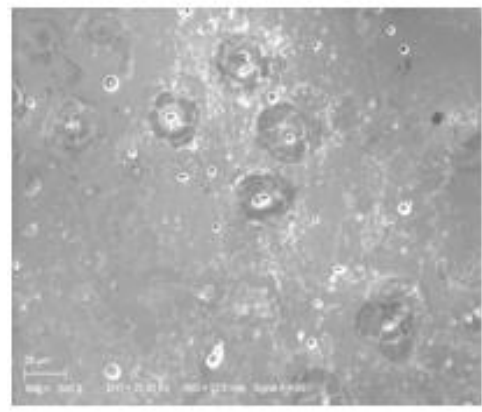

D

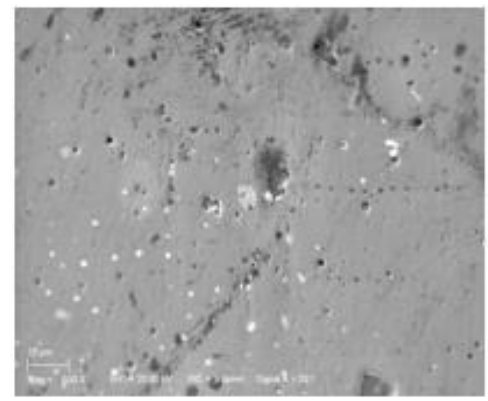

B

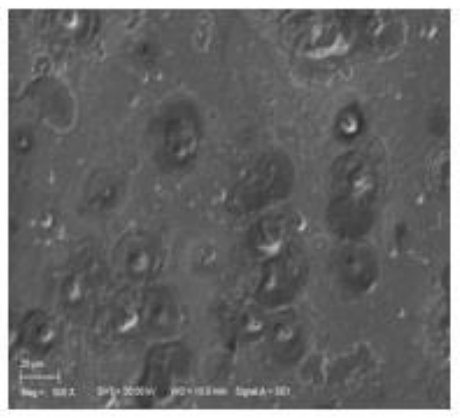

E

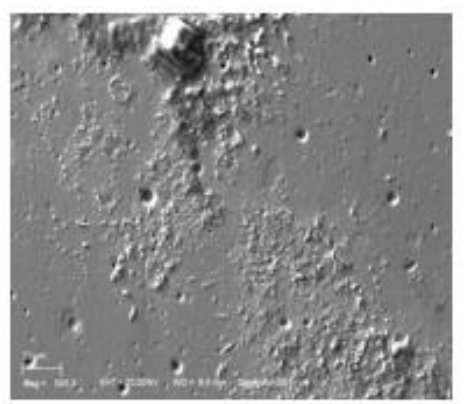

C

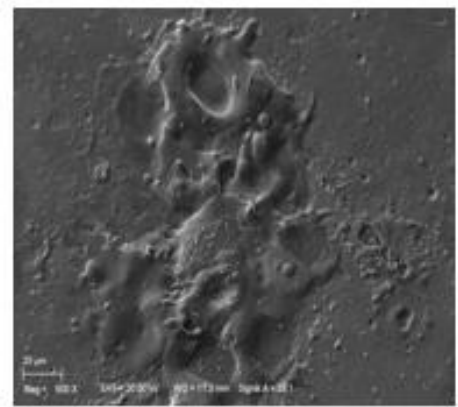

$\mathbf{F}$

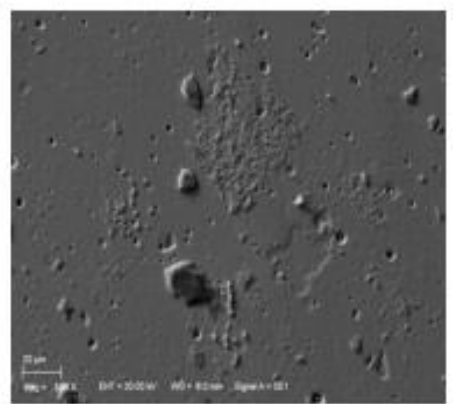

Figure 2-7. Damage done to the surface of Zirconium Nitrate knee implant at 500x

(A) Bovie 30W (B) Bovie 45W (C) Bovie 60W (D) Aquamantys 140W (E) Aquamantys $180 \mathrm{~W}(\mathrm{~F})$ Aquamantys 220W 
A

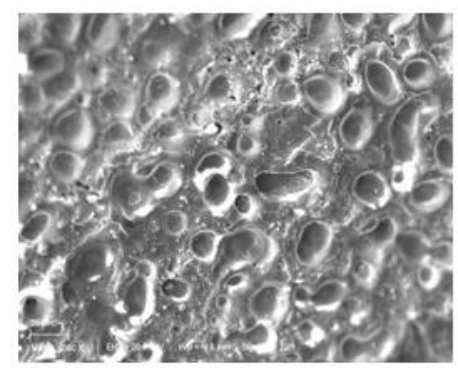

D

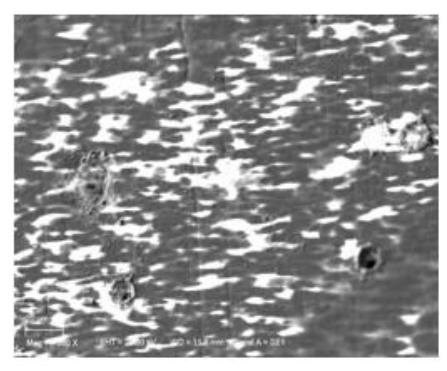

B

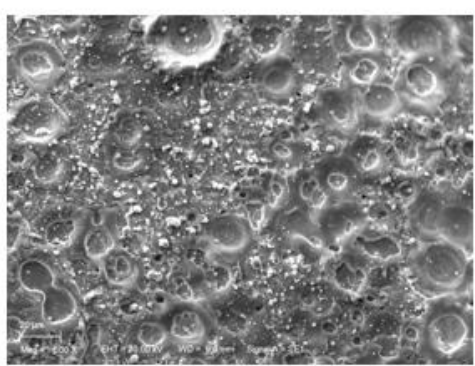

E

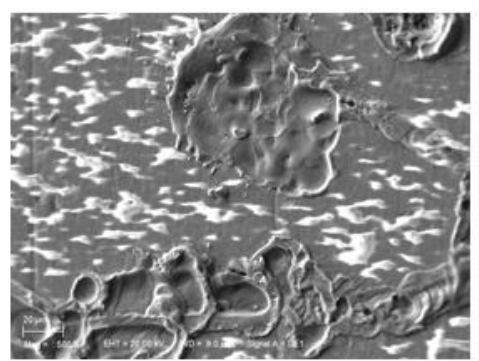

C

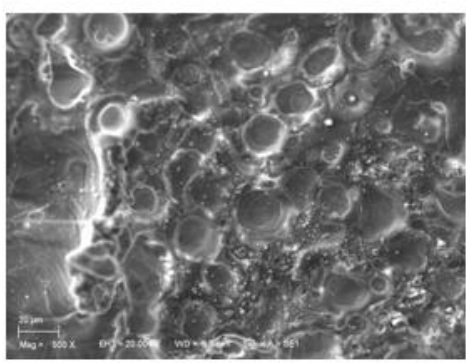

$\mathbf{F}$

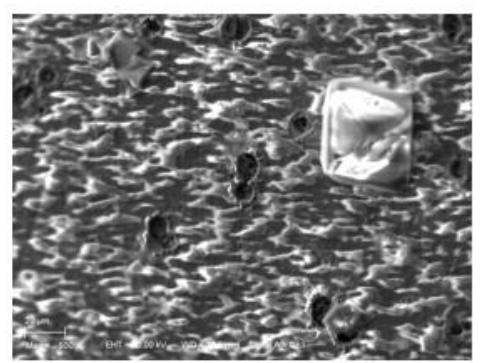

Figure 2-8. Damage done to the surface of Oxinium knee implant at 500x

(A) Bovie 30W (B) Bovie 45W (C) Bovie 60W (D) Aquamantys 140W (E) Aquamantys $180 \mathrm{~W}$ (F) Aquamantys 220W 


\section{Elemental Profile Zirconium Nitride}

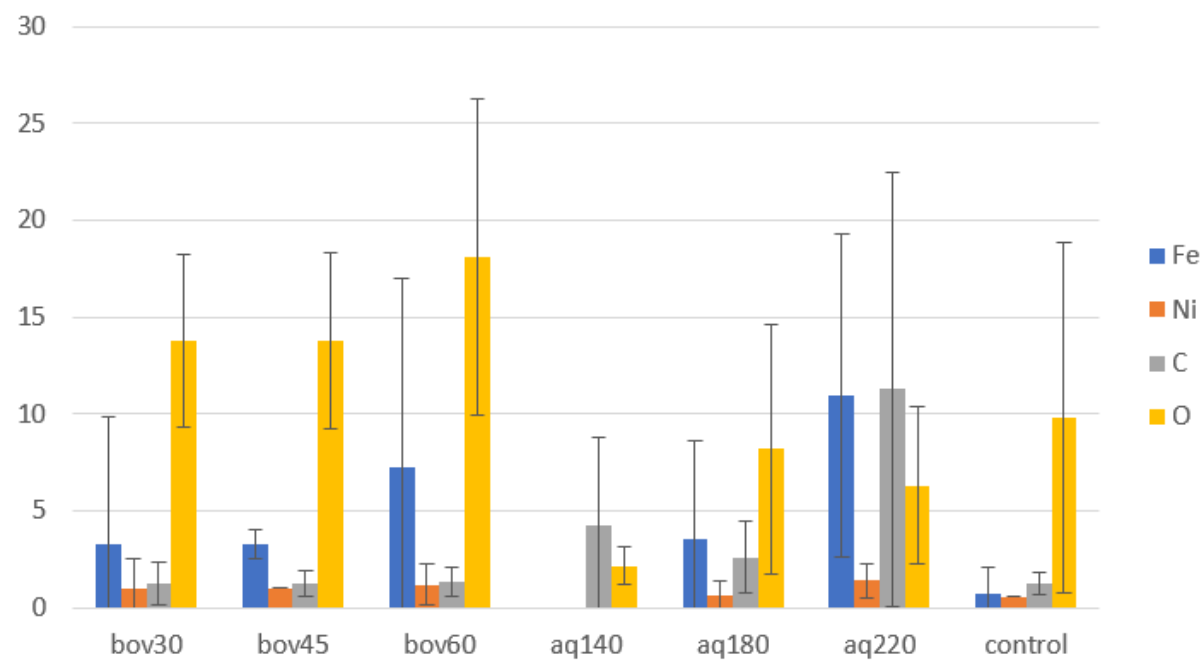

Figure 2-9. Average percent weight of each element detected by EDS at the base of pits on the surface of a Zirconium Nitride knee implant. Error bars indicate means \pm one standard deviation.

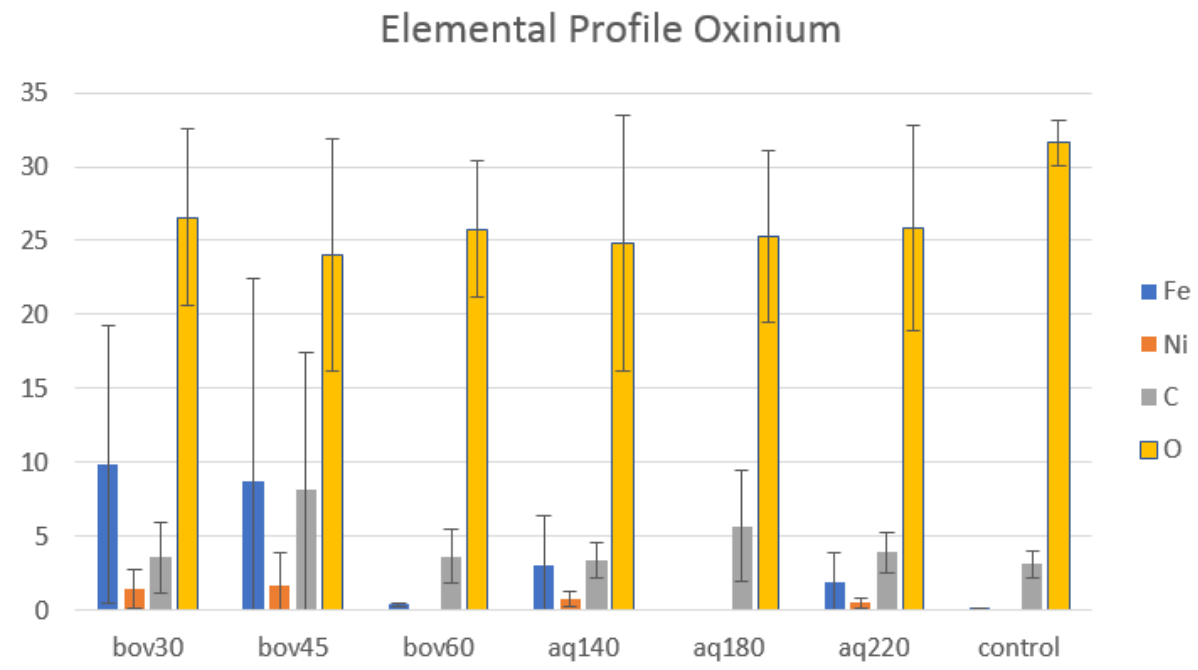

Figure 2-10. Average percent weight of each element detected by EDS at the base of pits on the surface of an Oxinium knee implant

Error bars indicate means \pm one standard deviation. 
Table 2-1. Median (IQR) measurements of $\mathbf{R}_{\max }, \mathbf{R}_{\mathrm{a}}, \mathbf{R}_{\mathrm{sk}}$, and $\mathbf{R}_{\mathrm{k}}$ obtained via white light interferometry of $\mathrm{CoCr}$ implants

\begin{tabular}{ccccc}
\hline Group & $\mathrm{R}_{\max }(\mu \mathrm{m})$ & $\mathrm{R}_{\mathrm{a}}(\mu \mathrm{m})$ & $\mathrm{R}_{\mathrm{sk}}(\mu \mathrm{m})$ & $\mathrm{R}_{\mathrm{k}}(\mu \mathrm{m})$ \\
\hline Bovie damaged areas & $50.3(12.7-63.8)$ & $0.17(0.14-0.19)$ & $-2.03(-6.13-3.63)$ & $82.2(37.6-787)$ \\
Aquamantys damaged areas & $8.36(4.56-58.8)$ & $0.06(0.04-0.14)$ & $-1.30(-4.19-(-0.398))$ & $59.6(18.5-66.2)$ \\
ICIC damaged areas & $91.4(17.2-129.9)$ & $0.22(0.18-0.28)$ & $-1.02(-15.1-(-0.18))$ & $68.4(16.3-2880)$ \\
\hline
\end{tabular}

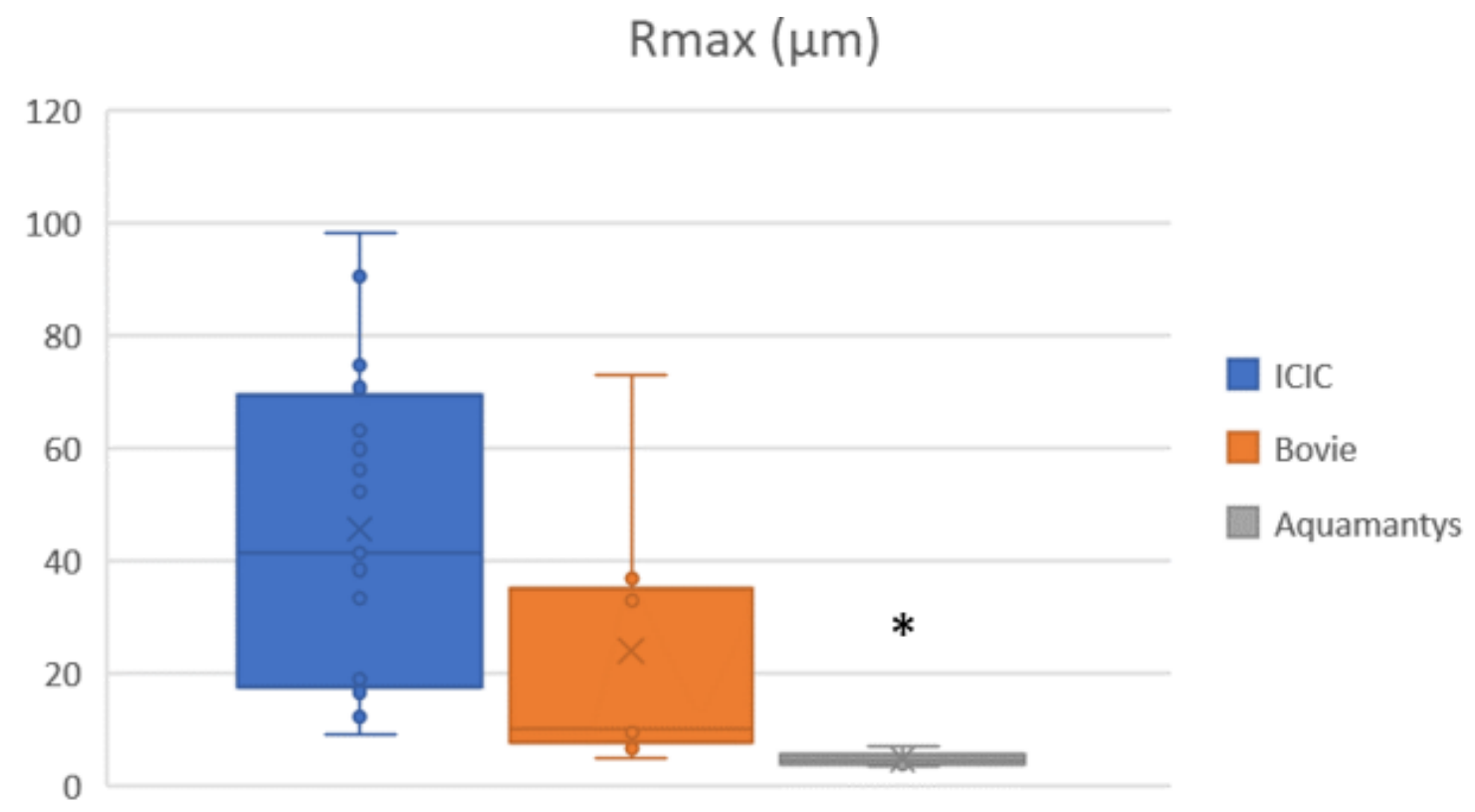

Figure 2-11. $R_{\max }(\mu \mathrm{m})$ measurements of $\mathrm{CoCr}$ damage groups obtained via white light interferometry

* indicates statistical difference compared to ICIC group. Within each box, horizontal lines denote median values; boxes extend from the 25 th to the 75 th percentile of each group's distribution of values; extending vertical lines denote 1.5 times IQR; dots denote outliers outside the 1.5 times IQR range. 
$\operatorname{Ra}(\mu \mathrm{m})$

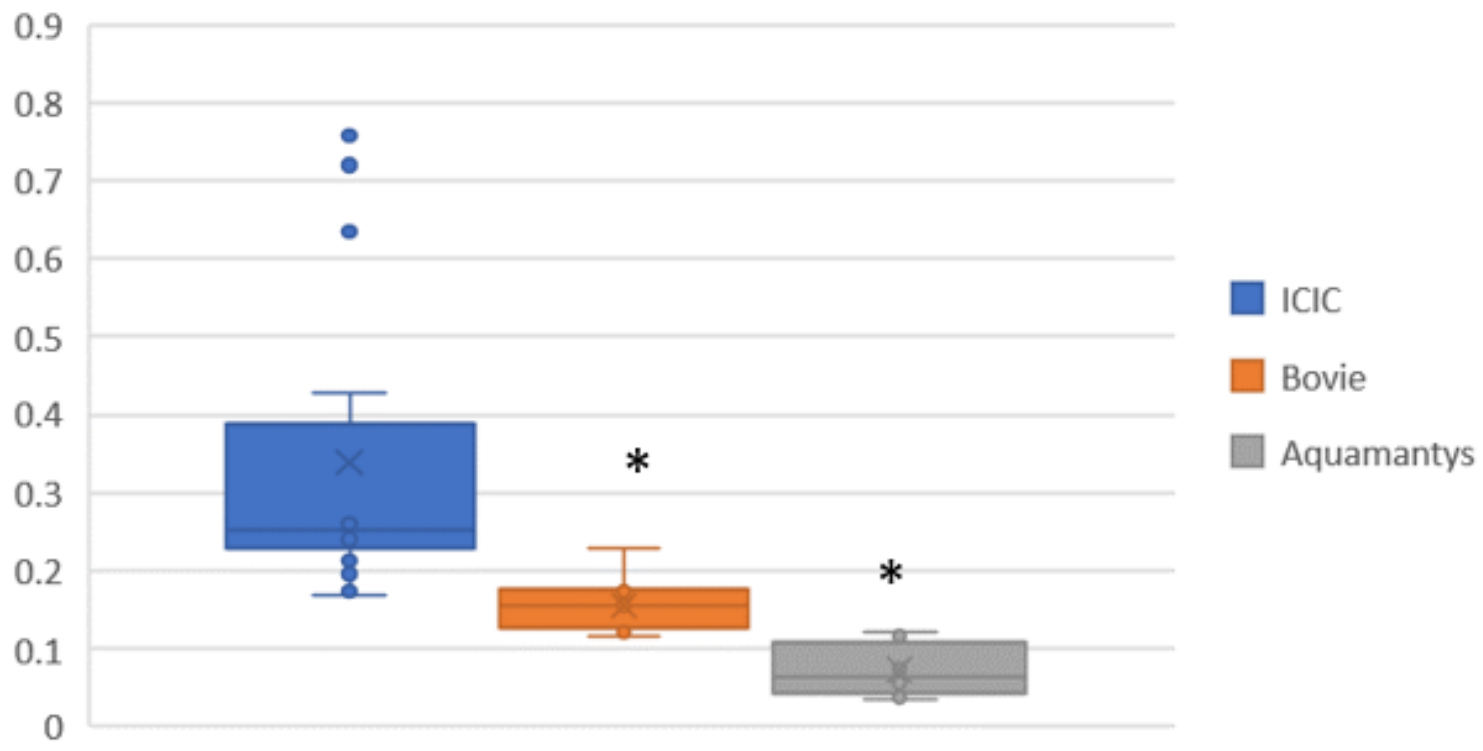

Figure 2-12. $\quad R_{a}(\mu \mathrm{m})$ measurements of $\mathrm{CoCr}$ damage groups obtained via white light interferometry

* indicates statistical difference compared to ICIC group. Within each box, horizontal lines denote median values; boxes extend from the 25 th to the 75 th percentile of each group's distribution of values; extending vertical lines denote 1.5 times IQR; dots denote outliers outside the 1.5 times IQR range. 


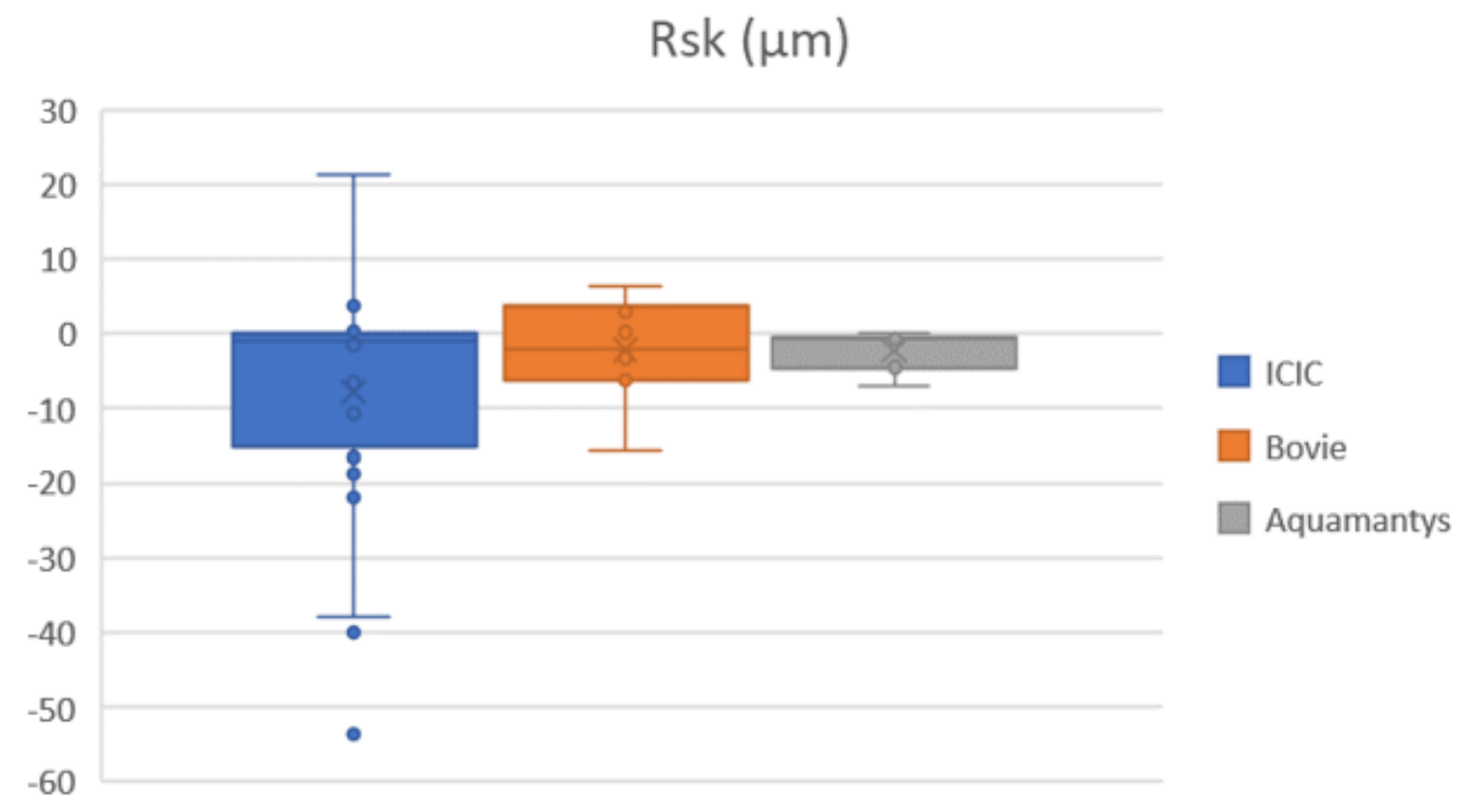

Figure 2-13. $\mathbf{R}_{\text {sk }}(\mu \mathrm{m})$ measurements of $\mathrm{CoCr}$ damage groups obtained via white light interferometry

* indicates statistical difference compared to ICIC group. Within each box, horizontal lines denote median values; boxes extend from the 25 th to the 75 th percentile of each group's distribution of values; extending vertical lines denote 1.5 times IQR; dots denote outliers outside the 1.5 times IQR range. 


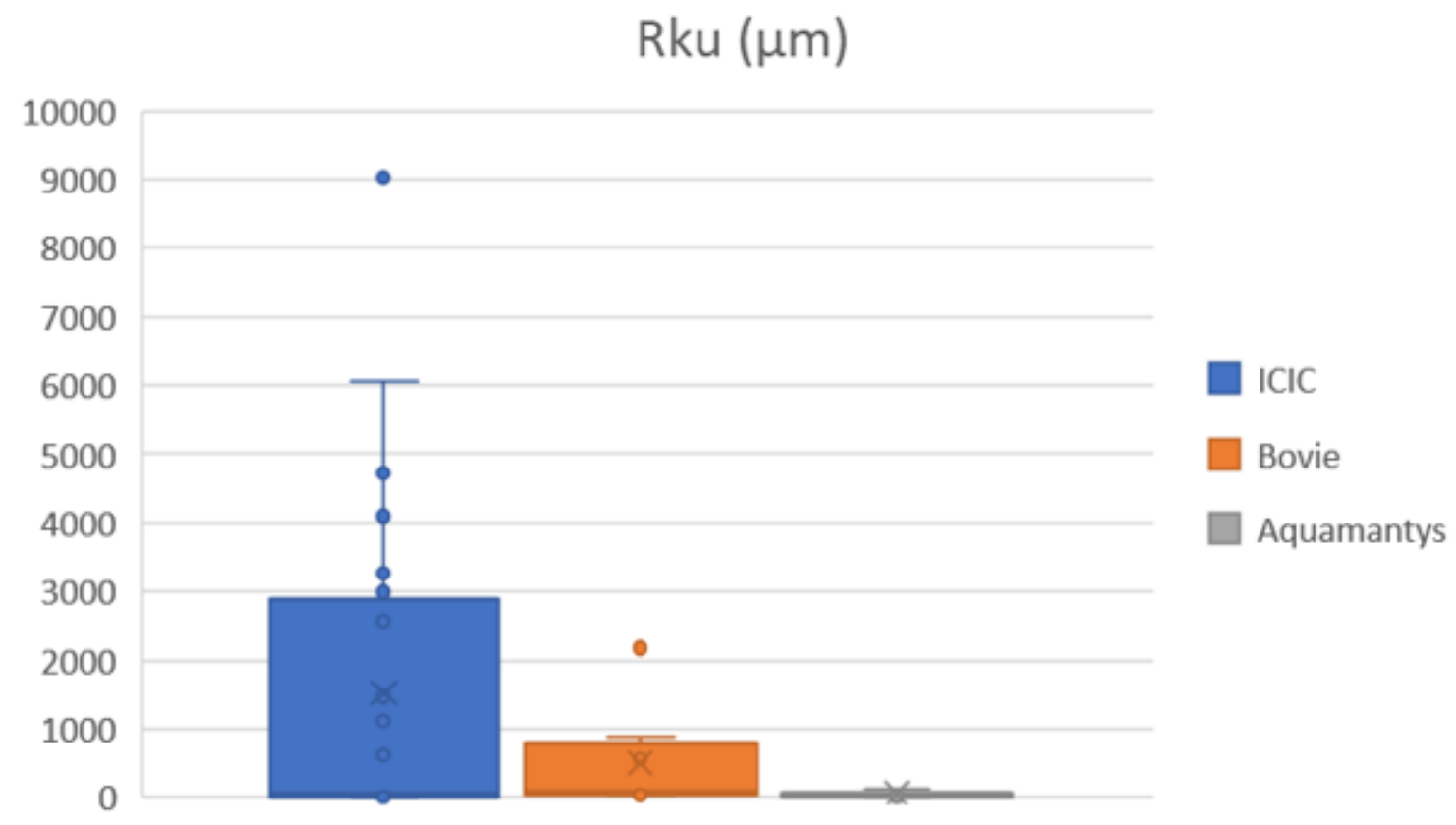

Figure 2-14. $R_{k}(\mu \mathrm{m})$ measurements of $\mathrm{CoCr}$ damage groups obtained via white light interferometry

* indicates statistical difference compared to ICIC group. Within each box, horizontal lines denote median values; boxes extend from the 25th to the 75 th percentile of each group's distribution of values; extending vertical lines denote 1.5 times IQR; dots denote outliers outside the 1.5 times IQR range. 
Table 2-2. Median (IQR) measurements of $\mathbf{R}_{\max }, \mathbf{R}_{\mathrm{a}}, \mathbf{R}_{\mathrm{sk}}$, and $\mathbf{R}_{\mathrm{k}}$ obtained via white light interferometry of a Zirconium Nitride coated implant

\begin{tabular}{ccccc}
\hline Group & $\mathrm{R}_{\max }(\mu \mathrm{m})$ & $\mathrm{R}_{\mathrm{a}}(\mu \mathrm{m})$ & $\mathrm{R}_{\mathrm{sk}}(\mu \mathrm{m})$ & $\mathrm{R}_{\mathrm{k}}(\mu \mathrm{m})$ \\
\hline Bovie damaged areas & $5.0(4.8-6.2)$ & $0.17(0.07-0.12)$ & $0.07(-1.17-0.24)$ & $12.0(7.8-14.6)$ \\
Aquamantys damaged areas & $4.6(4.3-5.7)$ & $0.06(0.04-0.14)$ & $-2.6(-3.6-(-1.6))$ & $31.0(23.7-66.0)$ \\
Undamaged areas & $3.9(3.5-4.4)$ & $0.03(0.03-0.03)$ & $-9.7(-10.6-(-7.3)$ & $178(116-245)$ \\
\hline
\end{tabular}

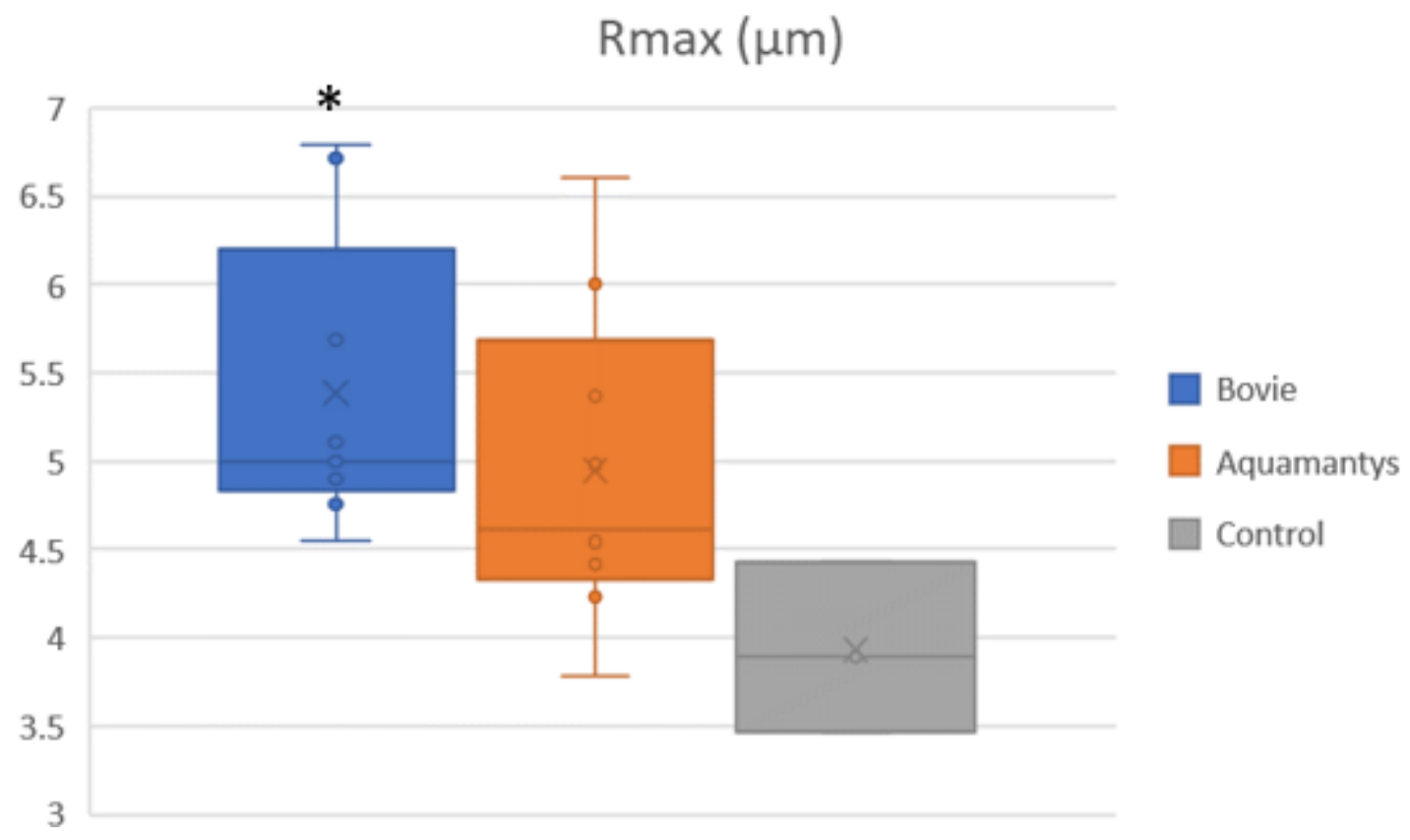

Figure 2-15. $R_{\max }(\mu \mathrm{m})$ measurements of Zirconium Nitride damage groups obtained via white light interferometry

* indicates statistical difference compared to non-damaged area group. Within each box, horizontal lines denote median values; boxes extend from the 25th to the 75th percentile of each group's distribution of values; extending vertical lines denote 1.5 times IQR; dots denote outliers outside the 1.5 times IQR range. 


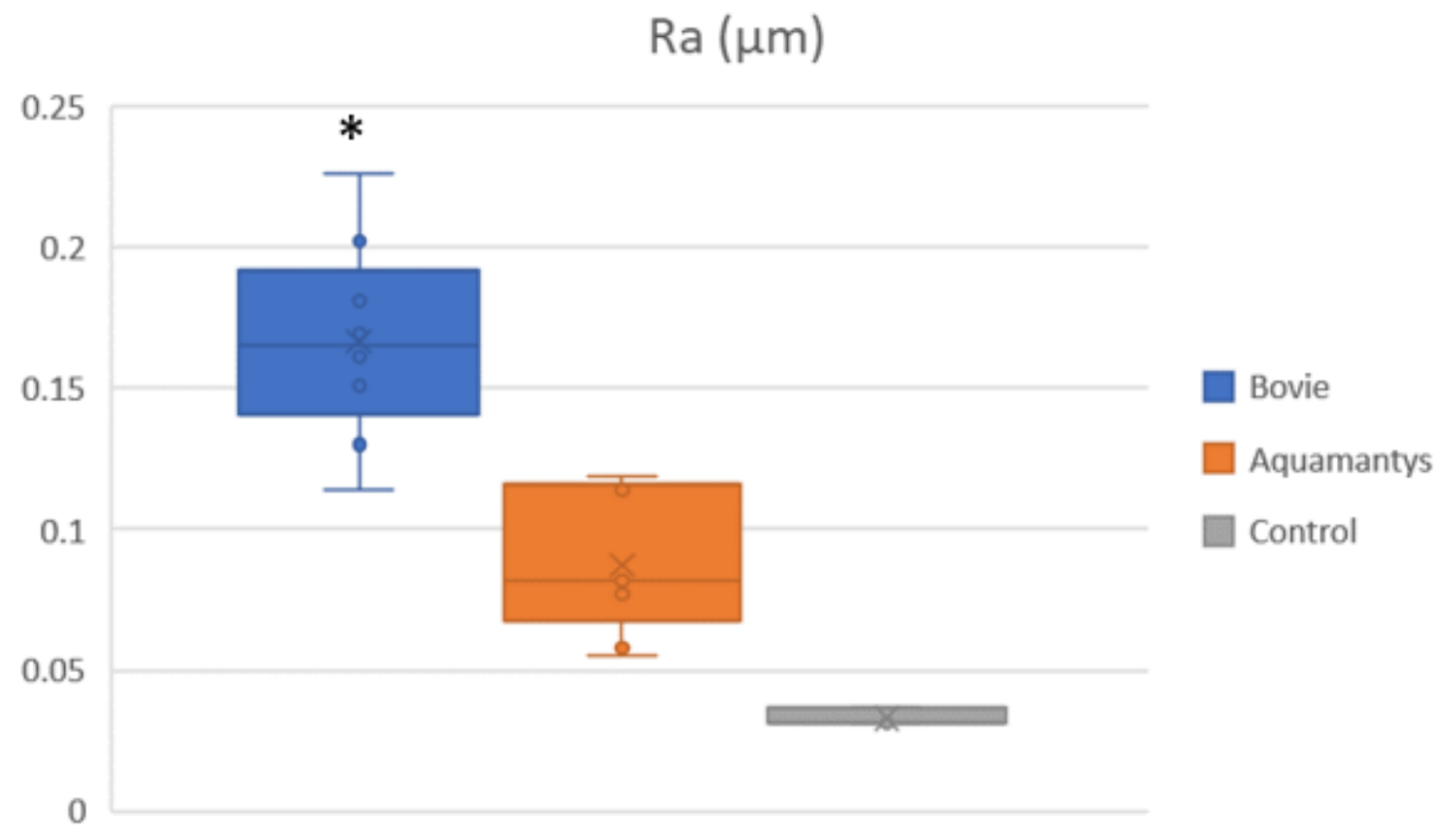

Figure 2-16. $\quad R_{a}(\mu \mathrm{m})$ measurements of Zirconium Nitride damage groups obtained via white light interferometry

* indicates statistical difference compared to non-damaged area group. Within each box, horizontal lines denote median values; boxes extend from the 25 th to the 75 th percentile of each group's distribution of values; extending vertical lines denote 1.5 times IQR; dots denote outliers outside the 1.5 times IQR range. 


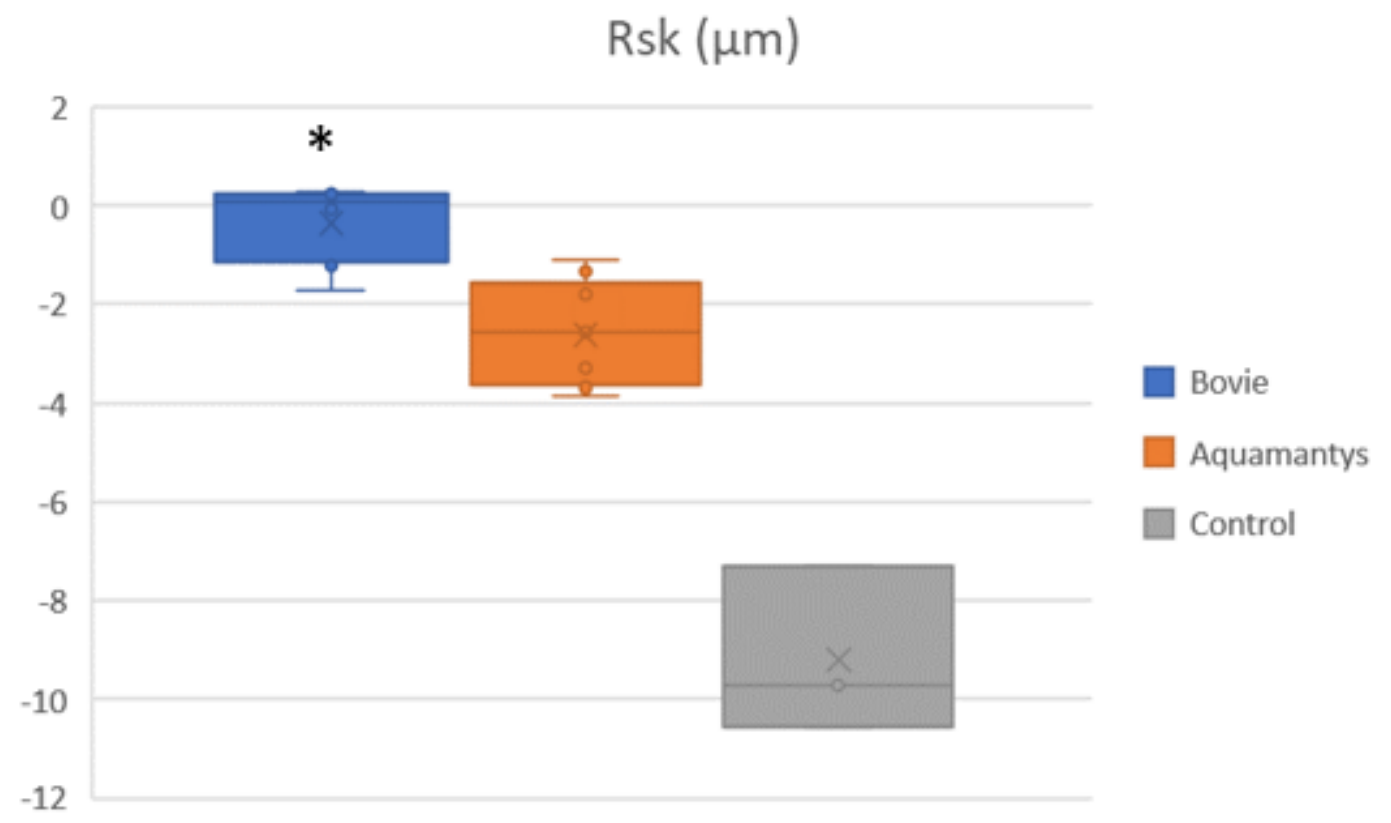

Figure 2-17. Rsk $(\mu \mathrm{m})$ measurements of Zirconium Nitride damage groups obtained via white light interferometry

* indicates statistical difference compared to non-damaged area group. Within each box, horizontal lines denote median values; boxes extend from the 25th to the 75th percentile of each group's distribution of values; extending vertical lines denote 1.5 times IQR; dots denote outliers outside the 1.5 times IQR range. 


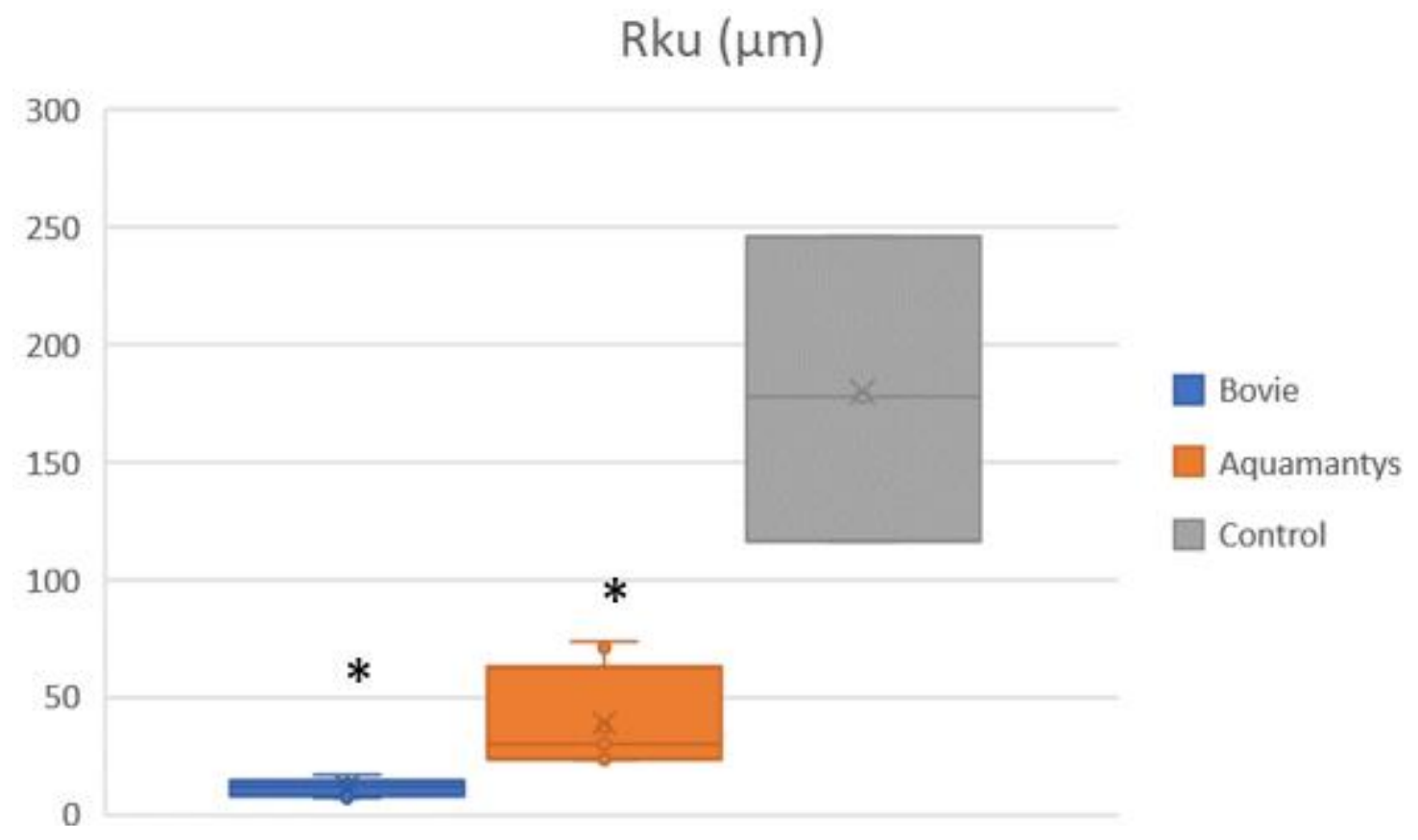

Figure 2-18. $\quad R_{k}(\mu m)$ measurements of Zirconium Nitride damage groups obtained via white light interferometry

* indicates statistical difference compared to non-damaged area group. Within each box, horizontal lines denote median values; boxes extend from the 25 th to the 75 th percentile of each group's distribution of values; extending vertical lines denote 1.5 times IQR; dots denote outliers outside the 1.5 times IQR range. 
were shown to be statistically higher $(\mathrm{p}=0.025, \mathrm{p}=0.001, \mathrm{p}=0.001, \mathrm{p}<0.001$ respectively) for Bovie damaged areas compared to non-damaged areas on $\mathrm{ZrN}$ coated implants. $\mathrm{R}_{\mathrm{k}}$ measurements were shown to be statistically lower ( $\mathrm{p}<0.001, \mathrm{p}=0.006$ respectively) for both Bovie and Aquamantys damaged areas compared to non-damaged areas on $\mathrm{ZrN}$ coated implants.

\section{Discussion}

Release of metal ions and debris remains a concern among patients that have undergone total joint arthroplasty due to the many adverse effects seen in local tissues surrounding the implant $(9,64,65)$. One of the more recently investigated processes leading to these adverse effects is ICIC. It is believed that inflammatory cells react to an immune response by attaching to the implant surface and releasing reactive oxygen species (ROS) that can lead to disruption of the oxide layer (46). This mechanism has been under investigation in both total hip and total knee arthroplasty $(46,47,50,51)$.

Gilbert, Kurtz, and Hart analyzed femoral components of failed CoCr implants retrieved via revision surgery for ICIC. Our SEM and EDS findings support previous reported observations of evidence of cellular corrosion occurring on the surface $(46,47,50,51)$. Damaged areas consisted of light frosted and discolored regions with pitting and crater-like features. The dimensions of the pits found in these areas were around 10-20 $\mu \mathrm{m}$, which correlates with the size of inflammatory cells. We also found evidence suggesting the migration path a cell travels as it moves across the surface and releases ROS. Iron nodules were also found among damaged areas, suggesting Fentonlike reactions are taking place. Iron is a fundamental component of phagocytic cells and is known to aggravate inflammation when ROS are present. These findings support the hypothesis that this damage is caused by inflammatory cells corroding the surface. Previous retrieval studies remain unclear on how often the occurrence of ICIC on femoral components takes place, with prevalence ranging from $29 \%$ to $74 \%(46,50)$. These results may be skewed by reporting both ICIC and electrocautery damage. Our study is the first to focus on femoral components of necropsy retrieved implants. No revision surgery took place for the removal of the implant, so there is minimal chance that the implant came into contact with electrocautery tools. Our results showed ICIC on $17 \%$ of the implants examined.

Recently, there have been concerns that this damage type is actually caused by electrocautery damage during revision surgery (66). Our study aimed to examine both ICIC and electrocautery damage mechanism in order to create a distinction between the two. SEM results for the electrocautery damaged $\mathrm{CoCr}$ implant showed features visually similar to those found on the necropsy retrieved specimens. However, further examination of the pits showed different elemental compositions. While both groups had iron found in the damaged areas, the iron was found more consistently and in higher concentrations among the electrocautery damaged implants. It is believed that the iron debris was left due to the use of a stainless steel tip with the electrocautery tools. Higher

concentrations of carbon were also found among the necropsy retrieved implants. Iron to 
carbon ratios were created to represent the difference in concentrations found on the surface of the various groups. The iron to carbon ratios of the three Bovie groups were shown to be significantly higher than that of ICIC $(p<0.001)$. This method creates a way to distinguish between the two damage mechanisms for future studies. However, this method was only effective for comparison with damage induced by a Bovie. Aquamantys damaged areas showed no statistically significant difference in median iron to carbon ratios when compared to necropsy retrieved specimens.

The topography left behind on the surface by the two damage mechanisms was examined by calculating the $\mathrm{R}_{\mathrm{a}}, \mathrm{R}_{\mathrm{max}}, \mathrm{R}_{\mathrm{sk}}$, and $\mathrm{R}_{\mathrm{k}}$ roughness parameters. According to Heyse et al., the mean ( \pm standard deviation) roughness parameters of pristine CoCrMo knee implants are as follows: $R_{a}=0.04 \mu \mathrm{m}( \pm 0.003), R_{\max }=0.636 \mu \mathrm{m}( \pm 0.042)$, and $R_{\mathrm{sk}}$ $=0.33 \mu \mathrm{m}( \pm 1.17)(67)$. Both Bovie and Aquamantys electrocautery damaged areas showed an increase in $R_{\max }$ and $R_{a}$ and a decrease in $R_{s k}$ roughness parameters when compared to non-damaged areas. ICIC measurements among all 4 roughness values showed higher IQR values compared to the electrocautery groups, possibly indicating that the damage caused by ICIC is less consistent in severity across the surface. Previous studies have shown that increased roughness values indicate implant damage and possible debris on the surface [68-70]. This dramatic increase in roughness parameters could be caused by pitting and electrocautery byproducts on the surface. An increase in roughness values was also observed in the ICIC damaged group, indicating that pits are forming in the oxide layer. Although it was hypothesized that the $\mathrm{R}_{\mathrm{a}}$ would be larger for Bovie damaged implants compared to ICIC implants, our results indicate that the opposite trend is occurring. Unlike electrocautery, the damaged caused by ICIC takes place over many years, thus it is not surprising that the surface area is rougher. There was no significant difference found between the bearing and non-bearing surfaces on the ICIC damaged implants. However, the sample size for ICIC found on the bearing surface is much smaller than those found on non-articulating surfaces. This is likely due to the repetitive articulation during motion of the joint from daily activities seen at the surface of these areas. This would make it more difficult for cells to securely attach to the surface for enough time to release ROS leading to corrosion. ICIC was only found in a single area within the bearing surface on one of the implants. Therefore, this could be an inaccurate representation. More data is needed before a more definitive conclusion can be made.

One major limitation in this study was the inability to compare Zirconium Nitride and Oxinium electrocautery damaged implants with damage believed to be caused by ICIC. Both of these materials are used less frequently than $\mathrm{CoCr}$ implants in total knee arthroplasty, thus they were not included in the necropsy retrieval group. Oxinium was introduced in 2004 in an attempt to reduce implant failure due to PE wear debris (71). While in vitro wear testing of the implants did show wear reduction compared to traditional CoCr implants, reports from the National Joint Registry showed an increase in revision rates after 12 years compared to $\mathrm{CoCr}(72,73)$. Zirconium Nitride coated implants were created as an alternative implant material for patients with metal hypersensitivity issues. Results have been promising, showing a decrease in wear rate in laboratory simulation compared to non-coated $\mathrm{CoCr}$ implants (74-76). Both of these materials show promise as alternatives to traditional orthopaedic metal alloys. However, 
little research has been made on the biological reactions to these new implant materials. With corrosion by cells gaining attention on CoCr implants, it is possible that other implant materials have similar responses. The elemental profiles found in this study could be used to distinguish electrocautery damage in future studies involving ICIC on Oxinium and Zirconium Nitride.

Roughness measurements collected from the surface of the Zirconium Nitride coated implant followed similar patterns as those found on the CoCr implant. While none of the median measurements were shown to be statistically different compared to that of non-damaged areas, both forms of electrocautery showed an increasing trend in $\mathrm{R}_{\max }, \mathrm{R}_{\mathrm{a}}$, and $\mathrm{R}_{\mathrm{sk}}$ and a decreasing trend in $\mathrm{R}_{\mathrm{k}}$ compared to non-damaged areas.

Roughness values were unable to be obtained for the Oxinium implant due to the surface being incompatible with white light interferometry. White light interferometry obtains measurements by measuring light interference when there is a difference in distance traveled by light waves from the surface being examined. Oxinium implants have a black surface so little to no light is reflected off of the surface back towards the machine. Future studies should take this into consideration when examining Oxinium.

In summary, the elemental compositions found within the pits believed to be caused by ICIC on necropsy retrieved CoCr implants were found to be different than those on Bovie induced electrocautery damage. Surface topographies, examined by measuring $R_{a}, R_{\max }, R_{s k}$, and $R_{k}$ roughness parameters, were also proven to be unique between ICIC damaged and electrocautery damaged groups from both Bovie and Aquamantys sources on $\mathrm{CoCr}$. $\mathrm{R}_{\mathrm{a}}, \mathrm{R}_{\max }, \mathrm{R}_{\mathrm{sk}}$ measurements collected from electrocautery damaged areas were shown to be consistently less than those found on ICIC damaged areas. These results support our hypothesis that comparisons between ICIC and electrocautery damage mechanisms can be made in order to discern which type of damage is truly occurring on the surface of an implant. With the number of total joint arthroplasties increasing every year, it is important to understand the mechanisms causing implants to fail over time. This study was able to shed some light on which type of corrosion is occurring on $\mathrm{CoCr}$ implants, leading to future studies possibly being able to understand the underlying mechanisms of ICIC. 


\section{CHAPTER 3. IN VITRO EFFECTS OF MACROPHAGES ON ORTHOPAEDIC IMPLANT ALLOYS AND LOCAL RELEASE OF METALLIC ALLOY COMPONENTS}

\section{Background}

Metal alloys have been used for decades for orthopaedic implants due to their advanced mechanical properties and generally good biocompatibility with typically minimal effects on the host tissue (77). However, all alloys are still susceptible to a variety of corrosion mechanisms due to the harsh environment and repetitive motion in joints $(78,79)$. Despite the progress in using metal alloys as relatively bioinert materials in orthopaedics, release of metal ions and debris remains a concern among patients that have undergone total joint arthroplasty due to the many adverse local tissue reactions (ALTR) seen in tissues surrounding the implant $(64,65,80)$. One of the more recently investigated processes that may be contributing to ALTR is corrosion caused by inflammatory cells. In this mechanism of corrosion, it is believed that inflammatory cells react with the surface of the implant and release reactive oxygen species (ROS), leading to disruption of the oxide layer (46). In support of this mechanism there has been elevated concentrations of immune cells reacting to metal ions and wear debris found in patients in need of revision due to ALTRs and microscopic evidence of this mechanism on the surface of retrieved implants $(81,82)$.

There has been some evidence that cells can alter the corrosion behavior of alloys by releasing reactive chemical species (RCS) and ROS, limiting oxygen diffusion, and changing the $\mathrm{pH}$ in the area surrounding the implant (46,83-87). Macrophages play an important role in the wound healing process by mediating the release of enzymes, cytokines, and growth factors (88). During the inflammation stage of an immune response, the M1 macrophage phenotype is more prominent, clearing out wound debris, such as necrotic tissue, foreign particles, and pathogens. Towards the end of the wound healing process the cell populations shift to a more M2 phenotype suppressing the inflammatory cascade to begin healing (89). Macrophages are known to be particularly abundant in the periprosthetic tissue at the bone-implant interface (90). Studies have shown that the macrophages in this area may phagocytose the micron and submicron sized wear debris particles released by the implant and secrete cytokines to stimulate osteoclast activation and migration and inhibit osteoblast activation (89-93). These and other immune cells are capable of secreting proteolytic enzymes and ROS capable of local tissue destruction and corroding biomaterial surfaces such as polyurethane insulated leads in pacemakers $(94,95)$.

Orthopaedic implants used for joint replacement usually consist of cobaltchromium-molybdenum (CoCrMo) alloys, and Titanium (Ti) alloys because of their high strength, toughness, and fatigue and fracture resistance $(96,97)$. An additional advantage of these alloys is the presence of stable oxide film on the surface of the implant, thus increasing the corrosion resistance. Under normal conditions, when the metal-oxide film is damaged due to mechanically assisted crevice corrosion, the bare metal underneath the 
oxide layer will undergo rapid oxidation releasing metal cations and repassivation occurs to reform the oxide film (98). This process leads to ion and wear particles being released into the local tissue. When cells migrate to the implant site, ROS, proteins and enzymes are present at the implant surface. This harsh environment changes the electrochemical behavior of the oxide film.

The goal of this study is to examine one of the underlying mechanisms of cellular corrosion by examining the affect of macrophages on the surface of common orthopaedic metals in vitro. IC-21 murine peritoneal macrophages were cultured on 316 stainless steel, Ti6Al4V, and ASTM F75 CoCr discs with and without two known proinflammatory activators. It is hypothesized that both activated and non-activated cells will be able to corrode the surface of the alloys and release the corresponding metal ions into their environment. These three alloys were selected because they are some of the most commonly used implants in total joint arthroplasty.

\section{Materials and Methods}

\section{Disc Preparation}

316L stainless steel, Ti6Al4V, and ASTM F75 CoCr discs were lathed and cut with the help of the metal shop at University of Memphis down to an average diameter of $6.34 \mathrm{~mm}$ with varying thicknesses. The discs were polished to a mirror finish using an EXAKT 400CS Micro Grinding System. The discs were placed against rotating abrasive paper over multiple sets ranging from $500 \mathrm{p}$ to $2000 \mathrm{p}$. They were cleaned by sonication in warm alkaline detergent, rinsed in deionized water and passivated in $30 \%$ nitric acid. The discs were then rinsed in deionized sterile (ultra-pure) water and sterilized under a UV lamp in the culture hood.

\section{Macrophage Preparation}

IC-21 (ATCC TIB-186, American Type Culture Collection, Manassas, VA) peritoneal macrophages from Mus musculus were cultured to a concentration of $600 \times 10^{3}$ cells $/ \mathrm{ml}$. Cells were cultured with growth medium of RPMI 1640 (Sigma) with 10\% fetal bovine serum (FBS) (Sigma), 1\% L-glutamine (Sigma), and 0.13\% gentamicin (Sigma). Cells were plated in $75 \mathrm{~cm}^{2}$ flasks and cultured in a humidified incubator at $37^{\circ} \mathrm{C}$, with $5 \% \mathrm{CO}_{2}$. Growth medium was changed every 2 to 3 days. The IC-21 cell line was chosen because they share many similar characteristics of normal peritoneal macrophages, such as their presence of specific receptors and antigens and their phagocytic activity (99). As a transformed cell line, it can be easily cultured in large quantities, allowing for easy use and reproducibility for our study (100). 


\section{Experimental Conditions}

316L stainless steel, Ti6Al4V, and ASTMF75 CoCr discs were placed into separate 96 well plates and cells were added and allowed to adhere to the surface of the discs for 24 hours. Interferon Gamma (IFN $\gamma$ ) and Lipopolysaccharide (LPS) were used to induce activation of macrophages. The stainless steel discs were the first discs studied. Six experimental groups were used: Discs + (1) Medium, (2) $20 \times 10^{3}$ cells $/ 150 \mu 1(20 \mathrm{~K}$ group), (3) $20 \times 10^{3}$ cells $/ 150 \mu \mathrm{l}+20 \mathrm{ng} / \mathrm{mL}$ LPS $+20 \mathrm{ng} / \mathrm{mL}$ IFN $\gamma($ IFN $\gamma / \mathrm{LPS} 20 \mathrm{~K})$, (4) $40 \times 10^{3}$ cells $/ 150 \mu \mathrm{l}$ (40K group), (5) $40 \times 10^{3}$ cells $/ 150 \mu \mathrm{l}+20 \mathrm{ng} / \mathrm{mL} \mathrm{LPS}+20 \mathrm{ng} / \mathrm{mL}$ IFN $\gamma$ (IFN $\gamma /$ LPS 40K), (6) $40 \times 10^{3}$ cells/150ul + 20ng/mL LPS (LPS 40K). The experiment was replicated on a control plate (TCP) without discs in order to monitor the integrity and growth of the cells under light microscopy. Culture medium was changed every 48 hours for the first 4 days and every 24 hours thereafter. Supernatant was collected every 2 days and frozen for later analysis.

$\mathrm{CoCr}$ and Ti testing, performed at a later date, both included the following groups: (1) discs + only medium, (2) discs $+20,000$ cells, (3) discs $+20,000$ activated cells, (4) discs $+40,000$ activated cells, (5) no disc $+20,000$ activated cells, (6) no disc + 40,000 activated cells. Culture medium was changed every 12 hours and the supernatant was collected and frozen every 4 days starting on day 2 for future analysis. After 30 days, the discs were carefully removed from the 96 well plates and cleaned for later analysis. Removal of macrophages from the disc surface was accomplished via sequential cleaning. Discs were first soaked in a bath of water and detergent at a ratio of 10:1 for two consecutive 20 minute increments. Discs were ultrasonicated for two 30 minute periods in a water bath with diluted detergent.

\section{Scanning Electron Microscopy}

Scanning electron microscopy (SEM) (Zeiss, Oberkochen, Germany) was used to perform detailed microscopic analysis of the areas identified from the initial visual assessment. Second Electron Imaging at $20 \mathrm{kV}$ was used. This was used to access if the macrophages were able to alter the surface of the metal discs.

\section{Cell Viability}

After 30 days, the cells grown on the various stainless steel groups were tested for cell viability and the number of cells were determined using CellTiter 96® Aqueous One Solution Assay (Promega) per manufacturer protocol. In this assay, NAD(P)H dependent oxidoreductase enzymes that are primarily localized in the cytosol of the cell have the ability to reduce MTT [3-(4,5-dimethylthiazol-2-yl)-2,5-diphenyltetrazolium bromide] to an insoluble Formazan which is purple. Samples were read at 490nm and absorbance values and these converted to cell number based on a known titer of cells for a control. The Griess Reagent Assay (ThermoFisher) was used to indirectly measure NO 
production from supernatant collected off the various groups from all three metals disc experiments.

\section{Metal Content}

Trace metals in the collected supernatant were analyzed via direct analysis using inductively coupled plasma triple quadrupole mass spectrometry (ICP-QQQ-MS) conducted at Brooks Applied Labs (Bothell, WA). Supernatants were analyzed for ions from appropriate metals. The stainless steel experiment was tested for chromium $(\mathrm{Cr})$, iron $(\mathrm{Fe})$, manganese $(\mathrm{Mn})$, and nickel $(\mathrm{Ni})$. The Ti6Al4V experiment was tested for aluminum (Al), titanium (Ti), and vanadium (V). The CoCr experiment was tested for cobalt (Co), chromium (Cr), and molybdenum (Mo).

\section{Statistics}

Before statistical analyses were performed, all data were tested for normality. ShapiroWilk normality tests revealed the data sets were not normally distributed. A 2-way ANOVA for simple effects within days and Dunnett's multiple comparisons tests were utilized for comparing the NO2 measurements collected from the Griess assay among the various groups. A Kurskal-Wallis test and post hoc Tukey test were utilized to compare the metal contents of the supernatants collected. All statistical tests were conducted using SigmaPlot statistical software with an assumed significance of $\mathrm{p}<0.05$.

\section{Results}

\section{Cell Viability}

After 30 days, cell count was shown to be significantly higher $(\mathrm{p}<0.05)$ for the groups originally containing 40,000 cells, 20,000 cells activated via LPS and IFN $\gamma$, and 40,000 cells activated via LPS and IFN $\gamma$ when placed on stainless steel discs compared to a control plate (Figure 3-1). The majority of both the activated and non-activated IC-21 cells adhered on the stainless steel discs were viable based on visual observation throughout the experiment and results from the CellTiter $96 \AA$ Aqueous One Solution Assay.

\section{NO Content}

NO production was examined to determine if the cells were being affected by the metal surface (Figure 3-2). For the stainless steel experiment, IC-21 cells activated via LPS and IFN $\gamma$ produced significantly more NO compared to their control counterparts after 8-10 days and remained elevated for the duration of the experiment $(\mathrm{p}<0.01)$ in all 


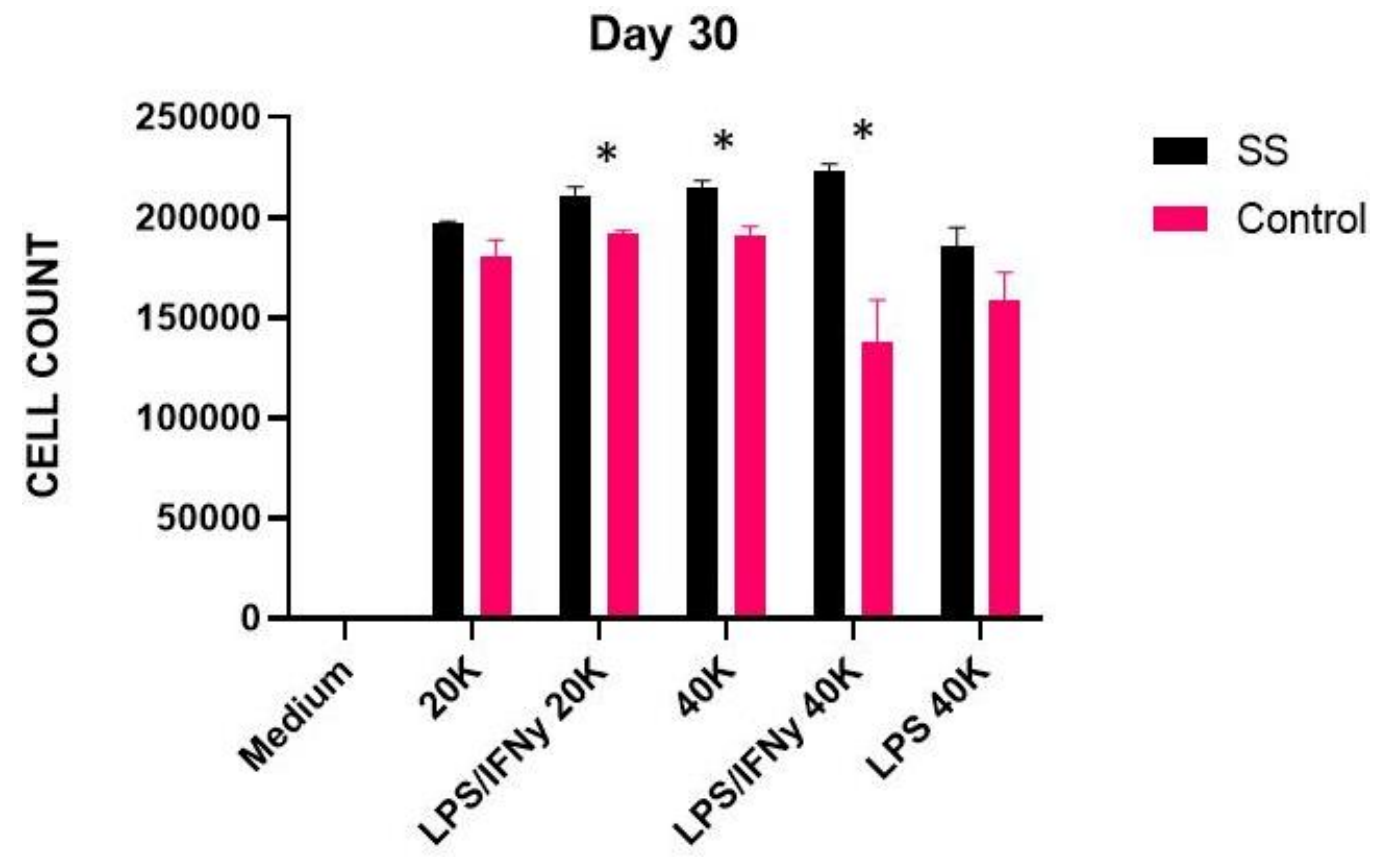

Figure 3-1. Cell count among the various groups involved in the stainless steel experiment at day 30

Bars represent means \pm SEM. * indicate statistical difference between between stainless steel group and control group $(\mathrm{p}<0.05)$

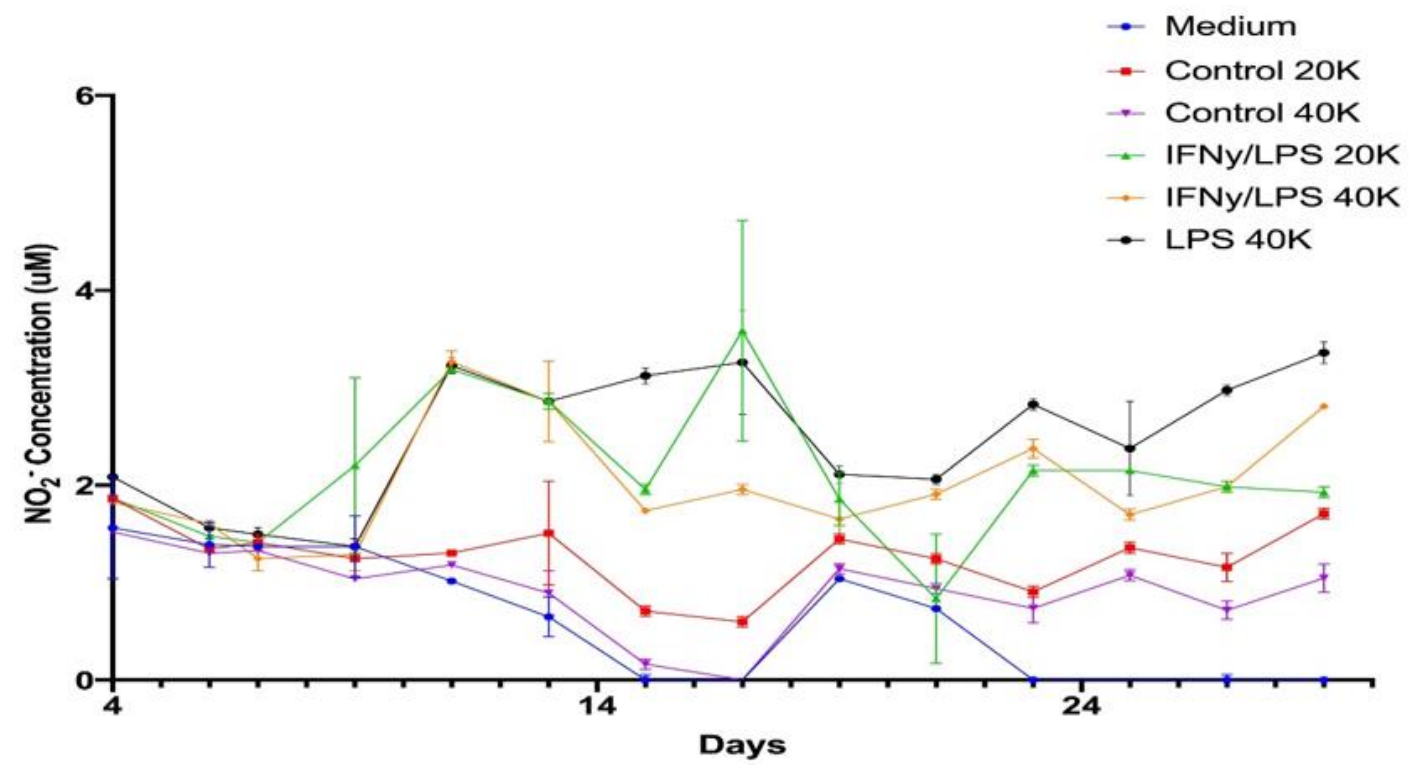

Figure 3-2. Griess assay results showing the amount of $\mathrm{NO}_{2}$ in the collected supernatant over the course of 30 days

Dots represent means \pm standard error of the mean 
cases except for IFN/LPS 20k group on day 21. All sample types showed similar NO activity up until day 8-10 of the study where the macrophage activated samples spiked and leveled off around $2.5 \mathrm{uM}$ for the remainder of the experiment. There was no difference among the groups for both the $\mathrm{Ti}$ and $\mathrm{CoCr}$ experiments.

\section{Scanning Electron Microscopy}

SEM analysis the stainless steel discs showed an indentation of approximately 5 to $10 \mu \mathrm{m}$ on one of the IFN $\gamma /$ LPS $20 \mathrm{~K}$ group discs (Figure 3-3). This indention indicates that a pit had been formed due to the IC-21 macrophages corroding the surface of the stainless steel. No indentions or any other visual evidence of corrosion was seen on the surface of any of the CoCr or Ti discs.

\section{Metal Content}

Cellular corrosion of stainless steel, $\mathrm{Ti}$, and $\mathrm{CoCr}$ was quantified by measuring the concentration of metal ions released into the culture supernatant over the course of 30 days. Graphical representation of the summations of the metal ion concentrations for all three metal alloy experiments can be found in Appendix B (Figures B-1 through B-10). On stainless steel, both non-activated and activated cell groups were shown to have a statistically significant increase in metal ion release for $\mathrm{Cr}, \mathrm{Fe}$, and $\mathrm{Ni}(\mathrm{p}<0.05)$ concentrations compared to standard culture medium only (Table 3-1). For Ti, there was a significant increase in $\mathrm{Al}(<0.001)$ and a significant decrease in $\mathrm{V}(\mathrm{p}=0.003)$ concentrations among all disc groups compared to medium (Table 3-2). No significant differences were seen among all the disc groups for the CoCr experiment (Table 3-3). However, there was still a noticeable increase in total metal content released into the supernatant over the course of 30 days (Figure 3-4). No significant differences were seen among activated and non-activated cells placed on all three types of discs. In some cases, the $\mathrm{V}$ measurements were under detection limits $(0.1 \mu \mathrm{g} / \mathrm{L})$, therefore the amount of $\mathrm{V}$ ions released into the supernatant is suspect.

\section{Discussion}

Metal implants have become a common therapeutic intervention in cardiovascular, dental, and orthopaedic surgery. Recent evidence of direct cellular corrosion has been seen in vivo (46). It is believed that inflammatory cells react to an immune response by attaching to the cell surfaces and releasing reactive oxygen species (ROS), thus increasing oxidation of the alloy and damaging the oxide layer (46). This mechanism has been investigated in both total hip and total knee arthroplasty $(46,47,50,51)$. The aim of this study was to investigate the possibility of corrosion due to macrophages on 316L stainless steel, Ti6Al4V, and ASTM F75 CoCr. For that purpose, we created an in vitro model using IC-21 murine peritoneal macrophages. These were selected because they share many similar characteristics of normal peritoneal 


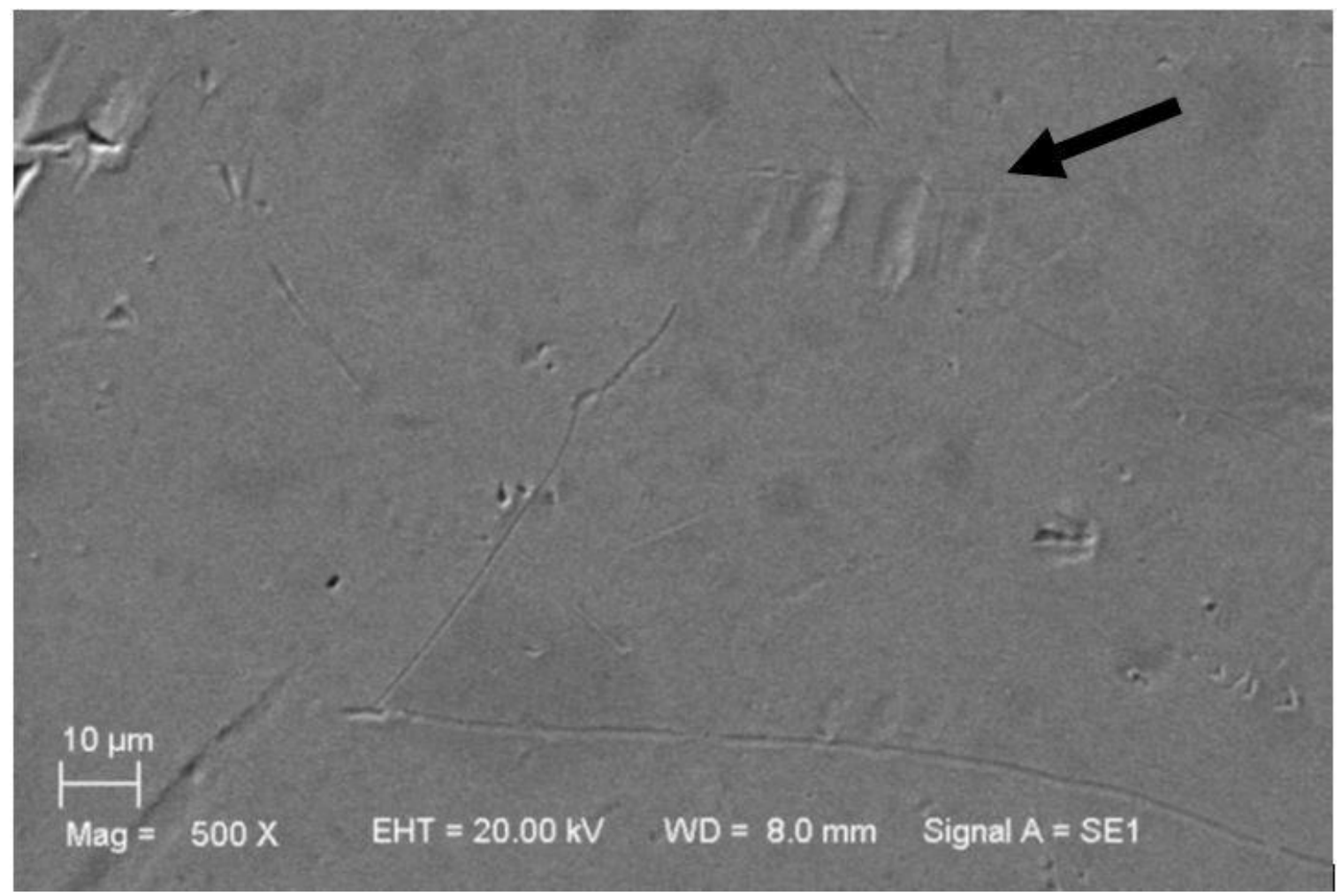

Figure 3-3. SEM image at 500x showing macrophage-sized indentions found on the surface of $316 \mathrm{~L}$ stainless steel

Table 3-1. Median metal concentrations found the supernatant collected off stainless steel

\begin{tabular}{ccccc}
\hline Group & $\mathrm{Cr}(\mu \mathrm{g} / \mathrm{L})$ & $\mathrm{Fe}(\mu \mathrm{g} / \mathrm{L})$ & $\mathrm{Mn}(\mu \mathrm{g} / \mathrm{L})$ & $\mathrm{Ni}(\mu \mathrm{g} / \mathrm{L})$ \\
\hline Medium (no cells) & 0.642 & 269 & 5.06 & 1.59 \\
Medium + LPS/IFN $\gamma(20 \mathrm{k})$ & $1.84^{* * *}$ & $283^{* *}$ & 5.11 & $2.50^{*}$ \\
Medium $(20 \mathrm{k})$ & $1.97^{* * *}$ & $303^{* *}$ & 5.25 & $2.77^{*}$ \\
Medium (40k) & $1.80^{* *}$ & $306^{*}$ & 5.59 & 2.37 \\
\hline
\end{tabular}

Statistical testing was performed to compare each group with that of the group containing medium with no cells attached to the disc. * indicates $\mathrm{p}<0.05$. ** indicates $\mathrm{p}<0.01$. $* * *$ indicates $\mathrm{p}<0.001$. 
Table 3-2. Median metal concentrations found the supernatant collected off Titanium alloy

\begin{tabular}{cccc}
\hline Group & $\mathrm{Al}(\mu \mathrm{g} / \mathrm{L})$ & $\mathrm{Ti}(\mu \mathrm{g} / \mathrm{L})$ & $\mathrm{V}(\mu \mathrm{g} / \mathrm{L})$ \\
\hline Medium (no cells) & 3.15 & 11.6 & 0.466 \\
Medium + LPS/IFN $\gamma(20 \mathrm{k})$ & $19.7^{* * *}$ & 5.95 & $0.298^{* *}$ \\
Medium (20k) & $14.8^{*}$ & 4.45 & $0.270^{*}$ \\
\hline
\end{tabular}

Statistical testing was performed to compare each group with that of the group containing medium with no cells attached to the disc. $*$ indicates $\mathrm{p}<0.05 .{ }^{* *}$ indicates $\mathrm{p}<0.01$. $* * *$ indicates $\mathrm{p}<0.001$.

Table 3-3. Median metal concentrations found the supernatant collected off $\mathrm{CoCr}$

\begin{tabular}{cccc}
\hline Group & Co $(\mu \mathrm{g} / \mathrm{L})$ & $\mathrm{Cr}(\mu \mathrm{g} / \mathrm{L})$ & $\mathrm{Mo}(\mu \mathrm{g} / \mathrm{L})$ \\
\hline Medium (no cells) & 33.0 & 3.45 & 5.68 \\
Medium + LPS/IFN $\gamma(20 \mathrm{k})$ & 36.6 & 3.36 & 2.58 \\
Medium (20k) & 25.2 & 3.31 & 2.49 \\
\hline
\end{tabular}

Statistical testing was performed to compare each group with that of the group containing medium with no cells attached to the disc. No significant differences were found among the various groups. 
Co Summation Over 30 Days

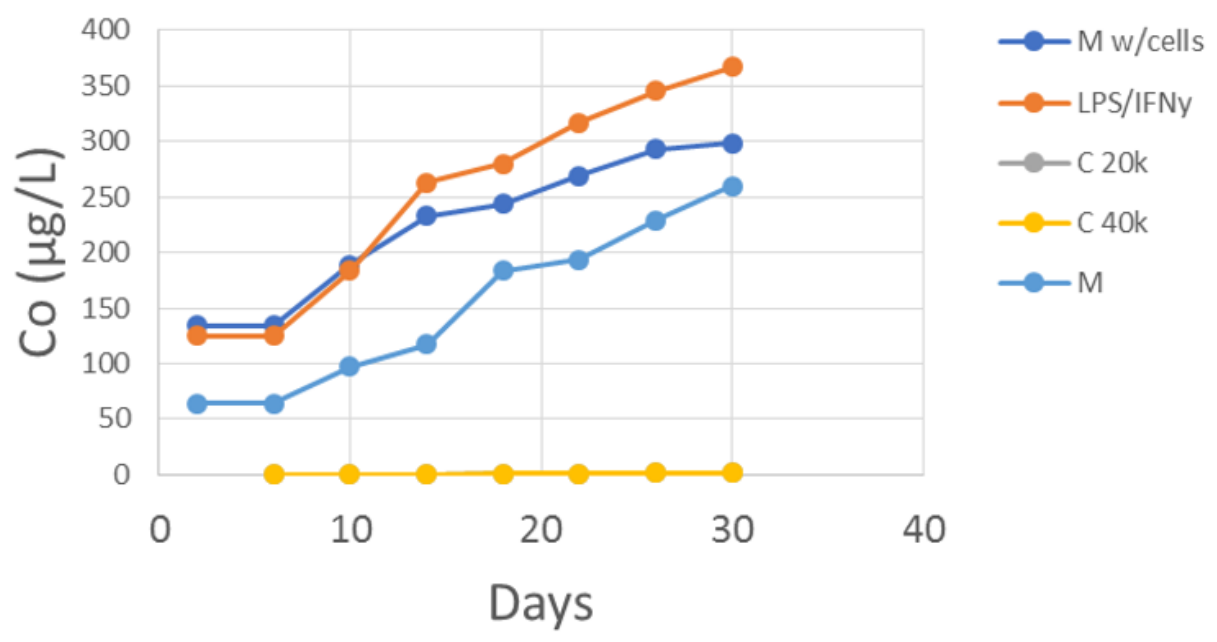

Figure 3-4. Total Co content found in the supernatant over the course of 30 days 
macrophages. They are also easy to culture and have shown good experimental reproducibility in the past $(100,101)$. The three metal alloys were selected because they are commonly used in a wide variety of orthopaedic applications.

Metal debris in the body have been shown to generate an immune response and influencing physiological activities. There remains concern regarding the release of soluble metal ions from implants which may bind to proteins, disseminate into the surrounding tissue, bloodstream, and organs. In this study, we observed a significant increase in $\mathrm{Cr}, \mathrm{Fe}$, and $\mathrm{Ni}$ ion release when macrophages are attached to the surface of stainless steel. $\mathrm{Ni}$ and $\mathrm{Cr}$ are known sensitizers and can lead to a hypersensitivity reaction. In this case, the ions bind with native proteins and form haptens. These metal hapten complexes are recognized by antigen presenting cells, such as macrophages and B cells, and present antigens to T lymphoctyes. The following immune response could lead to a variety of complications, such as redness, itching, hives, dermatitis, or vasculitis $(65,102)$.

This study was successful in showing that macrophages are capable of affecting the oxide layer of stainless steel and Ti by releasing components of the oxide surface within 30 days. A significant increase in $\mathrm{Cr}, \mathrm{Fe}$, and $\mathrm{Ni}$ ion release occurred when cells were cultured on the surface of stainless steel discs for 30 days. A previous study by Cadosh et al., also involving 316L stainless steel, has shown that osteoclasts cause a greater increase in $\mathrm{Cr}$ compared to $\mathrm{Ni}$ under similar conditions (41). Our results show that macrophages lead to a greater increase of $\mathrm{Ni}$ ions compared to $\mathrm{Cr}$. This increase suggests that various cell types may effectively change metal ion release profiles in different ways. When macrophages were placed on the surface of Ti, we saw a significant increase in $\mathrm{Al}$ ion release into the supernatant. These results match those previously found involving osteoclasts on titanium by Cadosh et al. (103). Their study showed that the metal ions released from the surface were taken up by the osteoclasts $(104,105)$. The Al ions were believed to eventually be released into the extracellular space leading to the increase in $\mathrm{Al}$ concentration found in the supernatant. However, $\mathrm{Ti}$ ions have the ability to bind to cytoplasmic and nuclear structures and form complexes that remained in the cell $(105,106)$. Similar mechanisms could be occurring in macrophages. This process would explain why no increase in Ti concentration was found in the supernatant of this study. The decrease in $\mathrm{V}$ concentration found in the supernatant collected off of discs with cells attached could indicate that the metal ions are being taken up into the cells and binding with cellular structures.

Based on the outcomes of this study, macrophages appeared to have the greatest effect on stainless steel. The significant increase in metal ion release is more prominent than in the other two alloys. It also had an increase in NO release, indicating that the cells are indeed activating and releasing chemical species in response to the metal. Evidence was further supported by the formation of a pit on the surface of one of the discs with cells activated with LPS and IFN $\gamma$. The indentions seen using the SEM were roughly 5 to $15 \mu \mathrm{m}$, matching the size of a macrophage. These indentions were not seen on the $\mathrm{Ti}$ or $\mathrm{CoCr}$ discs. However, it is possible that if the study went on for longer than 
30 days, we might have seen a similar visual effect start to appear on the surface of these two alloys.

This study produced no statistical evidence that cellular corrosion due to macrophages is occurring on $\mathrm{CoCr}$. There was no significant difference in $\mathrm{Co}, \mathrm{Cr}$, and Mo concentrations found in the supernatant collected off of discs with cells attached versus those with no cells. There was also no change in NO production or visual changes found on the surface. However, both activated and non-activated cell groups on $\mathrm{CoCr}$ discs showed similar patterns seen in the other two disc types, with total Co concentrations found in the supernatant over the 30 day experiment being much higher than that collected from discs with medium and no cells. Additionally, cases of cellular corrosion have been seen in retrieval studies involving CoCr implants used in knee and hip arthroplasty $(46,105-107)$. It is believed that inflammatory cell induced corrosion is caused by a reaction to the wear debris resulting from mechanically assisted crevice corrosion ${ }^{37}$. This corrosion takes place over many years while the implant is in the body. Therefore, it is possible that the macrophages showed no statistically significant indication of corroding the surface in this study because the experiment only took place over 30 days.

For a more accurate representation of an in vivo reaction of macrophages to $\mathrm{CoCr}$, a longer testing time may be necessary. However, extending the length of the experiment could lead to complications with keeping cells healthy as they differentiate and spread due to the limited space on the surface of the discs. Increasing the size of the discs used in future studies would allow for more cells to differentiate and adhere to the surface. The limited amount of supernatant collected from atop each disc also proved to be a problem. Only $150 \mu \mathrm{l}$ of medium was able to be placed on each disc, leading to relatively little supernatant analyzed using ICP-QQQ-MS for each group. In some cases, the V measurements were under detection limits $(0.1 \mu \mathrm{g} / \mathrm{l})$, therefore the amount of $\mathrm{V}$ ions measured in the supernatant might be inaccurate. If the amount of sample for each group is increased, ICP-QQQ-MS could be run multiple times with a lower detection limit. Another limitation was the inability to determine if ions were being taken up into cells and binding to cellular structures. Future studies should incorporate the use of confocal fluorescence microscopy. Past studies have shown success with the use of Newport Green $^{\mathrm{TM}}$ DCF diacetate ester staining with confocal microscopy to detect $\mathrm{Cr}, \mathrm{Co}, \mathrm{Mo}, \mathrm{Al}$, $\mathrm{Ti}$, and $\mathrm{V}$ ions in human monocyte-derived dendritic cells ${ }^{38}$. This method could be used to determine if ions are binding to cytoplasmic and nuclear structures in IC-21 macrophages.

In conclusion, this study was successful in showing that IC-21 macrophages were able to attach and multiply on 316L stainless steel, Ti6Al4V, and ASTMF75 CoCr. The cells were able to directly affect the surface oxide layer of stainless steel and Ti alloys by releasing corresponding metal ions into the surrounding environment. Similar processes may be taking place in vivo, leading to disruption of the oxide layers of orthopaedic implants and metal ions to be released into the surrounding area. This would cause an immune response, leading to migration of other inflammatory cells to the implant and 
causing further corrosion to occur. Further studies using other inflammatory cells should be conducted in order to better understand the mechanisms behind cellular corrosion. 


\section{CHAPTER 4. GENERAL DISCUSSION}

Metallic alloys have shown much promise as implants in total joint arthroplasty due to their excellent mechanical properties and generally good corrosion resistance due to the passive oxide film on the surface of the implants. However, release of metal ions and debris remains a concern due to the many adverse effects seen in local tissues surrounding the implant $(64,65,80)$. With the number of total joint arthroplasties steadily increasing, it is important to understand the factors that lead to failure to get better outcomes for patients. The biological response to wear debris remains complex and poorly understood. Most research in this area focuses on the inflammatory reactions to metal debris leading to osteolysis and ALTRs. This thesis, however, focused on how inflammatory cells directly affected the surface of the implant by measuring ion level and observed surface changes.

Recent evidence of extensive corrosion present on failed orthopaedic hip and knee implants show in vivo evidence of damage mechanisms attributed to cellular attack of the surface $(46,47,50,51)$. Other evidence suggests that this damage is truly caused by electrocautery tools used in revision surgeries $(59,66)$. During this work, we examine 41 primary TKA implants retrieved at necropsy (Appendix C, Table C-1). Fluoroscopic analysis determined that these implants were secure and showed no signs of osteolysis. Seven of these implants showed corrosive damage signs attributed to ICIC (17\%). Previous retrieval studies showed ICIC prevalence ranges from $29 \%$ to $74 \%$. Our study is the first to focus on femoral components retrieved during autopsy instead of those retrieved during revision surgery. Therefore, there is minimal chance of the implant coming into contact with electrocautery tools. We believe that our study has the most accurate representation of the prevalence of ICIC.a in vitro.

Examination of the visual patterns left by both ICIC and electrocautery damage showed similar damage patterns consisting of discolored regions with ruffled topography with small pits and crater-like features. However, further examination revealed different elemental compositions within the pits. The pits found of electrocautery damages surfaces showed higher concentrations of iron that was believed to be residue left due to the use of a stainless steel tip with the electrocautery tools. The pits found on ICIC damaged areas on the necropsy retrieved implants showed higher concentrations of carbon. The iron to carbon ratios among all Bovie groups were shown to be significantly higher than that of ICIC. Aquamantys groups showed no statistically significant difference when compared to ICIC. We believe that comparison of the elemental composition within the pits, specifically by creation of an iron to carbon ratio, is a possible way to distinguish between ICIC and Bovie damage mechanisms for future studies.

The topography of the damaged areas between ICIC and electrocautery on the CoCr implant was also examined in an attempt to find a distinction between the two. Both forms of electrocautery damage showed a significant increase in $R_{a}, R_{q}$, and $R_{\max }$ values. This increase in roughness parameters could be explained by pitting and 
electrocautery byproducts on the surface. An increase in these roughness values was also seen among ICIC damaged group, indicating that pits are forming in the oxide layer. Roughness values were shown to be higher among ICIC damaged areas from the necropsy retrieved implants compared to the those found on both forms of electrocautery damage. This method allows for another possible way to distinguish between the two damage mechanisms.

In vitro results showed that macrophages were able to adhere to the surface of 316L stainless steel, Ti6Al4V, and ASTM F75 CoCr discs. SEM images showed roughly 5 to $15 \mu \mathrm{m}$ indentions on the surface of a stainless steel disc that had cells activated with LPS and IFN $\gamma$ on the surface. This size roughly matches that of a macrophage, indicating that the cells were successful in corroding the oxide layer of stainless steel during the 30 day experiment. Another indication of corrosion occurring can be seen due to the significant increase in $\mathrm{Cr}, \mathrm{Fe}$, and $\mathrm{Ni}$ ion release when cells were cultured on the surface of stainless steel discs compared to that of discs with medium and no cells. There was a significant increase in $\mathrm{Ti}$ ions and a decrease in $\mathrm{V}$ ions measured in the medium when cells were present compared to when no cells were present. The decrease in $\mathrm{V}$ concentrations could be explained by uptake of the ions into the cells, where they were binding to cellular structures to form complexes. CoCr groups showed no statistical difference in metal ion release into the supernatant. However, examination of the summation of the Co content found in the supernatant showed similar patterns as those shown in statistically significant groups among the other two disc types. Both activated and non-activated cells caused the overall Co content to increase over the course of 30 days when adhered to the $\mathrm{CoCr}$ surface compared to just standard medium.

Being able to replicate surface damage seen in retrieval studies in an in vitro model is important for understanding the mechanisms involved in ICIC. Our results show that macrophages do play a part in ICIC on stainless steel and Ti. However, it appears that they are not able to affect the surface of $\mathrm{CoCr}$ within 30 days. Future in vitro studies should examine the effects of macrophages over a longer period. This could allow for $\mathrm{CoCr}$ to show similar effects as those seen in vivo. Many other types of inflammatory cells, such as neutrophils, giant body cells, and lymphocytes, are involved in the biological response to wear debris. These cells should also be examined on their effects on the surface of these common orthopaedic alloys. The production of inflammatory cytokines, such as IL-1b, IL-6, and TNF-a, during culture could also be examined via Cytometric Bead Array analysis. These cytokines are known to be involved in osteolytic processes and have been shown to induce an migration and activation of inflammatory cells during an immune response.

Future in vivo testing could also be done to get a more accurate representation within the natural environment. Monitoring the activity of inflammatory cells when a $\mathrm{CoCr}$, Ti, or stainless steel device is implanted is one option. The major challenge with animal studies would be selection of a suitable animal model and device to most accurately replicate the human environment around a joint while minimizing pain for the animal. Another drawback would be the limited production of metal ions and particles due to the small size of the implant and short implantation time compared to human 
specimens. Controlled damage to the surface of the disc would allow for an initial disruption of the oxide layer, thus increasing the metal debris in the local area at the beginning of the study. This would help accelerate the process if that proves necessary for more accurate results. 


\section{LIST OF REFERENCES}

1. Jones CA, Beaupre LA, Johnston DW, Suarez-Almazor ME. Total joint arthroplasties: current concepts of patient outcomes after surgery. Rheumatic Disease Clinics of North America. 2007 Feb 1;33(1):71-86.

2. Fitzgerald JD, Orav EJ, Lee TH, Marcantonio ER, Poss R, Goldman L, Mangione CM. Patient quality of life during the 12 months following joint replacement surgery. Arthritis care \& research. 2004 Feb 15;51(1):100-9.

3. Bashinskaya B, Zimmerman RM, Walcott BP, Antoci V. Arthroplasty utilization in the United States is predicted by age-specific population groups. ISRN orthopedics. 2012 Nov 14;2012.

4. Sloan M, Premkumar A, Sheth NP. Projected volume of primary total joint arthroplasty in the US, 2014 to 2030. JBJS. 2018 Sep 5;100(17):1455-60.

5. Sharkey PF, Lichstein PM, Shen C, Tokarski AT, Parvizi J. Why are total knee arthroplasties failing today-has anything changed after 10 years?. The Journal of arthroplasty. 2014 Sep 1;29(9):1774-8.

6. Sharkey PF, Hozack WJ, Rothman RH, Shastri S, Jacoby SM. Why are total knee arthroplasties failing today?. Clinical Orthopaedics and Related Research®. 2002 Nov 1;404:7-13

7. Kurtz SM, Gawel HA, Patel JD. History and systematic review of wear and osteolysis outcomes for first-generation highly crosslinked polyethylene. Clinical Orthopaedics and Related Research®. 2011 Aug 1;469(8):2262-77.

8. Williams DF. On the mechanisms of biocompatibility. Biomaterials. $2008 \mathrm{Jul}$ $1 ; 29(20): 2941-53$.

9. Neale SD, Haynes DR, Howie DW, Murray DW, Athanasou NA. The effect of particle phagocytosis and metallic wear particles on osteoclast formation and bone resorption in vitro. The Journal of arthroplasty. 2000 Aug 1;15(5):654-62.

10. Nine MJ, Choudhury D, Hee AC, Mootanah R, Osman NA. Wear debris characterization and corresponding biological response: artificial hip and knee joints. Materials. 2014 Feb;7(2):980-1016.

11. González O, Smith RL, Goodman SB. Effect of size, concentration, surface area, and volume of polymethylmethacrylate particles on human macrophages in vitro. Journal of Biomedical Materials Research: An Official Journal of The Society for Biomaterials and The Japanese Society for Biomaterials. 1996 Apr;30(4):463-73.

12. Sabokbar A, Pandey R, Athanasou NA. The effect of particle size and electrical charge on macrophage-osteoclast differentiation and bone resorption. Journal of Materials Science: Materials in Medicine. 2003 Sep 1;14(9):731-8.

13. Greenfield EM. Do genetic susceptibility, Toll-like receptors, and pathogenassociated molecular patterns modulate the effects of wear?. Clinical Orthopaedics and Related Research®. 2014 Dec 1;472(12):3709-17.

14. Hallab NJ, Jacobs JJ. Chemokines associated with pathologic responses to orthopedic implant debris. Frontiers in endocrinology. 2017 Jan 19;8:5.

15. Purdue PE, Koulouvaris P, Nestor BJ, Sculco TP. The central role of wear debris in periprosthetic osteolysis. HSS Journal. 2006 Sep 1;2(2):102-13. 
16. Hallab NJ, Jacobs JJ. Biologic effects of implant debris. Bulletin of the NYU hospital for joint diseases. 2009 Apr 1;67(2):182.

17. Abu-Amer Y, Darwech I, Clohisy JC. Aseptic loosening of total joint replacements: mechanisms underlying osteolysis and potential therapies. Arthritis research \& therapy. 2007 Jun 1;9(S1):S6.

18. Crotti TN, Smith MD, Findlay DM, Zreiqat H, Ahern MJ, Weedon H, Hatzinikolous G, Capone M, Holding C, Haynes DR. Factors regulating osteoclast formation in human tissues adjacent to peri-implant bone loss: Expression of receptor activator NFkB, RANK ligand and osteoprotegerin. Biomaterials. 2004 Feb 1;25(4):565-73.

19. Bao W, He Y, Fan Y, Liao Y. Metal allergy in total-joint arthroplasty: case report and literature review. Medicine. 2018 Sep;97(38).

20. Amini M, Mayes WH, Tzeng A, Tzeng TH, Saleh KJ, Mihalko WM. Evaluation and management of metal hypersensitivity in total joint arthroplasty: a systematic review. Journal of long-term effects of medical implants. 2014;24(1).

21. Hallab N, Merritt K, Jacobs JJ. Metal sensitivity in patients with orthopaedic implants. JBJS. 2001 Mar 1;83(3):428.

22. Roberts TT, Haines CM, Uhl RL. Allergic or hypersensitivity reactions to orthopaedic implants. Journal of the American Academy of Orthopaedic Surgeons. 2017 Oct 1;25(10):693-702.

23. Gibon E, Amanatullah DF, Loi F, Pajarinen J, Nabeshima A, Yao Z, Hamadouche M, Goodman SB. The biological response to orthopaedic implants for joint replacement: Part I: Metals. Journal of Biomedical Materials Research Part B: Applied Biomaterials. 2017 Oct;105(7):2162-73.

24. Cooper HJ. Diagnosis and treatment of adverse local tissue reactions at the headneck junction. The Journal of arthroplasty. 2016 Jul 1;31(7):1381-4.

25. Campbell P, Ebramzadeh E, Nelson S, Takamura K, De Smet K, Amstutz HC. Histological features of pseudotumor-like tissues from metal-on-metal hips. Clinical Orthopaedics and Related Research®. 2010 Sep 1;468(9):2321-7.

26. Doorn PF, Mirra JM, Campbell PA, Amstutz HC. Tissue reaction to metal on metal total hip prostheses. Clinical Orthopaedics and Related Research (1976-2007). 1996 Aug 1;329:S187-205.

27. Pandit H, Glyn-Jones S, McLardy-Smith P, Gundle R, Whitwell D, Gibbons CL, Ostlere S, Athanasou N, Gill HS, Murray DW. Pseudotumours associated with metal-on-metal hip resurfacings. The Journal of bone and joint surgery. British volume. $2008 \mathrm{Jul} ; 90(7): 847-51$.

28. Pandit H, Vlychou M, Whitwell D, Crook D, Luqmani R, Ostlere S, Murray DW, Athanasou NA. Necrotic granulomatous pseudotumours in bilateral resurfacing hip arthoplasties: evidence for a type IV immune response. Virchows Archiv. 2008 Nov $1 ; 453(5): 529$.

29. Kwon YM, Ostlere SJ, McLardy-Smith P, Athanasou NA, Gill HS, Murray DW. "Asymptomatic" pseudotumors after metal-on-metal hip resurfacing arthroplasty: prevalence and metal ion study. The Journal of arthroplasty. 2011 Jun 1;26(4):5118.

30. De Smet KA. Belgium experience with metal-on-metal surface arthroplasty. Orthopedic Clinics. 2005 Apr 1;36(2):203-13. 
31. Bitar D, Parvizi J. Biological response to prosthetic debris. World journal of orthopedics. 2015 Mar 18;6(2):172.

32. Urban RM, Jacobs JJ, Tomlinson MJ, Gavrilovic J, Black J, Peoc'h M.

Dissemination of wear particles to the liver, spleen, and abdominal lymph nodes of patients with hip or knee replacement. JBJS. 2000 Apr 1;82(4):457.

33. Macholz RM. Trace Metals in the Environment. Volume 6: Cobalt. An Appraisal of Environmental Exposure. 1982;26(9):746-.

34. Scharf B, Clement CC, Zolla V, Perino G, Yan B, Elci SG, Purdue E, Goldring S, Macaluso F, Cobelli N, Vachet RW. Molecular analysis of chromium and cobaltrelated toxicity. Scientific reports. 2014 Jul 17;4:5729.

35. Lloyd DR, Carmichael PL, Phillips DH. Comparison of the formation of 8hydroxy-2 '-deoxyguanosine and single-and double-strand breaks in DNA mediated by fenton reactions. Chemical research in toxicology. 1998 May 18;11(5):420-7.

36. Polyzois I, Nikolopoulos D, Michos I, Patsouris E, Theocharis S. Local and systemic toxicity of nanoscale debris particles in total hip arthroplasty. Journal of Applied Toxicology. 2012 Apr;32(4):255-69.

37. Gill HS, Grammatopoulos G, Adshead S, Tsialogiannis E, Tsiridis E. Molecular and immune toxicity of $\mathrm{CoCr}$ nanoparticles in MoM hip arthroplasty. Trends in molecular medicine. 2012 Mar 1;18(3):145-55.

38. Kwon YM, Xia Z, Glyn-Jones S, Beard D, Gill HS, Murray DW. Dose-dependent cytotoxicity of clinically relevant cobalt nanoparticles and ions on macrophages in vitro. Biomedical materials. 2009 Apr 6;4(2):025018.

39. Papageorgiou I, Brown C, Schins R, Singh S, Newson R, Davis S, Fisher J, Ingham $\mathrm{E}$, Case CP. The effect of nano-and micron-sized particles of cobalt-chromium alloy on human fibroblasts in vitro. Biomaterials. 2007 Jul 1;28(19):2946-58.

40. Bailey LO, Lippiatt S, Biancanello FS, Ridder SD, Washburn NR. The quantification of cellular viability and inflammatory response to stainless steel alloys. Biomaterials. 2005 Sep 1;26(26):5296-302.

41. Cadosch D, Chan E, Gautschi OP, Simmen HP, Filgueira L. Bio-corrosion of stainless steel by osteoclasts - in vitro evidence. Journal of Orthopaedic Research. 2009 Jul;27(7):841-6.

42. Navarro M, Michiardi A, Castano O, Planell JA. Biomaterials in orthopaedics. Journal of the royal society interface. 2008 Jul 30;5(27):1137-58.

43. Sansone V, Pagani D, Melato M. The effects on bone cells of metal ions released from orthopaedic implants. A review. Clinical cases in mineral and bone metabolism. 2013 Jan;10(1):34.

44. Savory J, Ghribi O. Can studies of aluminum toxicity in vivo and in vitro provide relevant information on the pathogenesis and etiology of Alzheimer's disease?. Journal of Alzheimer's Disease. 2007 Jan 1;11(4):429-30.

45. Yokel RA. The toxicology of aluminum in the brain: a review. Neurotoxicology. 2000 Oct;21(5):813-28.

46. Gilbert JL, Sivan S, Liu Y, Kocagöz SB, Arnholt CM, Kurtz SM. Direct in vivo inflammatory cell-induced corrosion of CoCrMo alloy orthopedic implant surfaces. Journal of Biomedical Materials Research Part A. 2015 Jan;103(1):211-23.

47. Cerquiglini A, Henckel J, Hothi HS, Di Laura A, Skinner JA, Hart AJ. Inflammatory cell-induced corrosion in total knee arthroplasty: a retrieval study. 
Journal of Biomedical Materials Research Part B: Applied Biomaterials. 2018 Jan;106(1):460-7.

48. Morris CJ, Earl JR, Trenam CW, Blake DR. Reactive oxygen species and iron-a dangerous partnership in inflammation. The international journal of biochemistry \& cell biology. 1995 Feb 1;27(2):109-22.

49. Winterbourn CC. Toxicity of iron and hydrogen peroxide: the Fenton reaction. Toxicology letters. 1995 Dec 1;82:969-74.

50. Di Laura A, Hothi HS, Meswania JM, Whittaker RK, de Villiers D, Zustin J, Blunn GW, Skinner JA, Hart AJ. Clinical relevance of corrosion patterns attributed to inflammatory cell-induced corrosion: A retrieval study. Journal of Biomedical Materials Research Part B: Applied Biomaterials. 2017 Jan;105(1):155-64.

51. Arnholt CM, MacDonald DW, Malkani AL, Klein GR, Rimnac CM, Kurtz SM, Kocagoz SB, Gilbert JL, Implant Research Center Writing Committee. Corrosion damage and wear mechanisms in long-term retrieved $\mathrm{CoCr}$ femoral components for total knee arthroplasty. The Journal of arthroplasty. 2016 Dec 1;31(12):2900-6.

52. Gallagher K, Dhinsa B, Miles J. Electrosurgery. Surgery (Oxford). 2011 Feb 1;29(2):70-2.

53. Gordon PH, Nivatvongs S, Mulholland MW. Principles and practice of surgery for the colon, rectum, and anus. Shock. 1999 Oct 1;12(4):328.

54. O'Connor JL, Bloom DA. William T. Bovie and electrosurgery. Surgery. 1996 Apr 1;119(4):390-6.

55. Glover JL, Bendick PJ, Link WJ. The use of thermal knives in surgery: electrosurgery, lasers, plasma scalpel. Current problems in surgery. 1978 Jan 1;15(1):1-78.

56. Doherty. CURRENT Diagnosis \& Treatment: Surgery, 14e. McGraw-Hill; 2014.

Doi: http://accessmedicine.mhmedical.com.ezproxy.uthsc.edu/content.aspx?bookid=120 2\&sectionid $=71516149$.

57. Cordero I. Electrosurgical units-how they work and how to use them safely. Community eye health. 2015;28(89):15.

58. Yuan N, Park SH, Luck Jr JV, Campbell PA. Revisiting the concept of inflammatory cell-induced corrosion. Journal of Biomedical Materials Research Part B: Applied Biomaterials. 2018 Apr;106(3):1148-55.

59. Kubacki GW, Sivan S, Gilbert JL. Electrosurgery induced damage to Ti-6Al-4V and CoCrMo alloy surfaces in orthopedic implants in vivo and in vitro. The Journal of arthroplasty. 2017 Nov 1;32(11):3533-8.

60. Gibon E, Goodman MJ, Goodman SB. Patient satisfaction after total knee arthroplasty: a realistic or imaginary goal?. Orthopedic Clinics. 2017 Oct 1;48(4):421-31.

61. Wylde V, Hewlett S, Learmonth ID, Dieppe P. Persistent pain after joint replacement: prevalence, sensory qualities, and postoperative determinants. PAIN®. 2011 Mar 1;152(3):566-72.

62. Beswick AD, Wylde V, Gooberman-Hill R, Blom A, Dieppe P. What proportion of patients report long-term pain after total hip or knee replacement for osteoarthritis? A systematic review of prospective studies in unselected patients. BMJ open. 2012 Jan 1;2(1):e000435. 
63. ASTM F561-13. Standard Practice for Retrieval and Analysis of Medical Devices, and Associated Tissues and Fluids. ASTM International: West Conshohocken, PA; 2013.

64. Jacobs JJ, Hallab NJ. Loosening and osteolysis associated with metal-on-metal bearings: a local effect of metal hypersensitivity?. JBJS. 2006 Jun 1;88(6):1171-2.

65. Jacobs JJ, Hallab NJ, Urban RM, Wimmer MA. Wear particles. JBJS. 2006 Apr 1;88(suppl_2):99-102.

66. Campbell P, Yuan N, Luck J, Courpron P, Park SH. Re-examining the concept of inflammatory cell-induced corrosion. InOrthopaedic Proceedings 2017 Feb (Vol. 99, No. SUPP_3, pp. 57-57). The British Editorial Society of Bone \& Joint Surgery.

67. Heyse TJ, Elpers ME, Nawabi DH, Wright TM, Haas SB. Oxidized zirconium versus cobalt-chromium in TKA: profilometry of retrieved femoral components. Clinical Orthopaedics and Related Research®. 2014 Jan 1;472(1):277-83.

68. Chapman-Sheath P, Cain S, Bruce WJ, Chung WK, Walsh WR. Surface roughness of the proximal and distal bearing surface of mobile bearing total knee prostheses. The Journal of arthroplasty. 2002 Sep 1;17(6):713-7.

69. Arnholt CM, MacDonald DW, Klein GR, Cates HE, Rimnac CM, Kurtz SM, Kocagoz S, Chen AF, Implant Research Center Writing Committee. What Is the Incidence of Cobalt-Chromium Damage Modes on the Bearing Surface of Contemporary Femoral Component Designs for Total Knee Arthroplasty?. The Journal of arthroplasty. 2018 Oct 1;33(10):3313-9.

70. Que L, Topoleski LT, Parks NL. Surface roughness of retrieved CoCrMo alloy femoral components from PCA artificial total knee joints. Journal of Biomedical Materials Research: An Official Journal of The Society for Biomaterials. 2000;53(1):111-8.

71. Laskin RS. An oxidized $\mathrm{Zr}$ ceramic surfaced femoral component for total knee arthroplasty. Clinical Orthopaedics and Related Research (1976-2007). 2003 Nov 1;416:191-6.

72. Spector M, Ries MD, Bourne RB, Sauer WS, Long M, Hunter G. Wear performance of ultra-high molecular weight polyethylene on oxidized zirconium total knee femoral components. JBJS. 2001 Nov 1;83(2_suppl_2):S80-86.

73. National Joint Registry for England, Wales and Northern Ireland. The 13th annual report. 2016.

74. Reyna AL, Fritz B, Schwiesau J, Schilling C, Summer B, Thomas P, Grupp TM. Metal ion release barrier function and biotribological evaluation of a zirconium nitride multilayer coated knee implant under highly demanding activities wear simulation. Journal of biomechanics. 2018 Oct 5;79:88-96.

75. Grupp TM, Giurea A, Miehlke RK, Hintner M, Gaisser M, Schilling C, Schwiesau $\mathrm{J}$, Kaddick C. Biotribology of a new bearing material combination in a rotating hinge knee articulation. Acta Biomaterialia. 2013 Jun 1;9(6):7054-63.

76. Reich J, Hovy L, Lindenmaier HL, Zeller R, Schwiesau J, Thomas P, Grupp TM. Präklinische Ergebnisse beschichteter Knieimplantate für Allergiker. Der Orthopäde. 2010 May 1;39(5):495-502.

77. Long M, Rack HJ. Titanium alloys in total joint replacement - a materials science perspective. Biomaterials. 1998 Sep 1;19(18):1621-39. 
78. Singh R, Dahotre NB. Corrosion degradation and prevention by surface modification of biometallic materials. Journal of Materials Science: Materials in Medicine. 2007 May 1;18(5):725-51.

79. Mischler S, Debaud S, Landolt D. Wear-accelerated corrosion of passive metals in tribocorrosion systems. Journal of the Electrochemical Society. 1998 Mar $1 ; 145(3): 750-8$.

80. Jacobs JJ, Gilbert JL, Urban RM. Current concepts review-corrosion of metal orthopaedic implants. Jbjs. 1998 Feb 1;80(2):268-82.

81. Fricka KB, Ho H, Peace WJ, Engh Jr CA. Metal-on-metal local tissue reaction is associated with corrosion of the head taper junction. The Journal of arthroplasty. 2012 Sep 1;27(8):26-31.

82. Cooper HJ, Urban RM, Wixson RL, Meneghini RM, Jacobs JJ. Adverse local tissue reaction arising from corrosion at the femoral neck-body junction in a dual-taper stem with a cobalt-chromium modular neck. The Journal of bone and joint surgery. American volume. 2013 May 15;95(10):865.

83. Bundy KJ. Corrosion and other electrochemical aspects of biomaterials. Critical Reviews in Biomedical Engineering. 1994;22(3-4):139-251.

84. Hallab NJ, Jacobs JJ, Skipor A, Black J, Mikecz K, Galante JO. Systemic metalprotein binding associated with total joint replacement arthroplasty. Journal of Biomedical Materials Research. 2000 Mar 5;49(3):353-61.

85. Lin HY, Bumgardner JD. Changes in surface composition of the Ti-6Al-4V implant alloy by cultured macrophage cells. Applied surface science. 2004 Mar 30;225(1-4):21-8.

86. Lin HY, Bumgardner JD. In vitro biocorrosion of $\mathrm{Co} \square \mathrm{Cr} \square$ Mo implant alloy by macrophage cells. Journal of Orthopaedic Research. 2004 Nov;22(6):1231-6.

87. Parker SH, Lin HY, Zardiackas LD, Bumgardner JD. Influence of macrophage cells on 316L stainless steel corrosion. InStainless steels for medical and surgical applications 2003 Jan. ASTM International.

88. George Broughton II, Janis JE, Attinger CE. The basic science of wound healing. Plastic and reconstructive surgery. 2006 Jun 1;117(7S):12S-34S.

89. Franz S, Rammelt S, Scharnweber D, Simon JC. Immune responses to implants-a review of the implications for the design of immunomodulatory biomaterials. Biomaterials. 2011 Oct 1;32(28):6692-709.

90. Goldring SR, Schiller AL, Roelke M, Rourke CM, O'neil DA, Harris WH. The synovial-like membrane at the bone-cement interface in loose total hip replacements and its proposed role in bone lysis. JBJS. 1983 Jun 1;65(5):575-84.

91. Goodman SB, Lind M, Song Y, Smith RL. In vitro, in vivo, and tissue retrieval studies on particulate debris. Clinical orthopaedics and related research. 1998 $\operatorname{Jul}(352): 25-34$.

92. Schwab LP, Marlar J, Hasty KA, Smith RA. Macrophage response to high number of titanium particles is cytotoxic and COX-2 mediated and it is not affected by the particle's endotoxin content or the cleaning treatment. Journal of Biomedical Materials Research Part A. 2011 Dec 15;99(4):630-7.

93. Aderem A, Underhill DM. Mechanisms of phagocytosis in macrophages. Annual review of immunology. 1999 Apr;17(1):593-623. 
94. Labow RS, Meek E, Santerre JP. Neutrophil-mediated biodegradation of medical implant materials. Journal of cellular physiology. 2001 Jan;186(1):95-103.

95. Christenson EM, Anderson JM, Hiltner A. Biodegradation mechanisms of polyurethane elastomers. Corrosion Engineering, Science and Technology. 2007 Dec 1;42(4):312-23.

96. Han X, Sawada T, Schille C, Schweizer E, Scheideler L, Geis-Gerstorfer J, Rupp F, Spintzyk S. Comparative analysis of mechanical properties and metal-ceramic bond strength of $\mathrm{Co}-\mathrm{Cr}$ dental alloy fabricated by different manufacturing processes. Materials. 2018 Sep 22;11(10):1801.

97. Gilbert JL. 1.2 Electrochemical Behavior of Metals in the Biological Milieu. Comprehensive Biomaterials II. 2017 Jan 1:19.

98. Gilbert JL. Mechanically assisted corrosion of metallic biomaterials. Corrosion: Environments and Industries. 2006;13:826-36.

99. American Type Culture Collection. Product Information sheet for TIB-186.

100. Daniels AU, Barnes FH, Charlebois SJ, Smith RA. Macrophage cytokine response to particles and lipopolysaccharide in vitro. Journal of Biomedical Materials Research: An Official Journal of The Society for Biomaterials and The Japanese Society for Biomaterials. 2000 Mar 15;49(4):469-78.

101. Glant TT, Jacobs JJ. Response of three murine macrophage populations to particulate debris: bone resorption in organ cultures. Journal of orthopaedic research. 1994 Sep;12(5):720-31.

102. Hallab NJ, Anderson S, Stafford T, Glant T, Jacobs JJ. Lymphocyte responses in patients with total hip arthroplasty. Journal of Orthopaedic Research. 2005 Mar;23(2):384-91.

103. Cadosch D, Al-Mushaiqri MS, Gautschi OP, Meagher J, Simmen HP, Filgueira L. Biocorrosion and uptake of titanium by human osteoclasts. Journal of biomedical materials research Part A. 2010 Dec 15;95(4):1004-10.

104. Salo J, Lehenkari P, Mulari M, Metsikkö K, Väänänen HK. Removal of osteoclast bone resorption products by transcytosis. Science. 1997 Apr 11;276(5310):270-3.

105. Meagher J, Zellweger R, Filgueira L. Functional dissociation of the basolateral transcytotic compartment from the apical phago-lysosomal compartment in human osteoclasts. Journal of Histochemistry \& Cytochemistry. 2005 May;53(5):665-70.

106. Wiegand MJ, Kubacki GW, Gilbert JL. Electrochemical potential zone of viability on CoCrMo surfaces is affected by cell type: Macrophages under cathodic bias are more resistant to killing. Journal of Biomedical Materials Research Part A. 2019 Mar;107(3):526-34.

107. Cadosch D, Meagher J, Gautschi OP, Filgueira L. Uptake and intracellular distribution of various metal ions in human monocyte-derived dendritic cells detected by Newport Green ${ }^{\mathrm{TM}}$ DCF diacetate ester. Journal of neuroscience methods. 2009 Mar 30;178(1):182-7. 


\section{APPENDIX A. SURVEY ON ELECTROCAUTERY USE ANSWERED BY 102 AAOS SURGEONS}

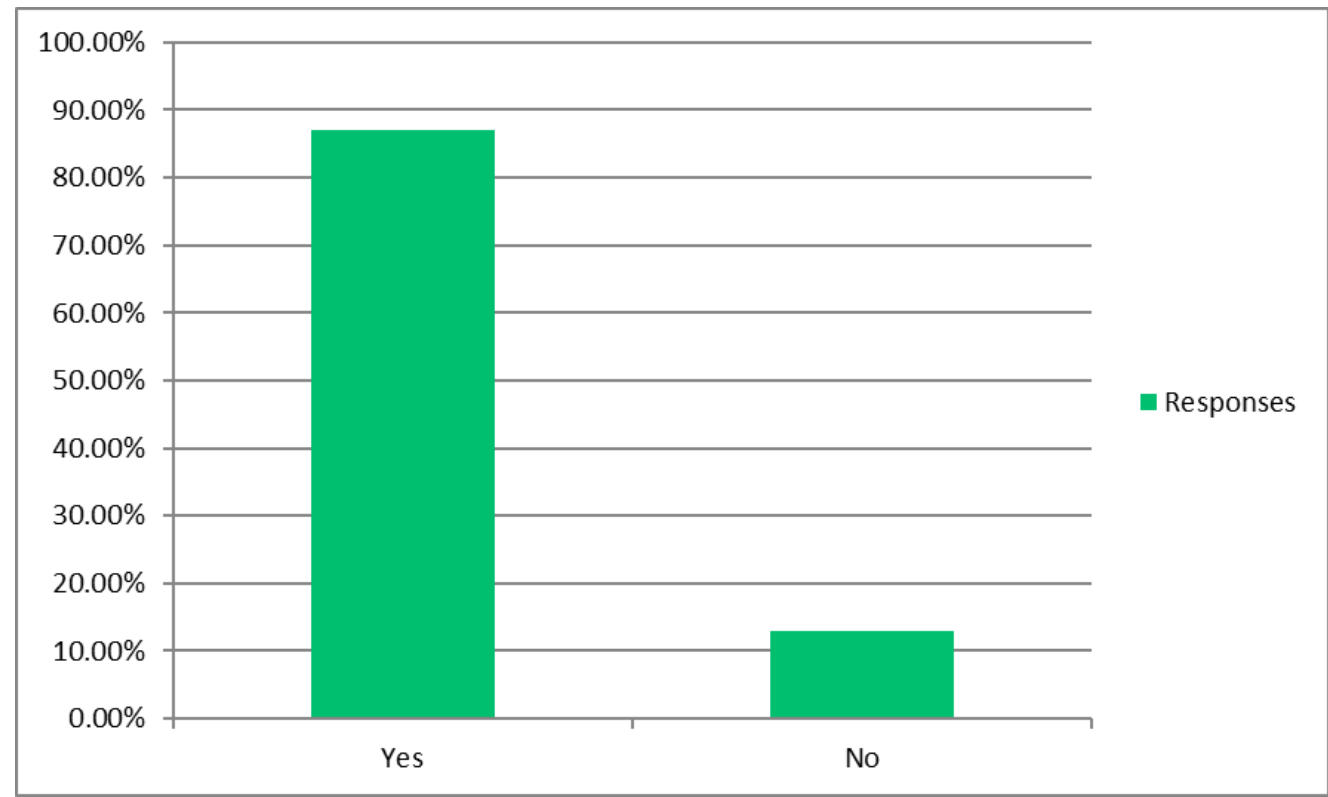

Figure A-1. When you perform a primary total knee replacement do you use an electro-cautery or Aquamantys device?

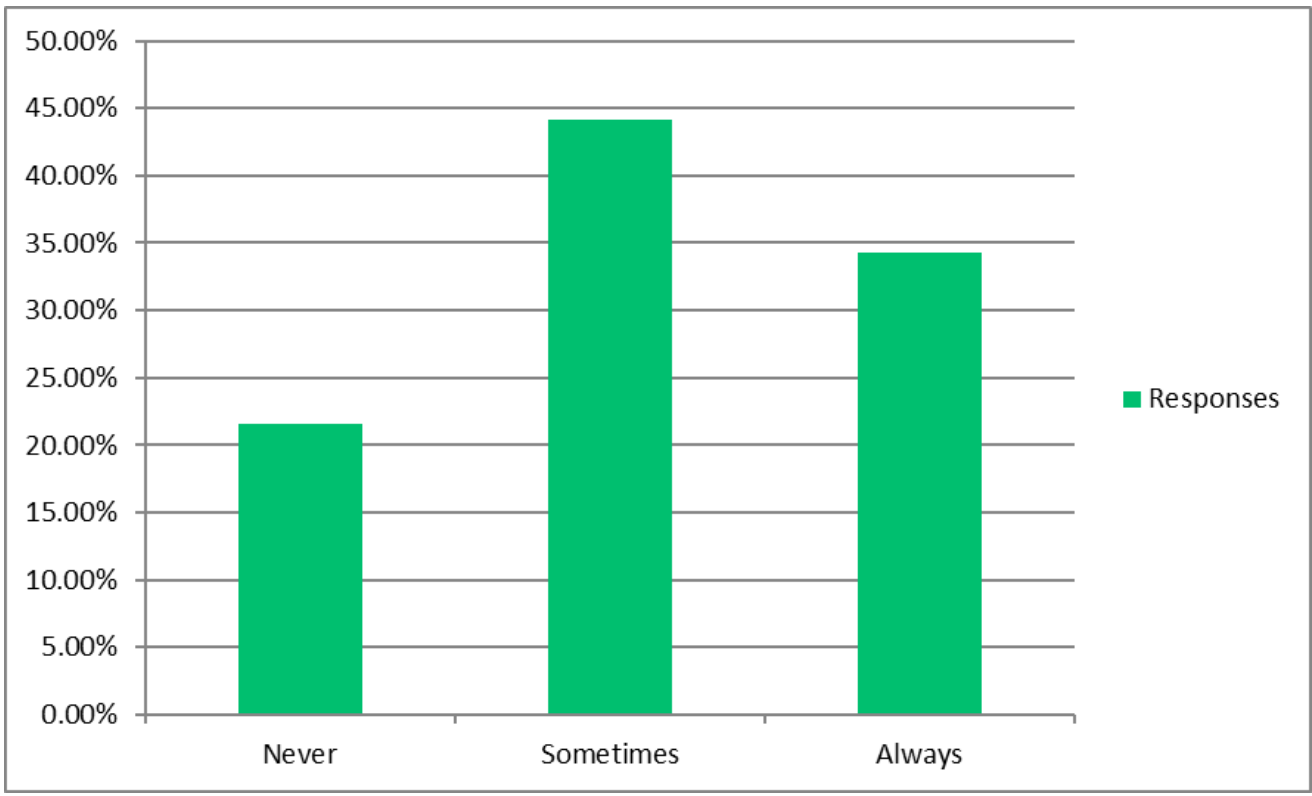

Figure A-2. How often do you use the electro-cautery or the Aquamantys AFTER you have implanted your prosthetic components in a primary TKA? 


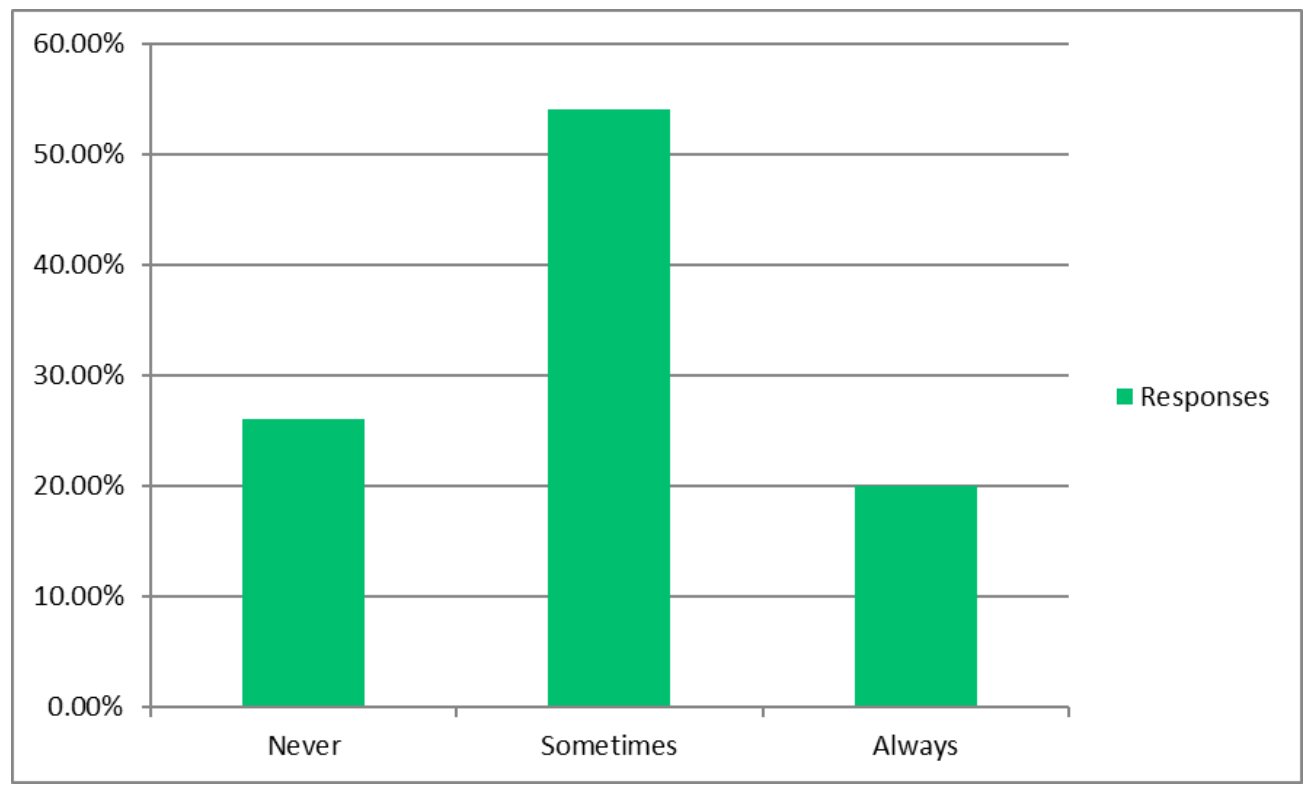

Figure A-3. How often do you use the electro-cautery or the Aquamantys AFTER you have implanted your prosthetic components in a primary THA?

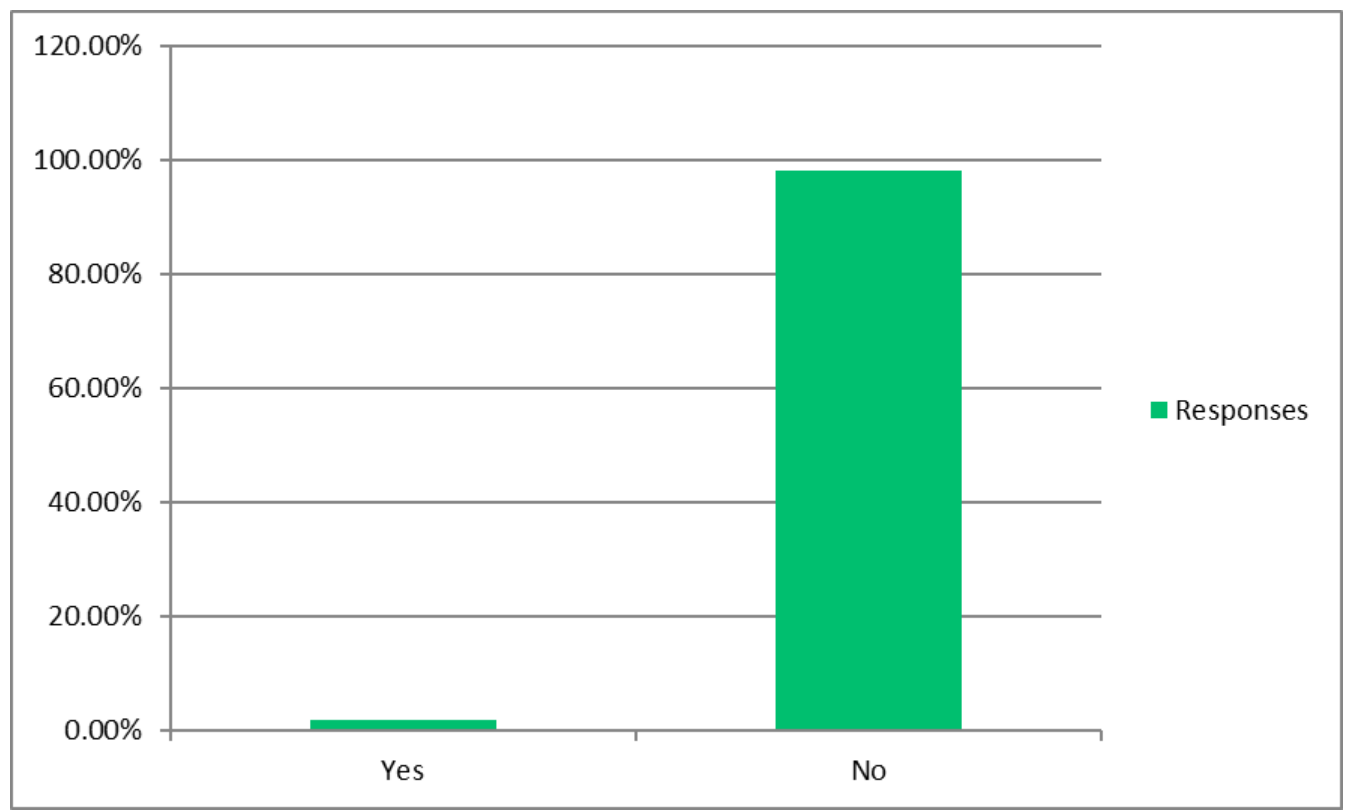

Figure A-4. After your prosthetic components are implanted during a primary TKA or THA do you ever touch the prosthetic metallic surfaces with the electrocautery or the Aquamantys? 


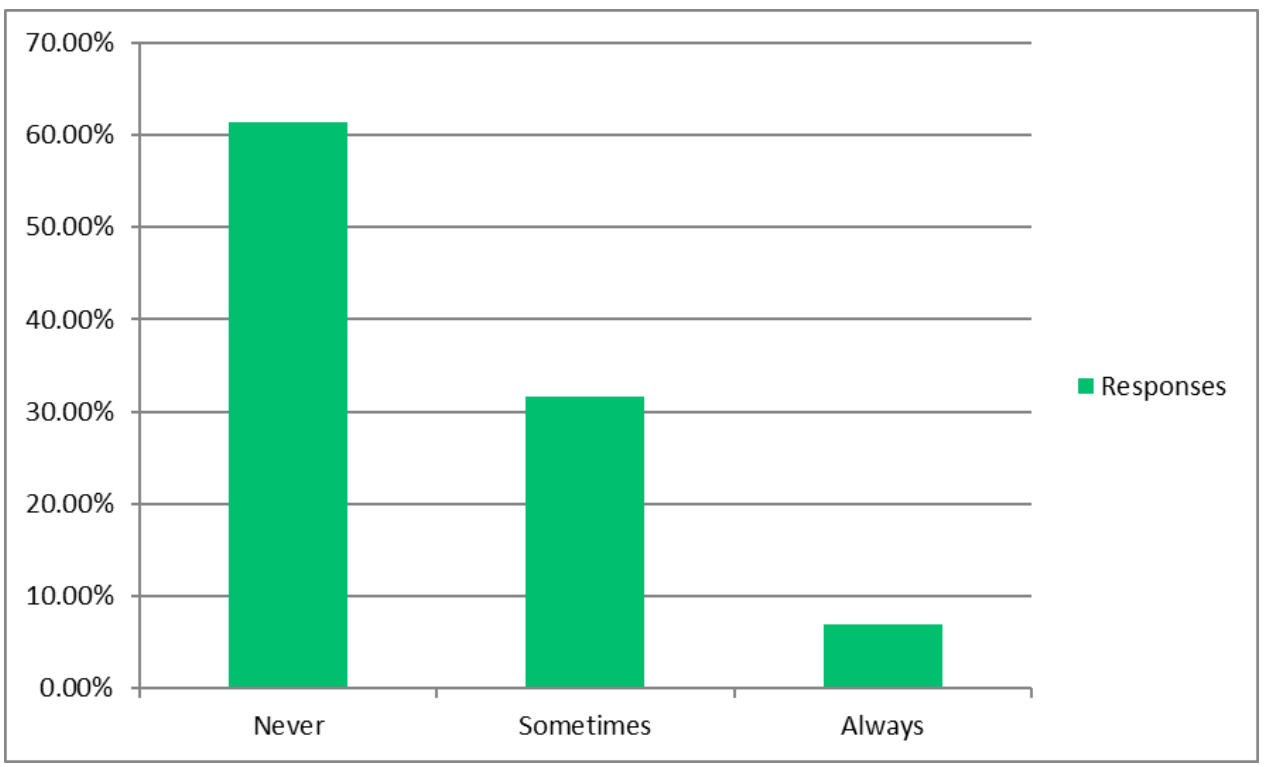

Figure A-5. When performing a revision TKA do you ever touch the metallic surfaces of the implants with the electrocautery or the Aquamantys prior to removal of the implants?

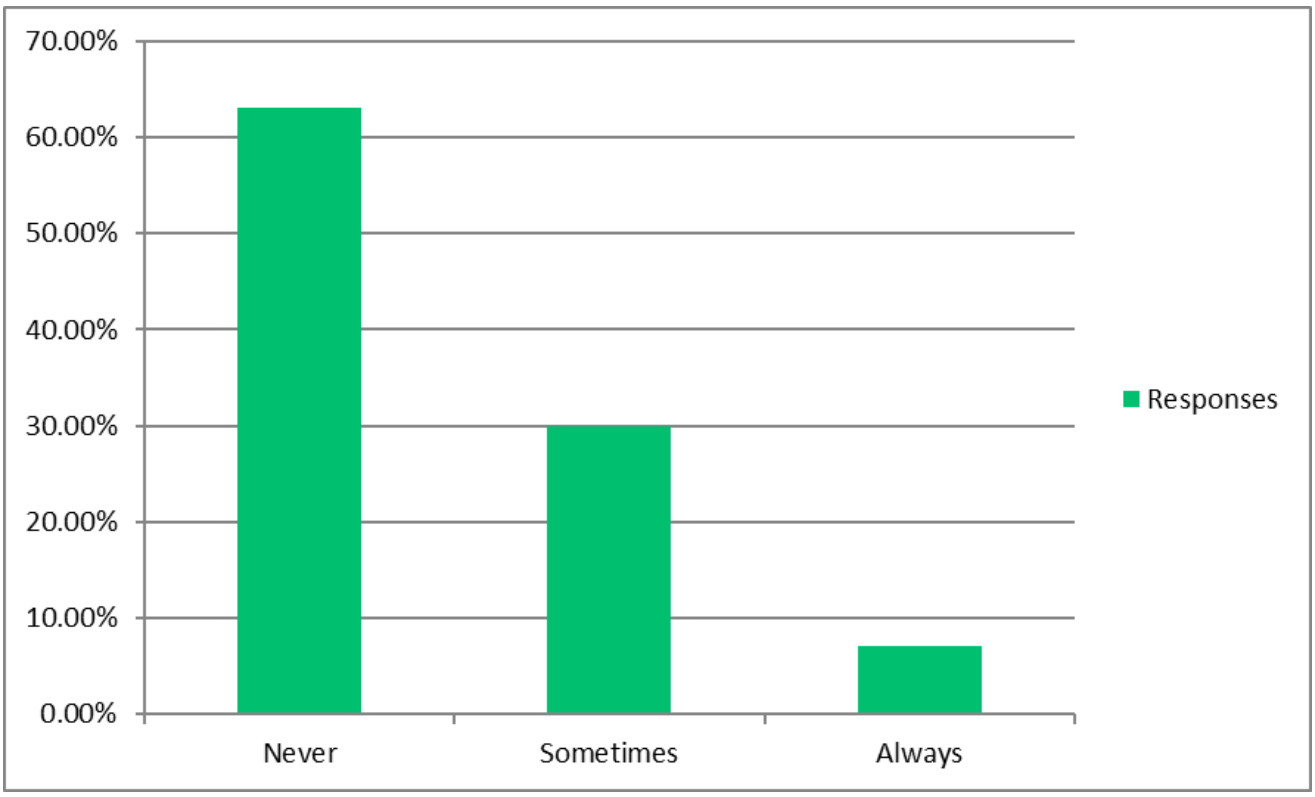

Figure A-6. When performing a revision THA do you ever touch the metallic surfaces of the implants with the electrocautery or the Aquamantys prior to removal of the implant? 


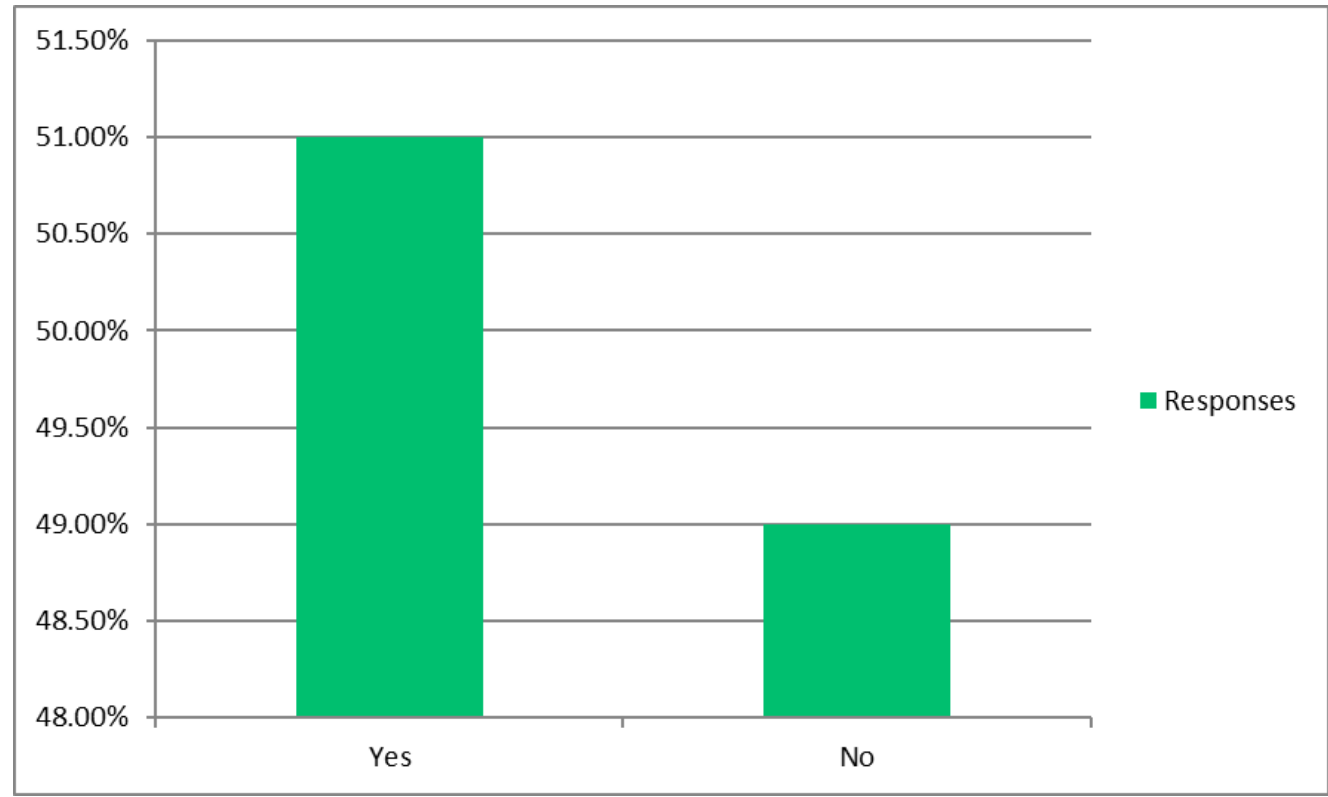

Figure A-7. Do you believe that touching the metallic implant surface of a THA or TKA implant with the electrocautery or the Aquamantys can cause damage to the bearing surface of the implant? 


\section{APPENDIX B. SUMMATION OF METAL CONTENT COLLECTED FROM 30 DAY IN VITRO STUDY}

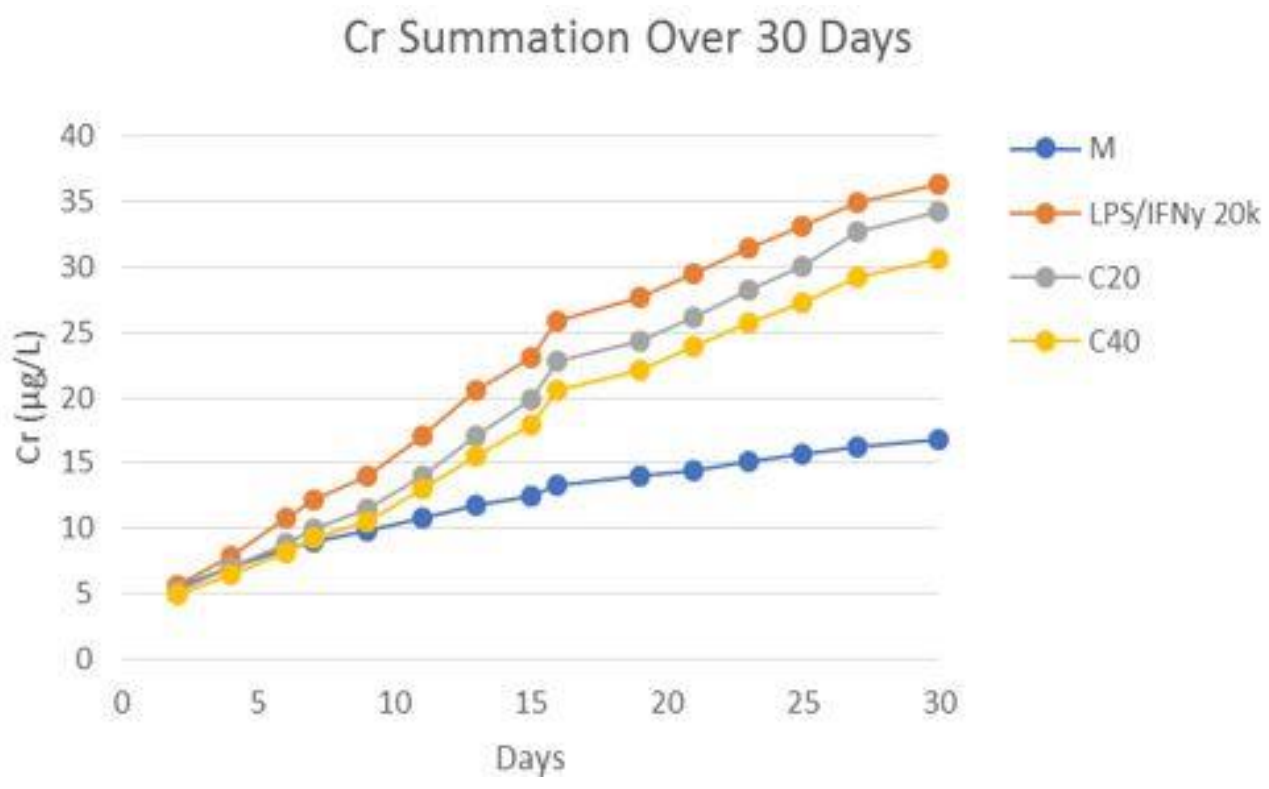

Figure B-1. Summation of Cr content collected off Stainless Steel over 30 days

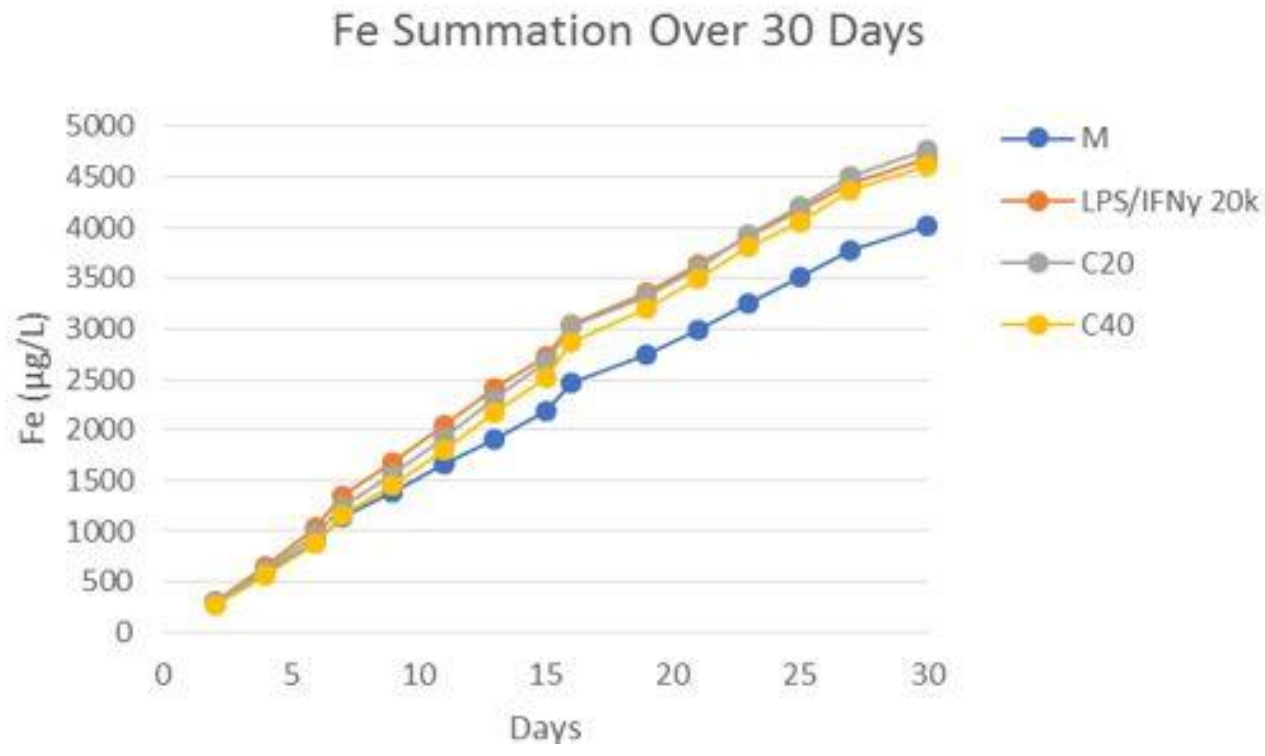

Figure B-2. Summation of Fe content collected off Stainless Steel over 30 days 


\section{Mn Summation Over 30 Days}

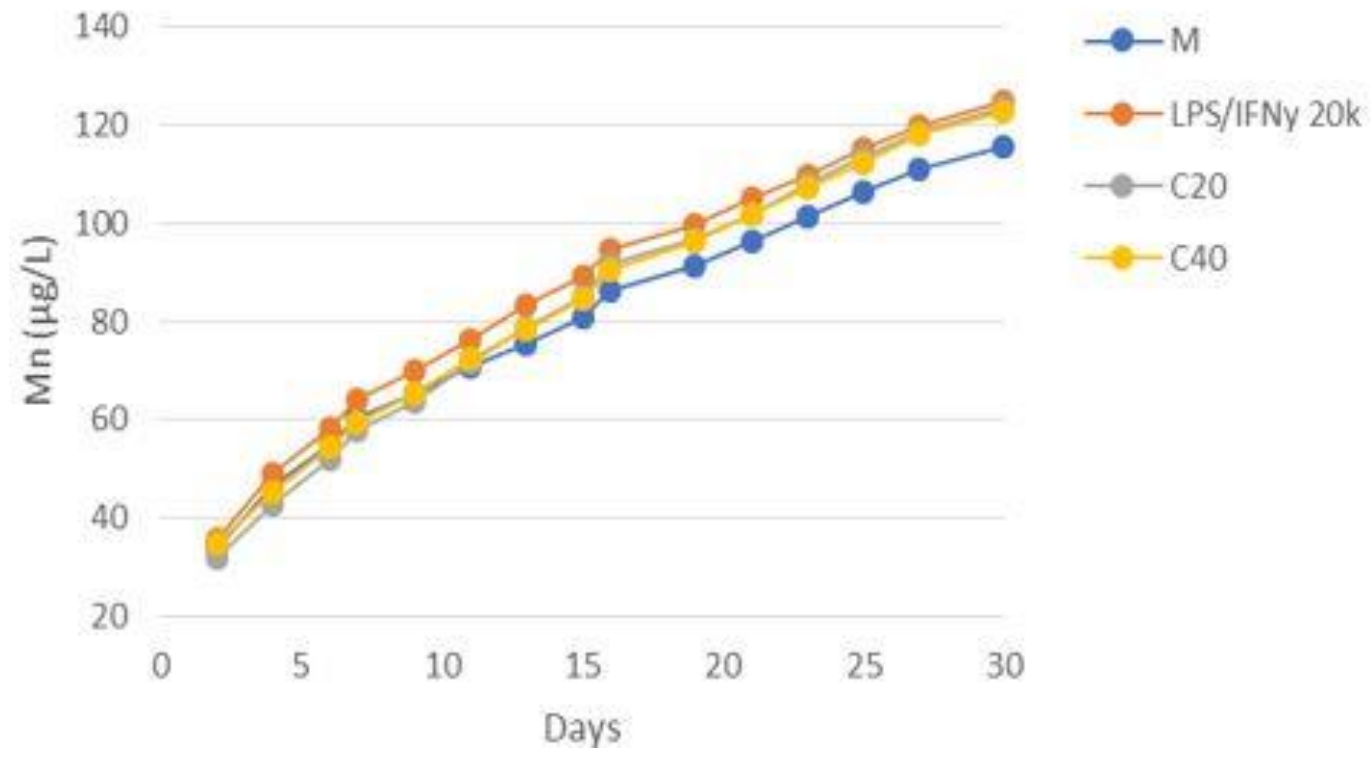

Figure B-3. Summation of Mn content collected off Stainless Steel over 30 days

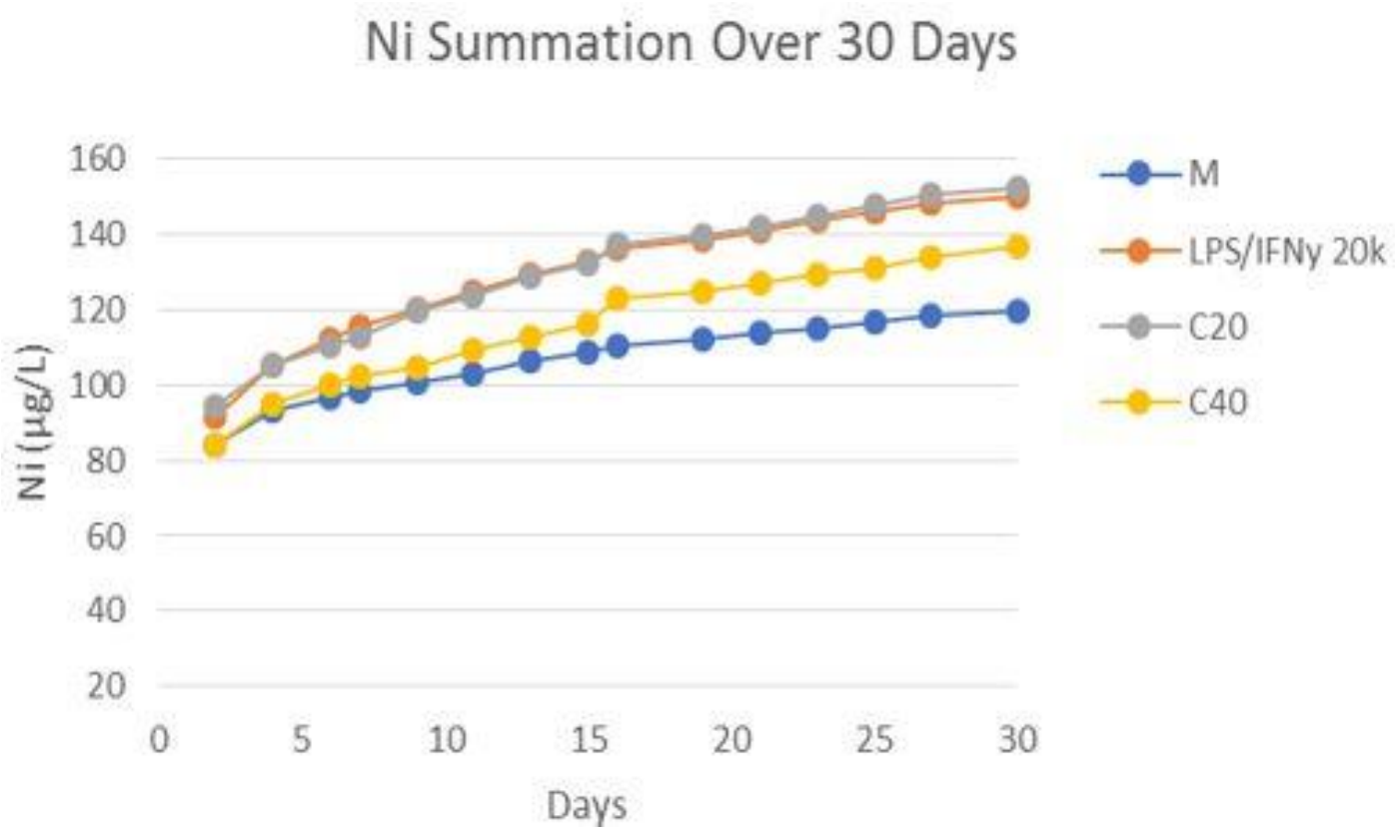

Figure B-4. Summation of Ni content collected off Stainless Steel over 30 days 


\section{Al Summation Over 30 Days}

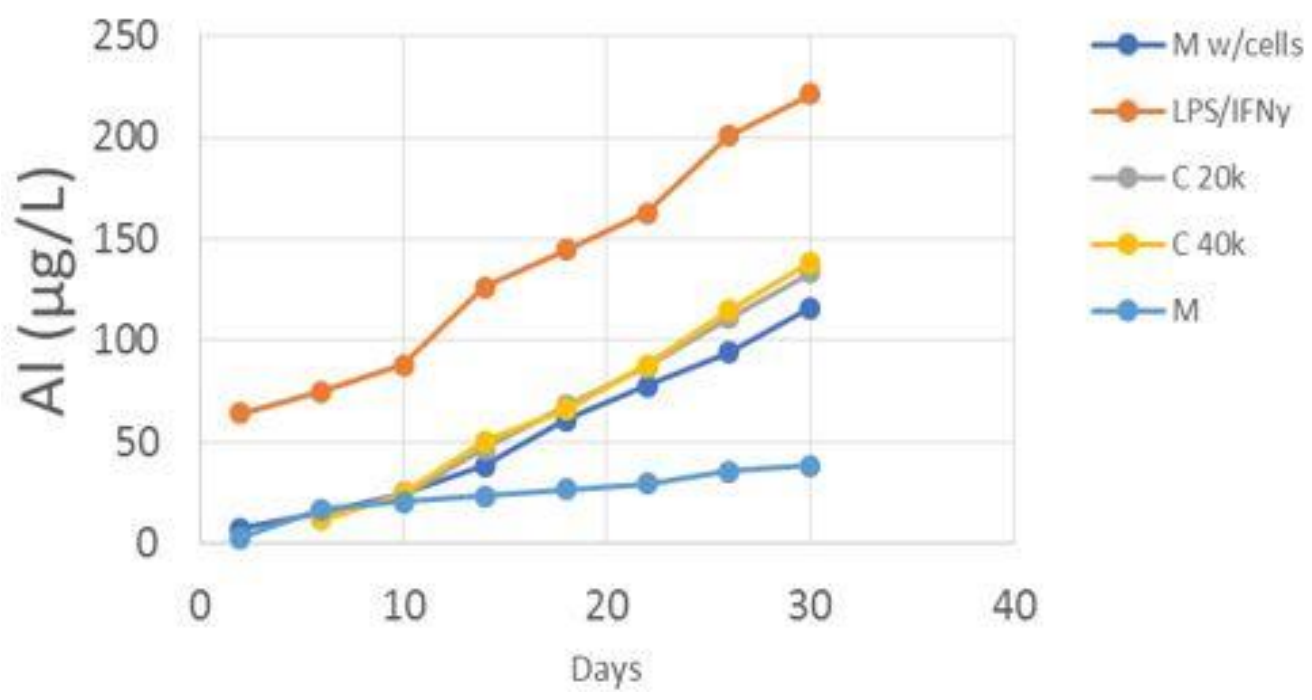

Figure B-5. Summation of Al content collected off Ti6Al4V over 30 days

\section{Ti Summation Over 30 Days}

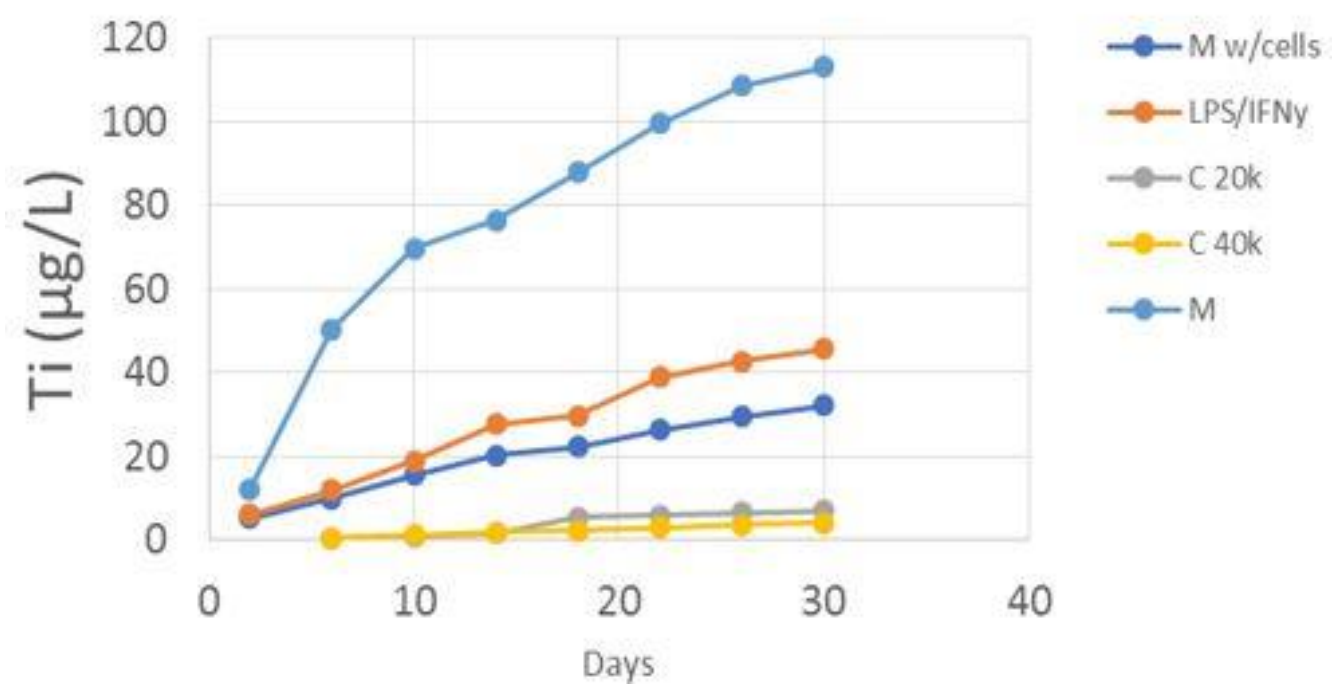

Figure B-6. Summation of Ti content collected off Ti6Al4V over 30 days 


\section{Summation Over 30 Days}

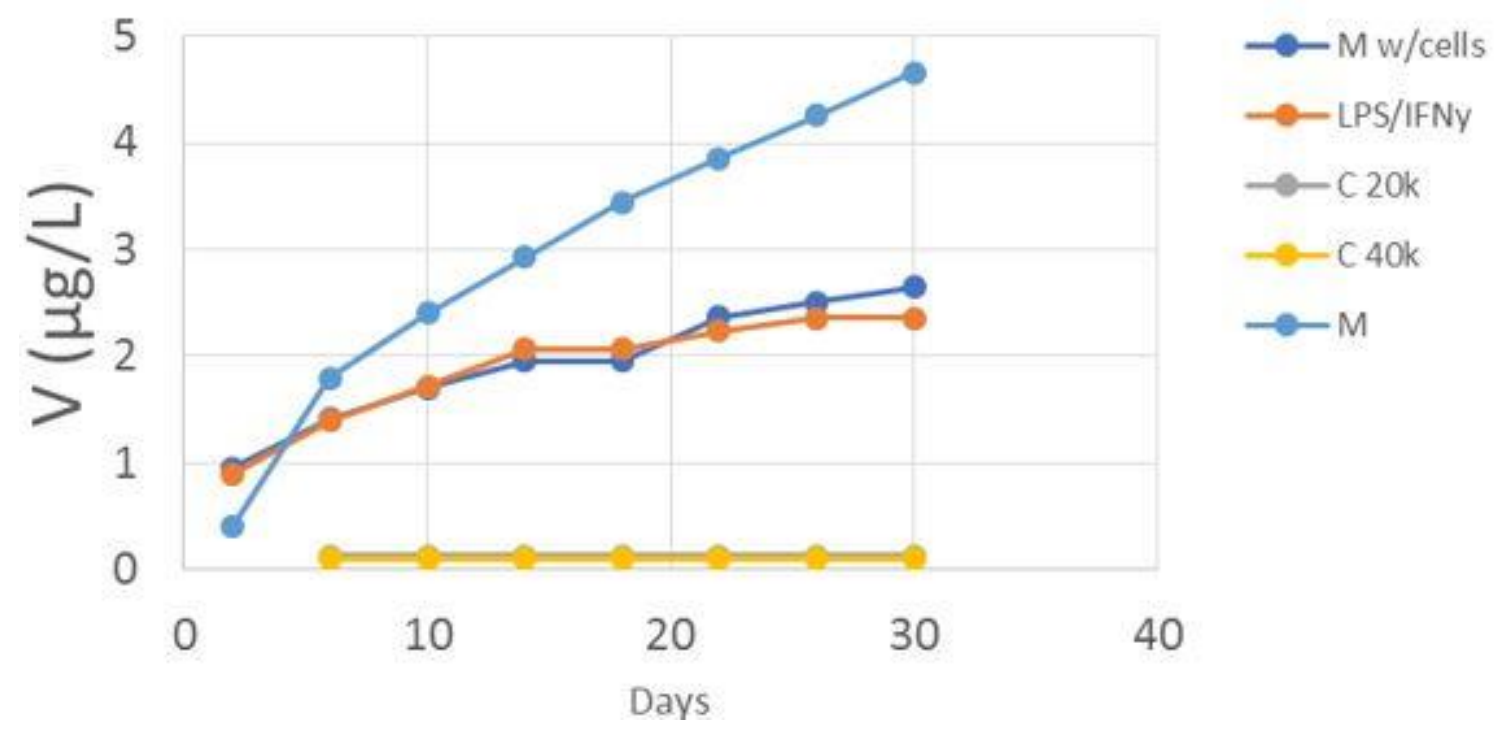

Figure B-7. Summation of $\mathrm{V}$ content collected off Ti6Al4V over 30 days

\section{Co Summation Over 30 Days}

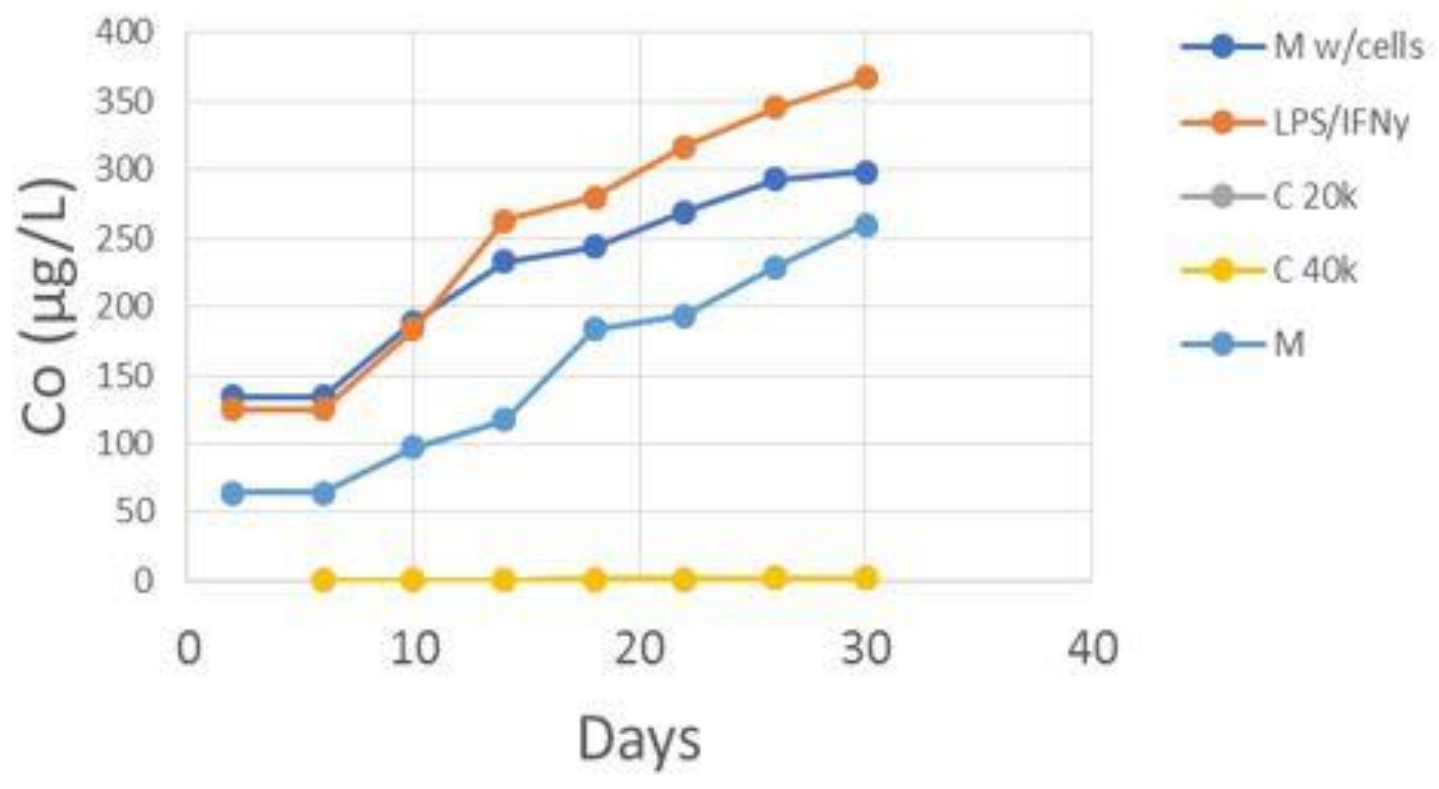

Figure B-8. Summation of Co content collected off CoCrMo over 30 days 


\section{Cr Summation Over 30 Days}

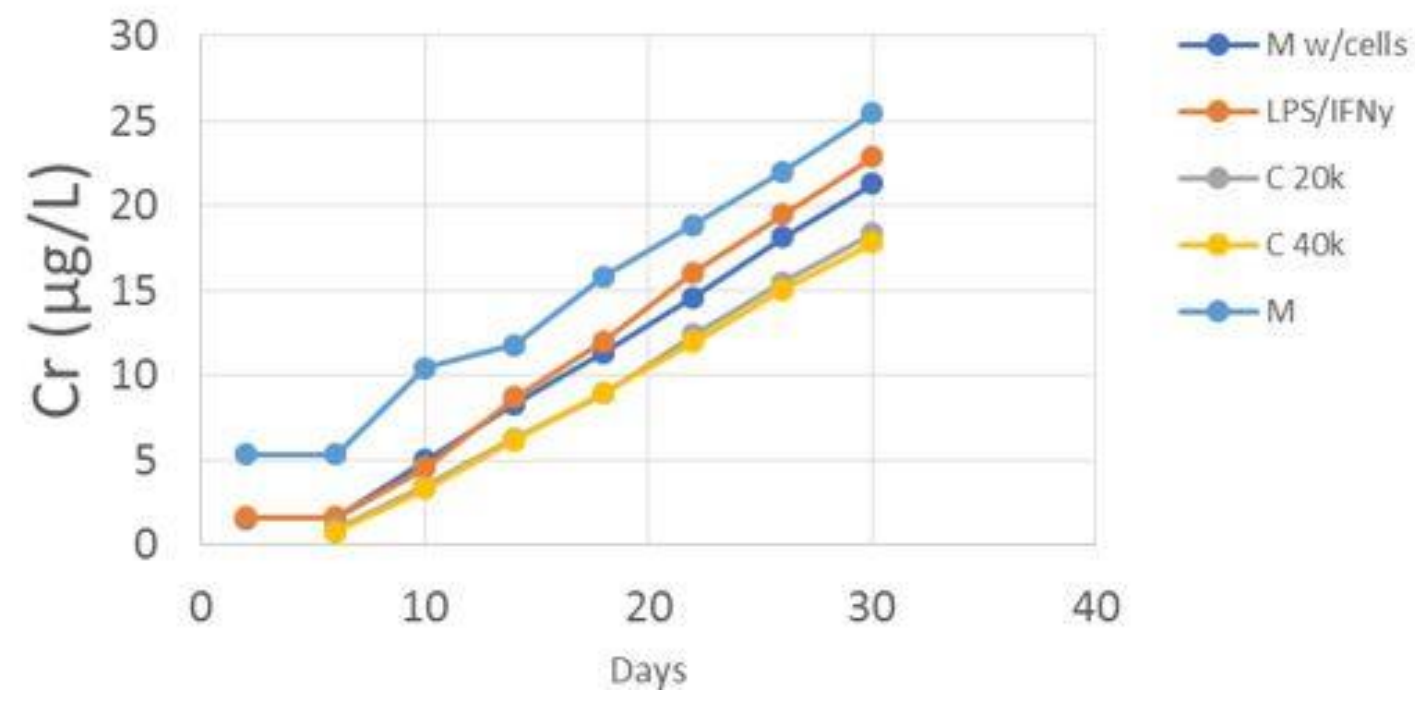

Figure B-9. Summation of Cr content collected off CoCrMo over 30 days
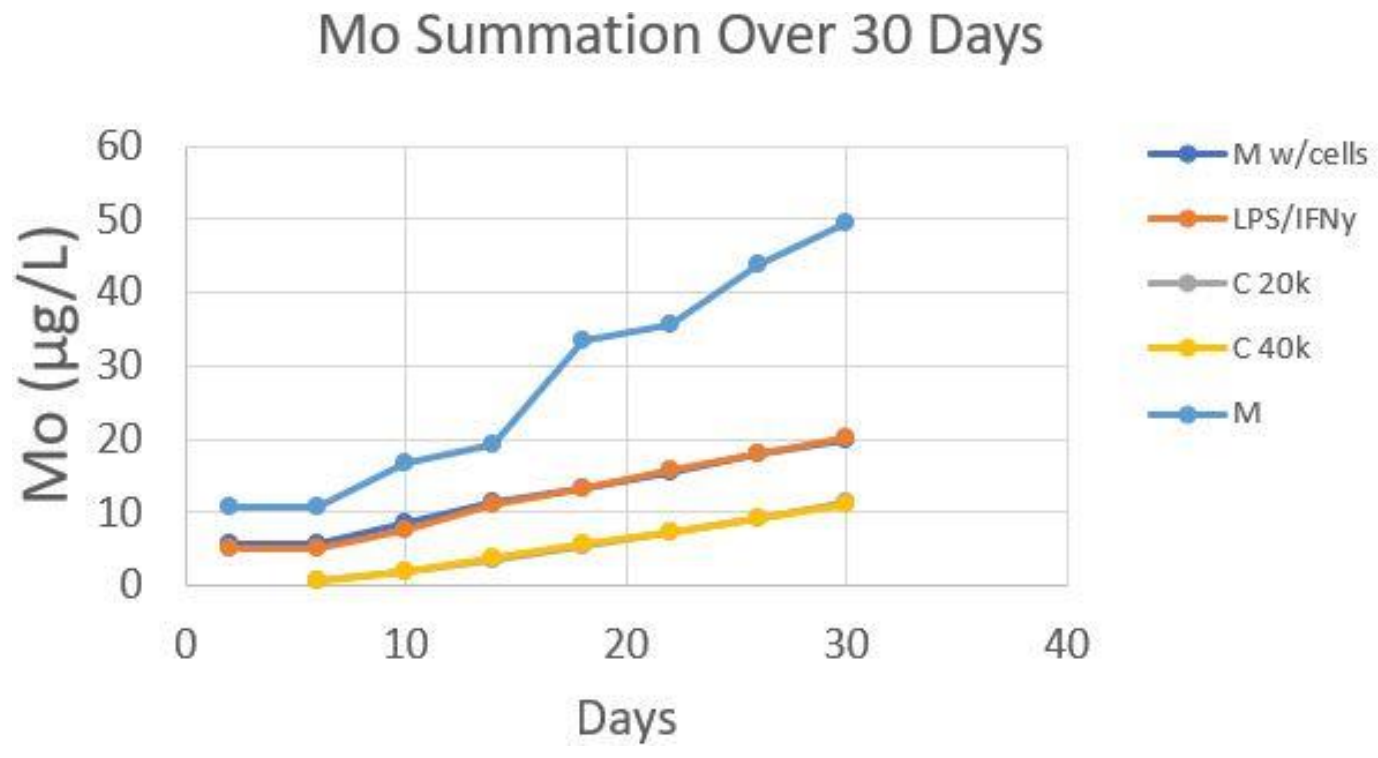

Figure B-10. Summation of Mo content collected off CoCrMo over 30 days 


\section{APPENDIX C. CLINICAL INFORMATION FOR IMPLANTS EXAMINED FOR ICIC}

Table C-1. Patient information for implants examined for ICIC

\begin{tabular}{|c|c|c|c|c|}
\hline Specimen \# & Age & Sex & Signs of ICIC & Time in Situ \\
\hline DRLU051714-L & 89 & $\mathrm{~F}$ & $\mathrm{~N}$ & $>10$ \\
\hline DRLU081315-R & 79 & M & $\mathrm{N}$ & 20 \\
\hline DRLU030815-R & 65 & M & $\mathrm{Y}$ & 15 \\
\hline DRLU121515-R & 76 & $\mathrm{~F}$ & $\mathrm{Y}$ & $>10$ \\
\hline DRLU010416-R & 69 & M & $\mathrm{N}$ & 21 \\
\hline DRLU112815A-R & 71 & $\mathrm{~F}$ & $\mathrm{~N}$ & 11 \\
\hline DRLU101615A-R & 83 & $\mathrm{~F}$ & $\mathrm{Y}$ & 22 \\
\hline RLU1016151A-L & 83 & $\mathrm{~F}$ & $\mathrm{~N}$ & 21 \\
\hline 2013-678L & -- & -- & $\mathrm{N}$ & -- \\
\hline UTK0205R & -- & -- & $\mathrm{Y}$ & -- \\
\hline RLU0510162A-R & 62 & $\mathrm{~F}$ & $\mathrm{~N}$ & 7 \\
\hline RLU0728161A-L & 93 & M & $\mathrm{Y}$ & 27 \\
\hline RLU0309161B-L & 62 & M & $\mathrm{N}$ & 45 \\
\hline RLU0722161B-L & 63 & $\mathrm{~F}$ & $\mathrm{~N}$ & 40 \\
\hline RLU0126161C-L & 79 & $\mathrm{~F}$ & $\mathrm{~N}$ & -- \\
\hline RLU0510161A-L & 62 & $\mathrm{~F}$ & $\mathrm{Y}$ & 6 \\
\hline RLU0426161B-L & 66 & $\mathrm{~F}$ & $\mathrm{~N}$ & -- \\
\hline RLU0126162C-R & 79 & $\mathrm{~F}$ & $\mathrm{~N}$ & -- \\
\hline RLU0720161B-L & 93 & M & $\mathrm{N}$ & 13 \\
\hline RLU1028161B-L & 94 & M & $\mathrm{N}$ & 37 \\
\hline RLU1115162B-R & 80 & $\mathrm{~F}$ & $\mathrm{~N}$ & 11 \\
\hline RLU0913162A-R & 65 & M & $\mathrm{N}$ & 45 \\
\hline RLU0426162B-R & 66 & $\mathrm{~F}$ & $\mathrm{~N}$ & -- \\
\hline RLU0829162C-R & 68 & $\mathrm{~F}$ & $\mathrm{~N}$ & $<11$ \\
\hline 16-04-765R & 77 & $\mathrm{~F}$ & $\mathrm{~N}$ & -- \\
\hline $16-10-1103 R$ & 78 & M & $\mathrm{Y}$ & -- \\
\hline 16-10-1103L & 78 & M & $\mathrm{N}$ & -- \\
\hline RLU0204172A_R & 88 & M & $\mathrm{N}$ & 19 \\
\hline RLU0317172B_R & 84 & M & $\mathrm{N}$ & 15 \\
\hline RLU0319171A_L & 72 & $\mathrm{~F}$ & $\mathrm{~N}$ & 15 \\
\hline RLU1121161A_L & 87 & $\mathrm{~F}$ & $\mathrm{~N}$ & 27 \\
\hline RLU1121162A_R & 87 & $\mathrm{~F}$ & $\mathrm{~N}$ & 27 \\
\hline RLU1125161A_L & 68 & $\mathrm{~F}$ & $\mathrm{~N}$ & 22 \\
\hline RLU1125162A_R & 68 & $\mathrm{~F}$ & $\mathrm{~N}$ & 21 \\
\hline 18-04-2393L & 73 & M & $\mathrm{N}$ & -- \\
\hline 18-04-2393R & 73 & M & $\mathrm{N}$ & -- \\
\hline 18-04-2380R & 84 & M & $\mathrm{N}$ & -- \\
\hline $18-07-2584 \mathrm{~L}$ & 82 & M & $\mathrm{N}$ & 13 \\
\hline $18-07-2584 \mathrm{R}$ & 82 & M & $\mathrm{N}$ & 13 \\
\hline $18-07-2578 \mathrm{~L}$ & 51 & M & $\mathrm{N}$ & -- \\
\hline
\end{tabular}




\section{VITA}

Griffin McVay Heise was born in Chicago, Illinois in 1994. He attended University of Tennessee in Knoxville, Tennessee where he earned a Bachelor of Science in Biomedical Engineering in 2016. He then moved on the Memphis, Tennessee and began his work under Dr. William Mihalko as a graduate research assistant in the Joint Program in Biomedical Engineering at the University of Tennessee Health Science Center and the University of Memphis. He earned his Master's Degree in Biomedical Engineering in December 2019 